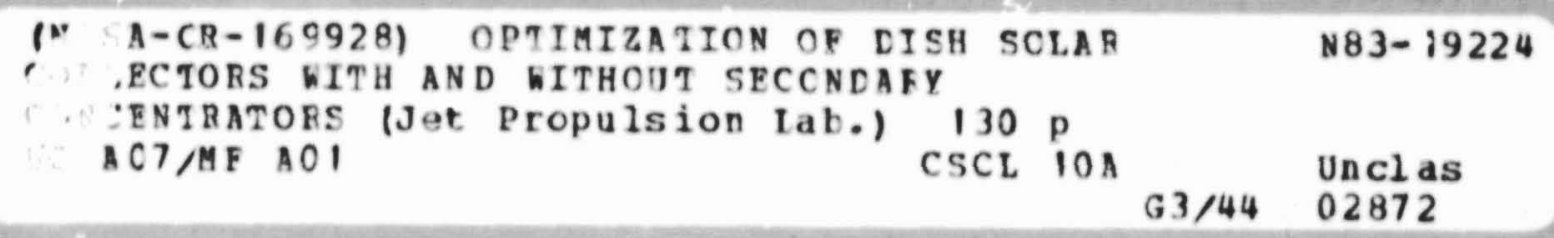

\title{
Optimization of Dish Solar Collectors With and Without Secondary Concentrators
}

L.D. Jaffe
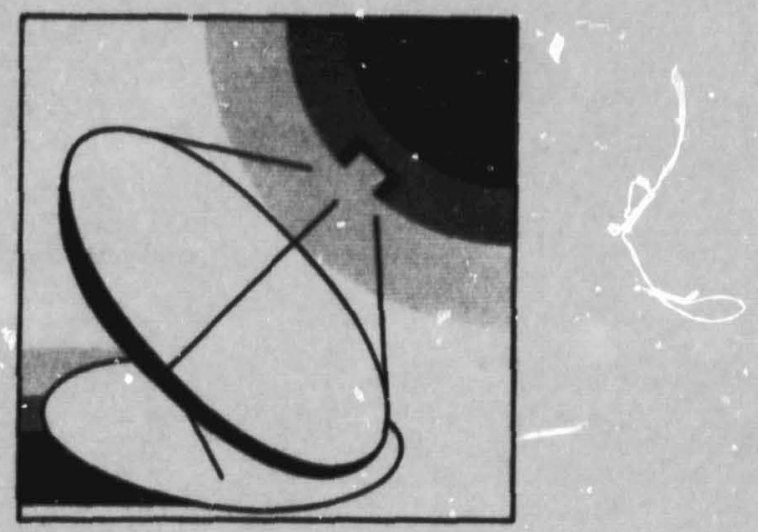

May 15, 1982

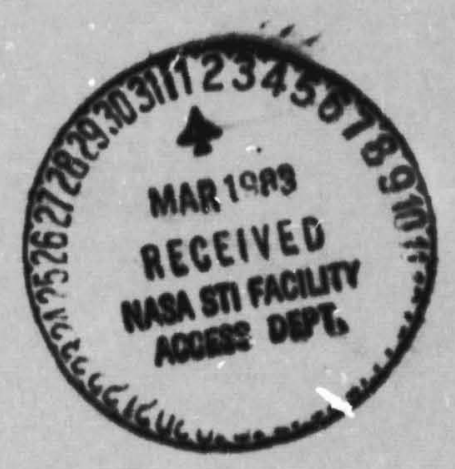

Prepared for

U.S. Department of Energy

Through an Agreement with

Nations , teronautics and Space Administration

by

Jet Propulsion Laboratory

California Institute of Technology

Pasadena, California

JFL PUBLICATION 82-103 


\section{Optimization of Dish Solar Collectors With and Without Secondary Concentrators}

L.D. Jaffe

May 15,1982

Prepared for

U.S. Department of Energy

Through an Agreement with

National Aeronautics and Space Administration

by

Jet Propulsion Laboratory

California Institute of Technology

Pasadena, California

JPL PUBLICATION 82.103 
Prepared by the Jel Propuls in Laboratory, Callfornia Institute of Technology, for the U.S. Department of Bneray through an agroemen! with the National Aoronautics and Space Admis: teisation.

The JPL. Solat Thermal Power Systems Project is sponacted by the U.S. Department of Energy and forns a part of the Solar Thermal Program to develop low. cost solar thermal and electric power plants.

This report was prepared as an acrount of work sponsored by the United States Government. Nelther the United Stater nor the Unitod States Department of Energy, not any of their employoes, nor any of theis contractors, subcontractors. or thels employees, makes any warranty, express or implied, or assumes any lezal liablity of responsibility for the accuracy, completeness or usefulness of any information, apparatus, product of process disclosed, of represents that its use would not infringe privately owned rights.

Reference herein to any speciftic comme: . moduct, process, or service by trade name, trademark, manufacturet, of oth :.. , does not necessurlly constifute or unply its ondorsement, recommen' ... : fovoring by the United States Government or any agency thereof. The views and opinions of authors expressed herein do not necessarlly state or reflect those of the United States Government or any agency thereof. 


\section{ABstract}

Methode for optimizing parabolic dish oolar collectors and the consequant effects of varioue optical, thermal, mechanical, and cost variables are examined in this report. The moot important performance optimiration is adjuting the recelver aperture to maximize collector afficiency. Other parameters that can be adjusted to optimize efficiency include focal langth, and, if heat ongine is used, the receiver temperature. The officiency maxiru associated with focal length and receiver cemperature are relatively broad; it may, accordingly, be desirable to design somewhat away from the maxima.

Performance optimization is sensitive to the olope and specularity errore of the concentrator. Other optical and thermal variables affecting optimization are the reflectance and blocking factor of isie concentrator, the absorptance and $108 \mathrm{Bas}$ of the receiver, and, if a heat engine is used, the shape of the engine efficiency versus temperature curve. Performance may sometimes $b$ improved by use of an additionsl optical element (a secondary concentrator) or a receiver window if the errors of the primary concentrator are large or the receiver temperature is high.

Such factors as receiver temperature affect not only efficiency, but also maintenance, reliability, and availability. All of these affect the cost of the energy produced, as does, of course, the initial installed cost of the collector itself. Both collector costs and efficiency have strong effects upon the cost of the energy produced; trade-offs of system performance versus system cost are needed. 
William Revere and Peter Poon provided helpful information during the course of thin work. Comente on the manuecript by Jamee Bowyer, Philip Moynihan, William Owen, Loule Rubenotein, and Brank Burber led to eignificant improvements in the papar. The work was eponeored by the $U .8$. Department of Energy through a interagency egreement with MASA (NASA TA8K RE-152; ANENDMRNT 327, DOE/MASA IAA DE-ANU4-80AL13137). 
contenrs

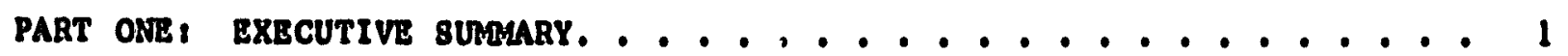

PART TWO OPTIMIZATION OR DI8H SOLAR COLLECTORS WITH ANE WITHOUT SECONDARY CONCENTRATORS. . . . . . . . . . . . 1-1

I. Introduction ......................... 1-3

II. METHODS fOR PERPORMANCE OPTIMIZATION. .............. 2-I

A. Bas IS for PERformance optimization ............ . 2-1

B. COLLECTOR PERFORMance CALCULATION WITH SIMPLE

DISH CONCENTRATORS. . . . . . . . . . . . . . . . 2-2

C. PERfoRmance OPTIMIZATION FOR SIMPLE DISH COLLECTORS . . . 2-4

D. SYSTEM PERfORMANCE Calculation. . . . . . . . . . 2-9

E. EfFects of SEconcary concentrators. . . . . . . . . . . 2-1:

F. PERformance calculation and optimization for COMPOUND COLLECTORS .................... 2-11

G. SYSTEM PERFORMANCE OPTIMIZATION . . . . . . . . . 2-14

III. RESULTS OF PERFORMANCE OPTIMIZATION . . . . . . . . . . . 3-1

A. EFFECTS OF OPTICAL EFFICIENCY AND GEOMETRIC CONCENTRATION RATIO .................. . 3-1

B. RECEIVER APERTURE OPTIMIZATION . . . . . . . . . 3-1

C. EFFECTS OF REfLeCtANCE AND BLOCKING FACTOR . . . . . . . 3-4

D. EFFECTS OF SLOPE, SPECULARITY, AND POINTING ERRORS . . . . 3-5

E. EFFECTS OF FOCAL RA:'TO AND OVERALL SHAPE OF CONCENTRATOR . . . . . . . . . . . . . . . 3-6

F. EFFECTS OF RECEIVER TEMPERATURE . . . . . . . . . . . . 3-7

G. EFFECT OF ENGINE TYPE .................. 3-9

H. EFFECT OF RECEIVER ABSORPTANCE AND RECEIVER LOSSES. . . . . 3-11

I. EFFECTS OF INSOLATION LEVEL AND PART-LOAD PERFORMANCE . . . . 3-14

J. EFFECTS OF A SECONDARY CONCENTRATOR . . . . . . . . . 3-16 
R. BFEECTS OR HIND 8CREENS AND INERA-RED REELECTORS. $\cdot$. . 3-18

L. EEPECTS OF WINDOWB. . . . . . . . . . . . . 3-19

M. SYSTEM considerations . . . . . . . . . . . . . 3-20

IV. METHODS ROR COST OPTIMIZATION . . . . . . . . . . . . . 4-1

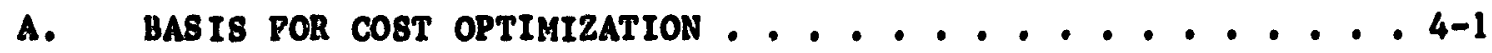

B. cost calculation and optimization . . . . . . . . . 4-2

v. RESULTS of cost ORTIMIZATION. . . . . . . . . . . . . 5-1

A. EFPECT OF COLLECTOR CO8T ................ 5-1

B. EFfects of COLLECTOR PERPORMANCE . . . . . . . . . . 5-1

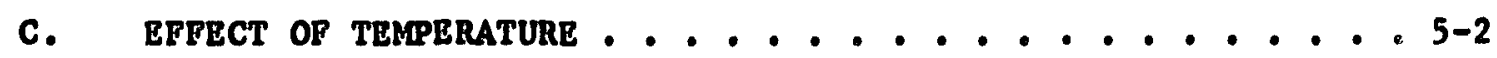

D. EFFECT OF MOdULE SIZE .................. 5-3

REFERENCES .......................... 6-1

APPENDIXES

A. ASSUMPTIONS FOR COST CALCULATIONS ........... A-1

B. FIGURES . . . . . . . . . . . . . . . B-1

Tables

3-1. Characteristics of Ideslized System . . . . . . . . . 3-2

3-2. Characteristics of Baseline system. . . . . . . . . . 3-3

3-3. Effects of Reflectance and Blocking-Shadowing

Factor upon Optimization of Receiver Aperture . . . . . . 3-5

3-4. Effect of Heat Transfer Coefficients upon

Collector Performance uptimization . . . . . . . . . 3-13 
PART ONE

EXECUTIVE SURALARY 


\section{BXECUTIVT SURAARY}

A dioh oolar collector conelets of dioh concentrator with a recelver mounted at ite focus. It provides a convenient meano of converting eolar energy into ligh-tomperature heat, which may be either used directly or converted to mechanical or electrical energy.

This paper addresese probleme of optimizing the optical characterietics of dish collectors for solar thermal power syetems, presente methode for optimization, and examines the effects of varioue optical, thermal, and cout variables. Performance optimization may be done on the basie of the collector efficiency or, more narrowly, on the ufficiency of the concentrate plue the receiver aperture; that is, the ratiol (net oolar energy into the receiver apertire)/(direct ounlight incident on the concentrator). If the collector formo part of a eyotem for production of mechanical work or electricity, performance optimization on the basib of eyotem efficiency is preferable. For present purposes, this can be replaced by optimization on the basis of the combined efficiency of the concentrator, receiver, and engine; that is, the ratio: (engine output power)/(direct sunlight incident on the concentrator). The report primarily considers performance at rated load but devotes ome attention to performance at part load. Part-load behavior can be important in determining performance on an annual basis because the syatem will probably run an appreciable fraction of the year under conditions of low inoolation (incoming sunlight) or low demand.

The most important performance optimization for a dish collector is that of collector efficiency as a function of receiver aperture. If the receiver aperture is too large, thermal losses out the aperture will reduce efficiency unnecessarily. If the receiver aperture is too small, a significant fraction of the concentrated sunlight will not enter the aperture and will be lost, again reducing efficiency. The collector efficiency is rather sensitive to the choice of aperture. Other optimizations include collector efficiency versus focal length, and, if a hest engine is used, system efficiency versus receiver temperature. The efficiency peaks associated with focal length and receiver temperature are relatively broad, so the efficiency obtained is not 
very cenoltive to changes in these characteriotica. In one example the tomperature at wich peak efficiency to echleved was $1000^{\circ} \mathrm{C}\left(1830^{\circ} \mathrm{F}\right)$, but at $675^{\circ} \mathrm{C}\left(1250^{\circ} \mathrm{F}\right)$ the efficiency was $95 \%$ of the peak efficiency. It may accordingly be deofrable to deelgn the oyotem to operate at a temperature conelderably below that correoponding to park efficiency.

Performance optimization is quite ceneitive to the elope and epecularity errors of the concentrator. 8lope errore in the concentrator optical surface result from the deaign, from inaccuracies in manufacturing and installation, and from deflectione in eervice due to gravity, wind, and comperature changeu. Minimising elope errors is often kay to the deeign of an efficient collector. Specularity opread (the angular opread of collimated light when reflected from a emell or flat portion of a mirror) depende etrongly on the mirror materials glase mirrore generally have better epecularity than metalor plastic-base mirrors. If the elope errors and epecularity epread of a concentrator are high, the efficlency of the collector will tend to be low, especially at high receiver temperatures; slope errors and epecularity are less important at low raceiver cemperatures.

Other optical and thermal variables affecting optimization are the reflectance and the blocking factor of the concentrator and the absorptance and thermal loses of the receiver. (The blocking and shadowing factor is the fraction of the sunlight that is not blocked or shadowed by elements of the concentratir, by equipment mounted on or near the concentrator or by nearby concentrators.) To reduce receiver losses, cavity receivers are almost always used in dish collectors. Cavity receivers have two advantages over open receivera: (1) For a given heat tranbfer area, cavity receivers provide a smaller exposed area for radiation and convection $1088 e s$, and (2) the cavity design increases the effective aborptance for oolar radiation.

If a heat engi is used, engine characteristics affect collector optimization, in particular the shape of the engine efficiency versuo temperature curve. For this reason, in examples examined, the efficiency of systems with Brayton engines peaked at receiver temperatures $330-400^{\circ} \mathrm{C}$ $\left(600-720^{\circ} \mathrm{F}\right)$ higher than did those with Rankine or stixling engines. 
Collector and engine perforwance at leos then nowinal incoletton (part-lood) ohould aloo be considared in etriving for optimum annual partoresence.

Performance may sometimas be improved by the uee of an additional optical element (a secondary concentrator) to provide addielonal concentrerton of the incoming ounlight or by the use of a windos over the recelver aperture. These optione are likely to be advantegeous only if tive errore of the primary concentrator are large or the recelver temperature is high. Use of a secondary concentrator oignificanty affecte optimization of other componentes thus, the optimum focal length of the primary concentrator and the iptimum temperature of the recelver may be changed by the introduction of a secondery concentrator. Collector elemente that in come circumetancee may improve collector performance include wind ecreene and infra-red reflectore to return some of the emitted radiation to the receiver aperture.

Cost optimization of dish solar coliectors and of dish solar tharmal systems tends to be difficult because of the lack of reliable cost data. Herdly any dish collecture are beyond the prototype otage; coote and pricos in volume production are therefore only estimates; coste of operation and maintenance are even more uncertain. To obtain meaningful data on the price differential between concentrators with different slope errors, for example, is almost impossible at present. still more difficult is determining how this differential varies with the production rate. In this paper, therefore, discussion of cost trade-offo is limited to those in which the collector cost and efficiency are asoumed to be known. Cost optimization is here made on the basis of the busbar energy cost of the electricity produced or the cost of the heat delivered, depending on the product. Other measures of cost, such as the cost per unit of installed capacity, could be utilized.

Projected collector costs are typically near $50 \%$ of total capital costs for a parabolic dish solar thermal power plant. In an example examined, a 17 increase in collector cost increased the cost of the electricity produced by 0.6\%. A 17 decrease in collector efficiency increased the cost of electricity produced by $2 \%$. As the efficiency continues to decrease, the cost of the electricity rises more rapidly; at low efficiencies, it is not posoible to obtain low electricity cost even if the collector is free. 
8lope errot hat a eafor effect on the efficiency that can be obtalnad and hence on the coet of electrictey produced. It also can be expected to have aignifisant effect on the cost of manufecturing and inotalling a collector. Conoldering only the efflelency effect, in an example conoldared, the levelised bubber enerey coet rose from about $70 \mathrm{mlllo} / \mathrm{kH}-\mathrm{h}$ at a diope error of 0.5 milliradians to $130 \mathrm{mille} / \mathrm{kW}-\mathrm{h}$ at $\mathrm{S}$ arad and over $200 \mathrm{milla} / \mathrm{kW}-\mathrm{h}$ at 10 mrad. The trade-off betwean manufacturing cost to ateain a epecifle -lope error and the reoulting parformance to thus quite importent.

Changes in receiver temperature al wo affect efficiency, and therefore cost, if electricity or mectianical work to baing produced. As mentioned above, eyotem efficiency goes through a rather flat paak as the temperature ie variad. High temperatures neceesltate use of more expeneive material and tend to exacerbate problem of lifetime, reliability, and maintenance. (Maintenance and operations costo over a 30-year plant lifetime are projected at more than $50 x$ of capital coet, in real dollare.) Thue, the optimum receiver temporature on the basis of cost will usually be well below that on the basis of efficiency.

In contrast, receiver aperture size, which has a strong effect on efficiency and hence on the coat of energy produced, has no significani direct effect on collector cost. Accordingly, the optinus. receiver aperture on the basis of efficiency will also be optimum on the basis of coet.

The use of accondary concentrator may sometimes permit attninment of adequate efficiency with a primary concentrator having larger olope errors than would otherwise be possible. The saving in cost of the primary may more than offset the cost of the small secondary. Because of efficiency considerations, this choice is likely to be advantageous only if the receiver temperature is high.

The cost/output ratio of a collector tends to be high at very small concentrator aizes because of the cost of concentrator drive and controls. It tends to be high at very large concentrator sizes because of the cost of concentrator structure: the output varies as the square of the linear dimension, but tile structural weight and cost vary as the cube. Minimum cost per unit output is obtained at intermediate size (5- to 15-m-diameter). 
The ainimum is very flat. However, tha thole eyetem, not arely the collector, ohould be conoldered. If an englne is wounted on each collector, engine oise and collector olse muet be matched. Very omall anglner (below $10 \mathrm{kH}$ output) tend to be lese efficlent than larger ones and to coet more por unit output. This drives the coet optinum to somowhet larger dises than if only the collector is examined.

$$
\text { Sowe cypical cherarestetce pertinent to dish noler collectore for }
$$
therral power syeteme are

\begin{tabular}{|c|c|}
\hline Concentrator diamater & $5-15 \mathrm{~m}$ \\
\hline Concentrator - lope error & $1.5-10 \mathrm{mrad}$ \\
\hline Recelver type & Cavity \\
\hline Receiver aperture diameter & $0.1-0.5 \mathrm{~m}$ \\
\hline \multicolumn{2}{|l|}{ Receiver temperature } \\
\hline For production of hest & $150^{\circ} \mathrm{C}\left(300^{\circ} \mathrm{F}\right)$ and up \\
\hline For production of elecisicity or wirk & $350-900^{\circ} \mathrm{C}\left(700-1650^{\circ} \mathrm{F}\right)$ \\
\hline $\begin{array}{l}\text { Anticipetes for fusure } \\
\text { presuction of electricity }\end{array}$ & to $1300^{\circ} \mathrm{C}\left(2400^{\circ} \mathrm{F}\right)$ \\
\hline Collector efficiency & $0.4-0.9$ \\
\hline
\end{tabular}


PART TWO

OPTIMIZATION OF DISH SOLAR COLLECTORS WITH AND WITHOUT SECONDARY CONCENTRATORS

$1-1$ 


\section{SECTION I}

INTRODUCTION

A dish solar collector (Figure 1) consiete of a dish concentrator with a receiver mounted at $i t s$ focus and provides a convenient method of converting solar energy into high-temperature heat. This heat may be efther used directly or converted to mechanical or electrical energy. Diah concentrators may have a wide variety of optical, thermal, mechanical, and electrical configurations and may also differ in the materials and control systems used; many dish concentrators of current interest are reviewed in Reference 1. References 2 through 4 describe some receivers of interest for dish collectors. This report addresses problems of optimization of the optical characteristics of dish collectors for solar thermal power systems. Pertinent earlier work includes References 5 through 12. 
SBCTION II

METHODS FOR PERFORMANCE OPTIMIZATION

\section{A. Basis fOR performance optimization}

The most fundamental decioion in optimization to the choice of quantity to be optimized. For solar thermal power systems, one may optimize oome messure of performence or some quantity that relates output and cost. Efficiency is a good measure of performance, but efficiency of what? Can the efficiency of the concentrator and the efficiency of the receiver be optimized separately? It turus out that the efficiency of the receiver is oo strongly dependent upon the concentrator characteristics that a measure of concentrator performance which ignores the receiver is of little use, and vice verse. The size of the receiver aperture strongly affects both the solar power delivered to the receiver by the concentrator and the thermal power lost out the aperture by the receiver. A large receiver aperture permits more of the concentrated sunlight to enter the receiver but aleo increases radiative and convective losses out the aperture. Receiver aperture size thus must be optimized. This optimization interacts with the optimization of the concentracor itself: the concentrator performance needed dependo upon the receiver aperture size. The temperature of the receiver is also important, as it strongly affects the $108 s$ out the receiver aperture and hence the optimization of the aperture size, which in turn is critical in evaluating collector performance. Such other receiver characteristics as losses out the walls do not react back so much on concentrator optimization and may or may not be considered. Therefore, the efficiency of the collector as a whole (concentrator and receiver together) must be optimized, with receiver temperature and reseiver aperture size as key optimization parameters.

If the power system includes a heat engine for conversion of thermal to mechanical energy, there is an important interaction between the engine and the collector through the receiver temperature. The engine efficiency is strongly dependent on the engine inlet temperature, which usually approximates the receiver temperature. As the receiver temperature increases, the engine efficiency increases; however, the receiver thermal losses also increase, so 
the receiver efficiency decreases. This interaction between the receiver and the engine efficiencies affects the choice of receiver temperature, which in curn affects the selection of receiver aperture. To optimize the efficiency of a solar thermal power aystem whose output is mechanical work or electricity, one must consider the dependence of engine efficiency upon temperature as a factor in optimizing the collector.

If the input to a receiver or engine varies, the receiver or engine losses do not vary in proportion because receiver and engine efficiencies depend on the input or, corregpondingly, with the output. To optimize the performance of a plant that is to operate for years with varying insolation and varying demand, one should consider part-load as well as rated load efficiencies.

Solar power system components downstream of the engine, such as the alternator and power conditioning, usually do not interact strongly with collector performance and may ordinarily be diaregarded in collector optimization.

This report, therefore, deals specifically with optimization of collector performance in terms of: (1) the efficiency of the concentrator plus receiver aperture; that is, the ratio (net solar energy into the receiver aperture)/ (direct sunlight incident on the concentrator); and (2) the combined efficiency of the concentrator, receiver and engine; that is, the ratio (engine output power)/(direct sunlight incident on the concentrator). Relative values of engine efficiency are adequate for this purpose hecause multiplying all engine efficiencies by a constant will not affect the concentrator optimization. Performance at rated load will be consldered for the most part, but some attention will given to performance at part losd. (Direct sunlight, mentioned above, is sunlight that reaches the concentrator without having been scatered or reflected by the Earth's atmosphere or surface).

B. COLLECTOR PERFORMANCE CALCULATION WITH SIMPLE DISH CONCENTRATORS

The equation (modified from Reference 6) used for net rate of heat collection is

$$
\begin{aligned}
& Q_{c}=\operatorname{IA\rho G} \phi \alpha-A_{r}\left[\epsilon \sigma\left(T_{r}^{4}-T_{a}^{4}\right)+h_{c}\left(T_{r}-T_{a}\right)\right]-A_{w} k\left(T_{r}-T_{a}\right) \\
& \text { 2-2 }
\end{aligned}
$$


Qc - not rata of heat collaction

I - direct oular flux incident upon a plane perpendicular to the oun line

A - optical area of the concentrator, projected on a plane perpendicular to the mun line

P - reflectance of the concentrator mirror (or tranamittance of the cancentrator lons)

G - the geometric blocking and madowing factor (fraction of sunlight that is not blocked or whadowed by elemente of the concentrator. by equipment mounted on or near the concontrntor, or by nearby concent r....res)

- the intercept factor - (concentrated nolar power antering the receiver nperture)/(concentrated aolar power reaching the focal plano)

a - the effective ahnorptance of the receiver for nunlight

Ar - aron of the recoiver aperture

- Effective emitcance of the receiver for thermal radiation

o - Holtrmann'a conotant

$T_{r}$ - temperature of the recoiver, ahaolute

$\mathrm{T}_{\mathrm{s}}$ - Comperature (ambiant) of the surroundings, abaolute

h. - Nfective convection coefficient

$A_{w}$ - Preceiver cavity wall aroa

$k$ - conduction coefficient

Equation (1) assumes that the concentrator is pointed close to the sun line. This will ordinarily he true for a dish concentrator during operation. Rquation (1) also asaumes that a cavity recoiver is used, that the cavity can be trased as a hlack-body cavity (or hohlraum, with the receiver cemperatura taken as uniform and the rocoiver aperture area small compared to the cavity wall area): that one may neglect the fraction of energy radiated by the rocoiver which is returned to the receiver from the surroundings: that an effece ive convection coefficient, $h_{c}$, can he defined for the receiver aperture; and that the heat transfer coefficients, $h_{c}$ and $k$, are independent 


\section{ORIGINAL PACE I8 \\ OF POOR QUALT}

of temperature, of onvironmental effects such os wind, and of receiver aperture size. These are approximatione that are likely to be adequate for optimization of the kind treated in this report. Equation (1) should generally give results with an accuracy of 5 to $10 \%$.

The collector efficiency

$$
\begin{aligned}
& \eta_{\text {coll }}= \text { (rate of heat transfer to the working fluid)/(direct solar power } \\
& \text { incident upon the concentrator) } \\
&=Q_{c} / I A \\
&-\rho G \phi a-(1 / I C)\left[E \sigma\left(T_{r}^{4}-T_{a}^{4}\right)+h_{c}\left(T_{r}-T_{a}\right)\right]-\left(A_{w} / I A\right) k\left(T_{r}-T_{a}\right)
\end{aligned}
$$

where

$$
C=A / A_{r} \text {, the concentration ratio }
$$

The optical efficiency of the concentrator is defined as:

$\eta_{\text {opt }}=$ (solar power delivered to the receiver)/(direct solar power incident upon the concentrator)

This is equal to

Al 80

$$
\eta_{\text {opt }}=\rho G \phi
$$

$$
\eta_{\text {coll }}=\eta_{\text {opt }} \eta_{\text {rec }}
$$

where the receiver efficiency

$$
\begin{aligned}
& \eta_{\text {rec }}=\begin{array}{l}
\text { (solar power delivered to the receiver)/(rate of heat tranofer } \\
\text { to the working fluid) }
\end{array} \\
& =a-(1 / P G \phi)\left\{(1 / \mathrm{IC})\left[\epsilon \sigma\left(\mathrm{T}_{r}^{4}-\mathrm{T}_{a}^{4}\right)+h_{c}\left(\mathrm{~T}_{r}-\mathrm{T}_{a}\right)\right]-\left(A_{w} / I A\right) k\left(T_{r}-\mathrm{T}_{a}\right)\right\} \text { (6) } \\
& \text { C. PERFORMANCE OPTIMIZATION FOR SIMPLE DISH COLLECTORS }
\end{aligned}
$$

An optimization that is commonly done is that of selecting the receiver aperture area, $A_{r}$, to maximize the collector efficiency, $\eta_{c o l l}$, at a given receiver temperature, $T_{r}$, and with given values of $\rho, G, \alpha, \epsilon, T_{a}, h_{c}$, and $k$ (see Equation 2). The geometric concentration ratio, $C$, is an explicit function of $A_{r}$ (Equation 3 ). Increasing the receiver aperture, $A_{r}$, tends to decrease the collector efficiency, $\eta_{\text {coll }}$, by Equations (2) and (3) because 


\section{Oritainal pace to \\ OF Poon quakm}

it increasne the heat lost out the aperture by re-radiation and convection (the right-hand portion of Equation 2). The intercept factor, $\phi$, 10 also a function of $A_{r}$ because a larger receiver aperture will, in general, intercept more of the concentrated eunlight reaching the focal plane. This increases $\phi$, and, by Equation (2), tends to increase the collector efficiency, $\eta_{\text {coll }}$. There is, therefore, a receiver aperture at which $\eta_{\text {coll }}$ is maximum. To find this maximum, the intercept factor, $\phi$, must be expressed as a function of the aperture size. To do this, it is necessary to know how the concentrated sunlight is satially distributed in the focal plane.

For a given concentrator design, the flux distribution in the focal plane can be calculated by ray tracing, Monte Carlo, or cone optica methods. Ray tracing, even with a computer, tends to be tedious and somewhat expenoive. Monte Cariv and cone optics calculations are leas expensive. However, these methods still involve considerable cost and do not appear to be necessary for system studies and optimization although they are appropriate for detailed optical design of a selected concentrator. For optimization studies, less exict approyimations are ordinarily adequate.

The approximation used here, devised by Duff and Lameiro (Reference $13)$, treats the flux diatribution in the focal plane and the variables contributing to it as Gaussian distributions. For a point-focusing concentrator whose overall contour is that of a paraboloidal mirror, with a cavity or flat receiver, Duff and Lameiro find

$$
\begin{aligned}
\sigma_{\mathrm{f}}^{2} & =\frac{\sigma_{r}^{2}}{\mathrm{R}^{2}}=\delta^{2} \frac{1}{\theta \tan ^{2} \frac{\theta}{2}}\left[\frac{-1}{3 \sin ^{3} \theta \cos \theta}+\frac{2-\cos \theta}{3 \sin ^{3} \theta}+\frac{2-2 \cos \theta}{\sin \theta}\right. \\
& \left.+\frac{4 \sin \theta}{3 \cos \theta}-\ln \tan \left(\frac{\pi}{4}+\frac{\theta}{2}\right)+\ln \tan \left(\frac{\pi}{l_{t}}-\frac{\theta}{2}\right)\right]
\end{aligned}
$$

For a point-focusing concentrator (mirror or lens) whose overall1 contour is planar, with a cavity or flat receiver, Duff and Lameiro find

$$
\sigma_{f}^{2}=\frac{\sigma_{r}^{2}}{R^{2}}=8^{2} \frac{1+2 \cos ^{2} \theta}{3 \theta \cos \theta \sin \theta}
$$




\section{OAlGinal page is \\ OF POOR QUALITY}

Here (see Bigure 1):

$\sigma_{f}-\sigma_{r} / R=$ otandard deviation of the (Gaussian) flus distribution in the focal plane, in unite of concentrator radius.

$\sigma_{r}$ - standard deviation of the (Gauseian) flux distribution in the focal plane, in unito of length.

$R$ - radius of concentrator.

- rim angle of the concentrator, as seen from its focus (angle between the focus-to-vertex axial direction and the rim direction).

$$
8^{2}=\quad\left(2 \sigma_{\text {slope }}\right)^{2}+\sigma_{\omega}^{2}+\sigma_{p}^{2}+\sigma_{\text {sun }}^{2}
$$

Glope - standard deviation of the (Gauesian) slope errors of the concenirator.

$\sigma_{\omega}$ - standard deviation of the (Gansoian) specularity apread of the optical ourface(s). $\sigma_{p}=\begin{aligned} & \text { standard deviation of the (Gaussian) pointing error of the } \\ & \text { concentrator. }\end{aligned}$

$\sigma_{\text {sun }}$ - standard deviation of the (Gaussian) angular spread of the incoming direct sunlight.

Also, the rim angle, $\theta$, is related to the focal length, $F$, of the concentrator by

$$
f_{r}=F / D=(1+\cos \theta) /(4 \sin \theta)
$$

for a paraboloidal concentrator (see Figure 1)

and

$$
f_{r}=F / D=1 /(2 \tan \theta)
$$

for a planar concentrator, where

$$
\begin{aligned}
F_{r} & =\text { focal ratio } \\
F & =\text { focal length } \\
D & =2 R=\text { diameter of concentrator }
\end{aligned}
$$

The Duff-Lameiro approximation for paraboloidal mirrors resembles that of Aparisi (References 14 and 15) and is very close to the Aparisi approximation 


\section{ORIGINAL PAOE 18 \\ of POOR QuALim.}

for rim angles lee than $45^{\circ}$ (Plgure 2). However, the Apariol approximation

$$
\sigma_{f}^{2}-\sigma_{r}^{2} / R^{2}-8^{2} / \ln ^{2} \theta
$$

indicates that the eize of the focal opot, $\sigma_{f}$, decreases continuously as the rim angle, $\theta$, incresses over the range from 0 to $90^{\circ}$. The Duff-Lameiro approximation for paraboloidal mirror indicates that the focal of decreases to a minimum and then increases a the ritn angle increases (see figure 2). The latter characteristic accords with the resulto obtained with the more exact calculatione of cone optics and ray-tracing, whereas the Aparisi result does not (Reference 16 ). When wide range of $r$ im angles are to be conoidered, the Duff-Lameiro approximation appears, therefore, preferable. Also, Aparisi did not provide an expresoion for planar concentrators; Duff and Lameiro did (Equation 8 ).

Duff and Lameiro did not include the $\sigma_{\omega}^{2}$ term in Equation (9), but Wen et al (see Reference 10) have used it. The Duff-Lameiro derivation assumes that

$$
\theta>2 \sigma_{\text {slope }}+\sigma_{\omega}+\sigma_{p}+\sigma_{\text {sun }}
$$

which should be true for all practical concentrators. More aignificantly, it assumes that the concentrator slope errors, the concentrator specularity, the pointing errors, and the angular distribution of direct sunlight are all normally distributed (Gaussian). This is probably a reasonable firat approximation for slope errors though one may expect a different variance for circumferental slope errors than for radial. For lens concentrators, a term to account for spectral dispersion should be added to Equation ( 9 ). The angular distribution of a light beam after specular reflection from a flat glass mirror appears to be adequately described by a Gaussian distribution, but if reflection is from a metal or polymeric mirror, the sum of two norma: distributions may be needed for a good description (Reference 17). The pointing errors are probably Gaussian to a first approximation; their distribution will depend upon the control scheme used. For solar radiation, a Gausaian angular distribution is a rather crude approximation, though its accuracy dependo on atmospheric conditions (Reference 18). Unless the concentrator is unusually 
accurate, however, $\sigma_{\text {oun }}^{2}$ is conoiderebly analles then $\left(2 \sigma_{\text {olope }}\right)^{2}+\sigma_{\omega}^{2}+\sigma_{\mathrm{p}}^{2}$ (see Equation 9), so the inexactnese of the effect upon the flux dietribution in the foeal plane (Roference 10 ). Equationa ( 7 ) and (8) are probably accurate within $10 \%$ for most caces of practical intereat.

Utilizing Equation (7) or (8), the flux dietribution in the focal plane is

$$
J(x)=\operatorname{IApC} \frac{1}{2 \pi \sigma_{f}^{2}} e^{-r^{2} / 2 \sigma_{x}^{2}}
$$

where

$$
\begin{aligned}
& J(r) \text { - flux dietribution in the focal plane as a function of } r \\
& r \text { - radial distance from the focal point in the focal plane. }
\end{aligned}
$$

Then

$$
\begin{aligned}
\phi & =1-e^{-r^{2} / 2 \sigma_{r}^{2}} \\
& =1-e^{-A_{r} / 2 \pi \sigma_{r}^{2}} \\
& =1-e^{-A_{r} / 2 \pi R^{2} \sigma_{f}^{2}} \cdot 1-e^{-A_{r} / 2 A \sigma_{f}^{2}} \\
& =1-e^{-1 / 2 C \sigma_{f}^{2}}
\end{aligned}
$$

or

$$
c=1 /\left(2 \sigma_{f}^{2} \ln \frac{1}{1-\phi}\right)
$$

Figure 3 shows the geometric concentration ratio attainable with a paraboloidal mirror as a function of the slope error and the intercept factor, based on Equations (18), (12), and (9). 


\section{ORIGINAL PAOE IS \\ OF POOR QUALI'T}

Substituting Equation (15) in Equetion (1), dfferentieting with respect to $A_{r}$, and setting the recult equel to zero, we find that the heat collected, $Q_{c}$, and the collector efficiency, $\eta_{\text {coll, }}$ are meximized when

$$
\phi=1-2 \sigma_{f}^{2}\left[\epsilon \sigma\left(T_{t}^{4}-T_{a}^{4}\right)+h_{c}\left(T_{r}-T_{e}\right)\right] /[\rho G a
$$

This value of $\phi$ may be inserted in Equation (18) to give $C$, and these values of $\phi$ and $C$ may then be used in Equation (2) to detgrmine the maximum collector efficiency.

D. SY8TEM PERFOR:LWCE CALCULATION

The overall efficiency of the ooler thermal power oystem is taken as

$$
\eta_{\text {sys }}=\eta_{\text {coll }} \eta_{\text {pc }} \eta_{p p}
$$

where

$$
\begin{aligned}
& \eta_{p c}=\text { efficiency of power conversion } \\
& \eta_{p p}=\text { efficiency of power processing }
\end{aligned}
$$

Power conversion here designates the subsystem that converts the thermal energy from the receiver into mechanical or electrical energy. For a system producing electricity, the power conversion subsystem ordinarily consists of a heat engine, perhaps gearing, a generator, perhaps a rectifier, and auxiliaries. Then

$$
\eta_{\text {pe }}=\eta_{\text {eng }} \eta_{\text {gear }} \eta_{\text {gen }} \eta_{\text {rect }} \eta_{\text {aux }}
$$

where

$$
\begin{aligned}
\eta_{\text {eng }} & =\text { engine efficiency } \\
\eta_{\text {gear }} & =\text { gearing efficiency } \\
\eta_{\text {gen }} & =\text { generator efficiency }
\end{aligned}
$$




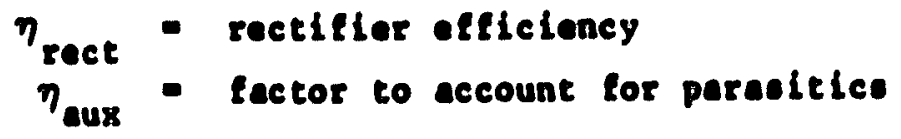

For a syotem producing mechanlcal output, the power converaion oubsyetem consiste of the heat engine, perhape gearing, and auxiliaries. For avetea producing only thermal output, there is no power converaion and $\eta_{p c}-1.0$.

Power processing here refers to elemente of the power eyotem, downetreat of power convervion, which trannmit and condition the energy. For an electrical oyotem, it may include an inverter, cablee, tranoformere, owitchgear, and parhape battery otorage. Tor a mechanical syetem it may include mechenical or hydraulic power tranemiseion and perhape etorage. For a thermal oyetem it may include piping, pumpo, valves, and perhape thermal storage. One may also include in the power processing efficiency the power coneumption for the controle, for etarting, and for power plant buildinge (such as lighting, heating, and air conditioning). The boundary between power conversion and power processing is somewhet arbitrary and may be chosen differently for different oyser designe.

It is cometimes convenient to express the efficiency of the engine in terms of the Carnot efficiency. Thus,

$$
\eta_{\text {eng }}=v\left(T_{i}-T_{0}\right) / T_{i}
$$

where $v$ - engine effectiveness - (engine efficiency)/(Carnot efficiency)

$T_{i}$ - engine inlet temperature, absolute,

$T_{0}$ - outlet temperature of the engine thermodynamic cycle, absolute

Also,

$$
\mathbf{T}_{\mathbf{i}}=\mathbf{T}_{\mathbf{r}}-\Delta \mathrm{T}
$$

where $\Delta T$ is the temperature drop between receiver and engine. 


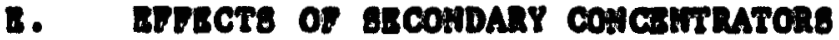

In optical terme, a oimple colar concentrator to one in which the ounlight to reflected or refrected onee by a oingle optleal element (a mirror or lens). A compound concentrator to one in whlch the sunllght is reflected and/or refracted wore than once through the use of two or wore optical elemente. If two are used, the flrot element that the ounlight otrikes lo called the primary concentrator and the eccond element it called the eccondary concentrator.

A collector may Include a eecondary concentrator for any of eeveral reseone. For example, the escondary mey be ueed to fold the optical peth, thus shortening the etructure and perwiteine placement of the receiver (with the pover converaion oubeyoter if one is used) in a more convenient location. It way be used to improve the opticel performance by increasing the geometric concentration ratio or the intercept fector. Different typee of eecondariee may be used for different purposeel thay we reviewed in References 19 and 20. Attention in this report is confined to secondaries intended to improve optical performance. Examples are eketched in Pigure $4(a, b, c$, and d).

By ading a outable eecondary, the flux distribution at the focue can be confined to omaller area then is possible by using only a primery concentrator (for any practical primary design). The geometric concentration ratio cen thus be increased at a given intercept factor, or vice versa. Thio can reduce receiver aperture losses or increase receiver tioperature, which in turn can increase power conversion efficiency. These advantages must be weighed against the light loss asoociated with the reflectance or tranamittance of the secondary mirror or lens.

F. PERORMANCE CALCULATION AND OPTIMIZATION FOR COMPOUND COLLECTORS

When a simple concentrator is replaced by a primary plus a secondary concentrator, the basic equations (Equations 1, 2 and 4 ) for collector performance need be modified only by setting

$$
P=P_{1} P_{2}
$$


where eubecript 1 refers to the primary concentrator and oubecrlpt 2 refaro to the eecondary consentrator.

One way likewlse wite the blocking and shadowing factor, 6 , the Intercept lactor, $\phi$, and the reometric concentration ratio, $C, a$ the producte of correeprinding seperate quentitiec for the prifary and eccondary or may conolder them at factore lor the compound concentrator (primery and escondary cogether).

The flux distribution in the focal plane of a secondary with good

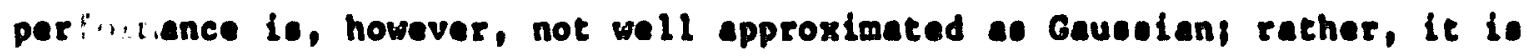
close to rectangular: 1.e., nearly uniform in the center, dropping oherply to near zero at a definite radius (Reference 21 ). This affecte the receiver eperture optimization. With euch a Elux dietribution, the receiver aperture, to alret approximation, should be set equal to the area over which the flux is uniform, and the fraction of the $f$ lux from the secondary that entere the receiver aperture is then 1.0 . With some secondary concentrator designe, the recelver aparture can coincide with the exit aperture of the eecondary concentrator (Figure $4 b, c$, and $d$ ).

The fraction of the flux from the primary liat is intercepted by the seconds: -hould also be optimized. A secondsry used to improve performance will usually be located near the focal plane of the primary. Ao a first approximation, therefore, the flus distribution at the entrance aperture of thi is idary may be approximated by Equation (8) or (9) but spread radially by aroportionality factor to account for the wider distribution in a plane not coincident with the focal plane.

On this basis, the intercept factor of the compound collector is determined by how much of the prinary flus enters the secondary. That is,

$$
\phi=\phi_{1}
$$

where $\phi_{1}$ is the fraction of the primary flux near the focal plane that enters the secondary. 


\section{orIanal PACE b \\ OF POOR QUALIT}

The geometric concentration ratio at this intercept factor to affected by the design of the oecondery, and may be written a

$$
C c_{10} c_{2}
$$

where

$$
\begin{aligned}
& c_{10} \text { - geometric concentration ratio with primary concantrator alono } \\
& c_{2} \text { - multiplicative increase in geometric concentration ratio due to } \\
& \text { the econdary concentrator }
\end{aligned}
$$

The $C$ that can be attainod by uoing a oecondary io limited in two ways. Firot, c cannot excoed the theoretical limit

$$
c_{\max }-1 / \sin ^{2} \psi
$$

at an intercept factor of 1.0 . Here $\psi$ is the half-angle of the sun as scen from Earth, about 4.65 milliradians. $C$, therefore, cannot exceed $1 /\left(4.65 \times 10^{-3}\right)^{2}$ or about 46,000. This is rarely limiting; rather, $C$ is constrained in practice by $\mathrm{C}_{2}$, which cannot exceed a value that depends on the focal ratio of the primary (References 22 and 23), and is generally not more than 30 (Fibure 5). This limiting $C_{2}$ is independent of 8 and hence of $\sigma_{0}$ lope' $\sigma_{\text {spec }}$ and $\sigma_{p}$. Practical secondary designs can come close to the theoretical $\mathrm{C}_{2}$; because $\mathrm{C}_{2}$ is small, it is insensitive to slope orrors and opecularity of the secondary.

On the basis of the above, for a compound collector the optimum intercept factor and geometric concentration ratio, analogous to Equations (19) and (18), are:

$$
\begin{gathered}
\phi=1-2 \sigma_{\mathrm{f}}^{2}\left[\epsilon \sigma\left(\mathrm{T}_{r}^{4}-\mathrm{T}_{\mathrm{\theta}}^{4}\right)+\mathrm{h}_{\mathrm{c}}\left(\mathrm{T}_{\mathrm{r}}-\mathrm{T}_{-}\right)\right] / \mathrm{I \rho CaC_{2 }} \\
\mathrm{c}=\mathrm{c}_{2} /\left(2 \sigma_{\mathrm{f}}{ }^{2} \ln \frac{1}{1-\phi}\right)
\end{gathered}
$$


If the eccondary is large, it will block some ounlight that would otherwise enter the primary concentrator aperture, thus decreasing the geometric blocking factor $G$ in Equation (28). This may require iteration to arrive at an optimum compound collector. Because the secondary size depends on its optical deoign and is not a function of $\mathrm{C}_{2}$ alone, the added blockage will not be evaluated here.

\section{¿. SYSTEM PERFORMANCE OPTIMIZATION}

If the oystem provides mechanical or electrical power, another performance optimization is that of optimizing the overall system efficiency with respect to receiver temperature. As the receive: temperature increases, the receiver losses increase and the collector efficiency falls (Equation 2). The engine inlet temperature is closely coupled to the receiver temperature; as the engine inlet temperature is increased the engine efficiency and, therefore, the power conversion efficiency rises. Because of these opposing effects, the overall system efficiency (Equation 20) will be maximum at some temperature.

To optimize the system efficiency, it is necessary to know the variation in power conversion (or engine) efficiency as a function of inlet temperature. Given this relationship, one may then find the system efficiency at various temperatures by numerical calculation, using Equation (2) and (20), and so locate the maximum. Even if the power conversion effectiveness, $v$, is independent of temperature, so that Equation (22) provides a simple expression for $\eta_{p c}$ as a function of $T_{i}$, substitution of Equations (2), (21), (22) and (23) in Equation (20) gives a fifth-power relation that requires numerical solution:

$$
\begin{array}{r}
T_{o}\left\{\rho G \phi \alpha I-\frac{1}{c}\left[\epsilon \sigma\left(T_{r}^{4}-T_{a}^{4}\right)+h_{c}\left(T_{r}-T_{a}\right)\right]-\frac{A_{w}}{A} k\left(T_{r}-T_{a}\right)\right\} \\
-\left(T_{r}-\Delta T\right)\left(T_{r}-\Delta T-T_{o}\right) \frac{1}{C}\left(4 \epsilon \sigma T_{r}{ }^{3}+h_{c}-\frac{A_{w}}{A} k\right)=0
\end{array}
$$


Computer techniques for obtaining numerical reeults from the equatione mentioned are obvioubly useful and have been utlized in this work.

Both the collector efficiency optimization and the oyotem efficiency optimization mentioned are for a fixed insolation, I. The insolation will, however, vary as a function of time. If detailed records of insolation versus time are available for a site, the output for a given design may be calculated for each short time interval and sum to give the total output over a year selected as typical. The incolation data are typically in form of insolation measurements at 15-minte intervalo, recorded on magnetic tape, which are input to a computer program calculating annual output. By computing the annual output for various receiver apertures or temperatures, the optimum based on yearly output may be determined. The results will differ from site to site.

This report does not consider specific sites. Rather, it uses the simpler but less exact approach of optimizing on the assumption that an insolation is selected as a typical operating point and the collector is optimized at this insolation. 
SECTION III

RESULTS OR PERPORMANCB OPTIMIZATION

Examples in this report are based primerily on two power sybtems. One is an idealized syotem whose charecteristics are given in Table 3-1. The other is the baseline oyotem whose characteristice are given Table 3-2; it wao chosen primarily because useful cost calculatione were already available since a similiar system was used as a baseline in the cost analyses of Revere (Reference 24) and Rosenberg and Revere (Reference 25).

\section{A. EFFECTS OF OPTICAL EFEICIENCY AND GEOMETRIC CONCENTRATION RATIO}

Figures $6 a$ and $6 b$ illustrate the effects of optical efficiency and geometric concentration ratio upon collector performance. For these plots the intercept factor, the receiver temperature, and other collector characteristics were held constant at the values listed for the idealized and baseline aystems, respectively (see Tables 3-1 and 3-2). (To permit changes in the geometric concentration ratio and optical efficiency, the slope error and the reflectance were allowed to vary). Figures $6 a$ and $6 \mathrm{~b}$ show that collector efficiency is very strongly dependent on optical efficiency. At low genmetric concentration ratios, the collector efficiency is olso very strongly dependent on geometric concentration ratio, but at higher geometric concentration ratios collector efficiency becomes almost independent of geometric concentration ratio.

\section{B. RECEIVER APERTURE OPTIMIZATION}

Figures $7 a$ and $7 b$ are plots of collector efficiency versus geometric concentration ratio for the idealized and baseline systems. The slope error was held constant for these plots, and the intercept factor allowed to vary. Shown in these figures are the intercept factor, the solar heat absorbed by the receiver, and the receiver thermal loss. The curves display maxima in collector efficiency at the geometric concentration ratio and intercept 
Table 3-1. Characteriatice of Idealized syotem (unless otherwioe otated)

Concentrator type: paraboloidal mirror

Overall concentrator shape: paraboloidal

$$
\begin{aligned}
& I=800 \mathrm{w} / \mathrm{m}^{2} \\
& p=1.0 \\
& G=1.0 \\
& \phi=0.98^{a} \\
& \text { C }=2500^{\circ} \\
& f_{r}=0.6 \\
& \sigma_{\text {slope }}=2.0 \mathrm{mrad} \\
& \sigma_{\omega}=0.5 \mathrm{mrad} \\
& \sigma_{p}=0.0 \\
& \sigma_{\text {sun }}=2.3 \mathrm{mrad} \\
& \alpha=1.0 \\
& \epsilon=1.0 \\
& T_{r}=1185 \mathrm{~K}=912^{\circ} \mathrm{C}=1674^{\circ} \mathrm{F}^{\mathrm{b}} \\
& T_{a}=293 \mathrm{~K}=20^{\circ} \mathrm{C}=68^{\circ} \mathrm{F} \\
& h_{c}=0.0 \\
& k=0.0 \\
& \Delta \mathrm{T}=0.0 \\
& \mathrm{~T}_{0}=293^{\circ} \mathrm{K}=20^{\circ} \mathrm{C}=68^{\circ} \mathrm{F} \\
& v=0.5 \\
& \eta_{\mathrm{pP}}=1.0
\end{aligned}
$$


Table 3-2. Characterietice of Baseline syatem (unless otherwise atated)

\section{Concentrator typel paraboloidal mirror \\ Overall concentrator ohapes paraboloidal}

$$
\begin{aligned}
& I=800 \mathrm{~W} / \mathrm{m}^{2} \\
& \text { P } 0.95 \\
& \text { G }-0.967 \\
& \phi=0.978^{\mathrm{A}} \\
& \text { c }=2500^{a} \\
& f_{r}-0.6 \\
& \begin{aligned}
\sigma_{\text {slope }} & =2.2 \mathrm{mrad} \\
\sigma_{\omega} & =0.5 \mathrm{mrad}
\end{aligned} \\
& \sigma_{p}=0.0 \\
& \sigma_{\text {sun }}=2.3 \mathrm{mrad} \\
& \alpha=0.982 \\
& \text { c } \quad 0.998 \\
& \mathrm{~T}_{\mathrm{r}}=1198 \mathrm{~K}=925^{\circ} \mathrm{C}=1700^{\circ} \mathrm{F} \\
& \mathrm{T}_{\mathrm{a}}-293 \mathrm{~K}=20^{\circ} \mathrm{C}=68^{\circ} \mathrm{F} \\
& h_{c}=16.0 \mathrm{~W} / \mathrm{m}^{2} \mathrm{~K} \\
& A_{w} / A=0.015 \\
& k=0.737 \mathrm{~W} / \mathrm{m}^{2} \mathrm{~K} \\
& \Delta \mathrm{T}=20.0 \mathrm{~K}=20^{\circ} \mathrm{C}=36^{\circ} \mathrm{F} \\
& \mathrm{T}_{\mathrm{O}}=323 \mathrm{~K}-50^{\circ} \mathrm{C}=122^{\circ} \mathrm{F} \\
& \eta_{\mathrm{pc}}=0.346 \\
& \text { Variation of } \eta_{p c} \text { with } T_{Y} \text { : } 8 \text { s shown for Brayton } \\
& \text { system in Figure } 17 \mathrm{~b} \text {. } \\
& \eta_{\text {pp }} \\
& =0.95
\end{aligned}
$$

If not optimized

bIf not varied 
factor given by Equatione (18) and (19): about $C=2500$ and $\phi-0.988$ for the idealized gyotem; $C=2400$ and $\phi-0.981$ for the baseline syotem. The peak is fairly sharp, illustrating the importance of optimizing the receiver aperture. A drop in geometric concentration ratio from 2500 or 2400 to 2000 or 1800 has very little effect on efficiency, but a drop to 1000 will appreciably lower efficiency. Below some limiting value of geometric concentration ratio ( 140 to 190 for these examples), the collector heat 1088 becomes equal to the solar energy entering the collector, and the efficiency falls to zero. Above the peak geometric concentration ratio, the efficiency falls because of the decrease in intercept factor.

In a practical concentrator, it may be tesirable to select a recaiver aperture different from that giving maximum efficiency. For example, it may be desirable to increase the aperture size beyond this optimum to reduce heating of the aperture lip by the concentrated ounlight.

Typical receiver aperture diameters are 0.1 to $0.5 \mathrm{~m}$ for concentrator diameters of 6 to $13 \mathrm{~m}$, providing geometric concentration ratios of 100 to 3000. Geometric concentration ratios below 500 may be considered low for dish collectors; ratios above 2000 may be considered high. The corresponding intercept factor io typically 0.9 or more. Typical optical efficiencies are 0.7 to 0.95 (see Reference 1 ).

\section{EFFECTS OF REFLECTANCE AND BLOCKING FACTOR}

The optimum values of geometric concentration ratio and intercept factor are dependent upon the product of the reflectance and the blocking-ahadowing factor. Table 3-3 illustrates the effect of changing these quantities. A moderate decrease in reflectance or blocking factor produces a corresponding decrease in collector efficiency; the optimum geometric concentration ratio is increased slightly; the optimum intercept factor decreases very slightly.

Typical values of reflectance are 0.8 ro 0.95 ; the blocking-shadowing factor is typically higher than 0.9 . 
Table 3-3. Effecto of Reflectance and Blocking-Shadowing Factor upon Optimization of Receiver Aperture

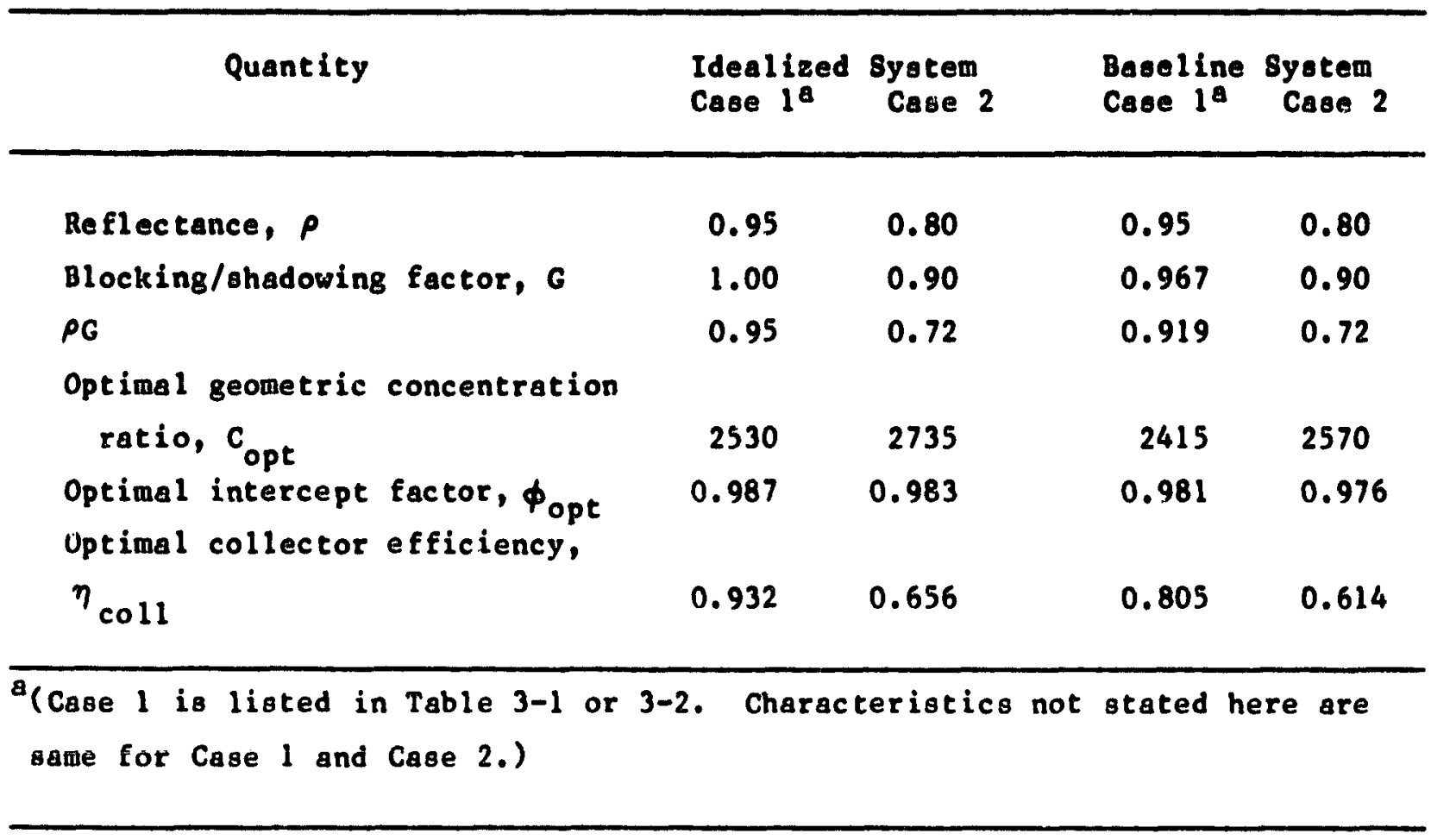

D. EFFECTS OF SLOPE, SPECULARITY, AND POINTING ERRORS

An error in slope of a (primary) concentrating mirror deviates the reflected beam through an angle twice the slope error. A deviation due to lack of specularity or to a pointing error deviates the reflected beam, with respect to the receiver aperture, by once the specularity or pointing deviation. Thus the flux distribution at the focal point, the intercept factor, and the collector efficiency are strong functions of the slope error and less strong functions of the specularity and pointing errors (Equations 9, $7,8,13-19$, and 2). Figure 8 shows the effect of slope error upon the collector efficiency and intercept factor. Figure 9 shows the ef sect of specularity apread; the effect of pointing error is similar.

As these figures indicate, the collector efficiency attainable with an optimized receiver aperture depends on the concentrator errors, as do the optimum geometric concentrator ratio and intercept function. If the 
concentrator errore ere $\mathrm{hlgh}$, the atcinable collector efflelency, the optinum intercept factor, and the optimum geometric concentration ratio will be low. As the concentrator arroro decrease, the optimized effleiency, geometric concentration ratio, and intercept factor increase coward 1 imiting valuec.

Dieh concentratore typically have elope errore of 1.5 to 10 mrads a - lope error 1080 than 2.5 mrad is uevally conaidered low a olope error more than 5 mrad may be considered high. The opecularity opread is typically about $0.5 \mathrm{mrad}$ for 8 lase mirrore and 2 to $10 \mathrm{mrad}$ for pleatic film and metal

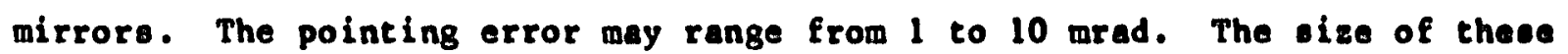
errorb, together with the reflectivity and blocking factor, may be taken to indicate the quality of the concentrator. (Low errore, high reflectivity, and high blocking-ahadowing factor correspond to high quality.) These factore may also correlate with the cost of the concentrator.

E. EFFECTS OF fOCAL RATIO AND OVERALL Shape OF CONCENTRATOR

The effect of focal ratio or, equivalenty, concentrator rim angle (Equation 12) upon collector efficiency is shown in Figure 10 . According to this figure (Duff-Lamerio approximation) the efficiency is maximum at a focal ratio of about 0.43 ( $\mathrm{rim}$ angle about $60^{\circ}$ ) for a mirror concentrator having an overall paraboloidal shape and at a focal ratio of about 0.22 ( $r$ im angle $67^{\circ}$ ) for a mirror or lens with an overall planar shape. These focal ratios (rim angles) are only approximate and depend on the approximations chosen for calculating the flux distribution near the focal point (Equations 7 and 8 ). For a more exact solution, a more exact method such as cone optics should be used. Such calculations (References 26 and 27) indicate that the focal ratio that provides maximum efficiency for an overall paraboloidal shape depends on the intercept factor and varies from a focal ratio of 0.6 (rim angle $45^{\circ}$ ) at an intercept factor close to 1.0 to a focal ratio of 0.4 or less ( $r$ im angle $65^{\circ}$ or more) at intercept factors below 0.8 (Figure 11 ).

To show the effect of slope error upon the focal ratio giving maximum efficiency, the curves of Figure 10 are plotted for both $\sigma_{\text {slope }}=2 \mathrm{mrad}$ and $\sigma_{\text {slope }}=10 \mathrm{mrad}$. The focal ratio for maximum efficiency is seen to be independent of slope error. 
Elgure 10 suggeste that performance will be olightly better if the overall concentrator contour to liet rather than parabololdal. Thle comperioon is Incomplete, however. It the that concentrator to a Franel mirror, the individual fecete will block some of the light reflected from adjacent facete, unlase gepe are left between lacete, and ouch gape will reduce the effuctive concentrator ares or the angles of llluminetion of the receiver aperture. (Altarnatively, facet edgee can be beveled to prevent blocking, but then cunlight otriking the bevele will be reflected away from the receiver and 00 lost.) If the flat concentrator to a Breenel lene, - imilar blocking effecte will occurs but in addition one must conoider apectral dieperaion of the cranemited light and the fact that the effect of lene surface olope errore upon the angular deflection of the ounlight will ganerally be wuch leee than that of mirror ourface lope errors. Accordingly, examination of the effect of concentrator ohape neede to be more detalled than that represented by Figure 10 .

Other coneideratione may also influence the choice of focal ratio. A short focal ratio reduces the length, weight, and cost of etructure to eupport the receiver and power converoion equipment. If the concentrator is a paraboloidal mirror, a short focal ratio meane that the surface must be curved more sharply, which may increase fabrication difficulty and coot. If the concentrator is planar in overall shape, it will probably be impractical to obtain the very hort focal lengtho that Figure 10 suggests ap desirable: practical Bimple lenses usually have focal ratios of 0.7 or more, and flat Fresnel mirrors with very short focal ratios have very high blockage or shadowing of facets by adjacent facets. Dish concentrator mirrora usually have focal ratios between 0.4 and 1.0 , with 0.4 to 0.6 being most conmon.

\section{F. EFFECTS OF RECEIVER TEMPERATURE}

If the receiver temperature is increased, the thermal losses from the receiver of course increase. The re-radiation lose through the receiver aperture increases as the fourth power of the absolute temperature. The free convective $108 s$ out an open aperture probably also increases as the temperature to a power somewhat greater than one, though a linear approximation is used in 
the computer model employed in this work. The forced convection (due to wind) and conduction losece increase approximately linearly with recelver temperature.

The reoult is thet the collector efficiency fallo so the receiver temperature is increased. Figure 12a lilustrates this at fired geometric concentration ratioa. The efficiency fall-off is greater at low geometric concentration ratios. To reduce the recelver aperture loseco, it is desirable to reduce the aperture eize (increase the geometric concentration ratio): the geometric concentration ratio should be rptimized eeparately at each temperaturt of interest (Pigure 13). Even with this optimieation, the collector efficiency continues to fall as the temperature rises and will eventually become zero at temperature where the losece equal the oolar energy into the receiver. This may be termed the "equilibrium temperature."

If the oyetem produces only heat, the receiver temperature is dictated by the use that will be made of the heat. Because of the increase in receiver losses and in heat transport losoes so the temperature rises, there is no advantage in running the receiver hotter than is required to oatisfy the use. If, however, the heat is used to drive heat engine for production of mechanical work or electricity, the effect of temperature upon engine performance must also be considered. The engine efficiency will almost always increase as the engine input temperature increases. The combination of collector efficiency decrease and engine efficiency increase as the temperature riseo means that, for a given system, there is a receiver temperature at which the system efficiency is maximum. Thus, the temperature for maximum system efficiency may be optimized.

In Figure 14, the collector, power conversion, and system efficiencies are shown as functions of receiver temperature. These efficiencies are for a syotem in which the power conversion effectiveness is constant (power conversion efficiency a fixed fraction of the Carnot efficiency) and the receiver aperture is optimized separately at each temperature. Corresponding efficiency curves with a fixed intercept factor are shown in Figure 11. The system efficiency peak is evident in these figures. As for most dish systems, the peak is rather flat. In Figure 14, the peak ( $\eta_{\text {sys-max }}$ ) occurs at 
$1000^{\circ} \mathrm{C}$, the eyotem efflclency to $\left(0.99 \eta_{\text {oyo-ans }}\right)$ at $850^{\circ} \mathrm{C},\left(0.98 \eta_{\text {eyo-max }}\right.$ ) at $785^{\circ} \mathrm{C},\left(0.95 \eta_{\text {oye-max }}\right)$ at $675^{\circ} \mathrm{C}$. Thus, the looe of eyotem efficiency incurred by operating ignificently belos the peak may be rather omall. An Inereace in operating cemperature to likely to ohorten equipment lifetime, increase maintenance and malntenance cost, require uee of more expenolve materiale, etc. Thue, the optimum tomperature on the basis of coet will ueually be lower than that on the basio of effleiency.

Por convenience, the $T_{r}$ at which cyetem efficiency $\eta_{\text {oye }}$ peake may be writcen as $\mathrm{T}_{\max }$, and the $\mathrm{T}_{\mathrm{r}}<\mathrm{T}_{\max }$ ot which $\eta_{\text {oys }}$ is 1 times $\eta_{\text {oys-max }}$ at $T$ : where $1=0.99,0.98,0.95,0.90, \ldots$

Pigure 15 thowe the combined effecte of receiver temperature and mirror nlope error upon collector and yetem efficiency, with the recelver aperture optimized at each temperature. The receiver temperature for peak oyetem efficiency decreasen greatly a sope error Increasen. To obtain high eyotem efficiency, both low lope errors and high receiver cemperatures are needed.

In dish collectors providing heat to engines, typical receiver temperatures currently range from $350^{\circ} \mathrm{C}\left(700^{\circ} \mathrm{P}\right)$ to $900^{\circ} \mathrm{C}\left(1650^{\circ} \mathrm{P}\right)_{\text {; }}$ receiver temperatures up to perhaps $1300^{\circ} \mathrm{C}\left(2400^{\circ} \mathrm{F}\right)$ are being discussed for future use (Reference 28). For process heat, dioh collectors are being used for temperatures as low as $150^{\circ} \mathrm{C}\left(300^{\circ} \mathrm{F}\right)$ (Reference 29).

\section{G. EFFECT OF ENGINE TYPE}

The variation of power conversion efficiency with temperature depends on the engine type. Accordingly, the engine type affects the shape of the curve of system performance versus receiver or engine inlet temperature and the temperature at which system performance is maximum. This in turn influences the selection of the receiver aperture and of the concentrator to be used.

To a first approximation, the effectiveness of a Rankine or stirling engine is independent of engine inlet temperature. The effectiveness (fraction of Carnot efficiency) may be as low as 0.2 for an engine with very low efficiency and perhaps as high as 0.6 for an engine with very high 
efficiency, but these differences In effectivenese morely aultiply the oyotem efflelency by different conetant factores they do not change lte thape, 00 do not change the collector optimisation. Brayton enginee, however, typically heve an effectivenese that increases with increasing inlet tomperature. (Their efflciency io a larger fraction of the Carnot afficiency at high inlet temperature than at low.) The Brayton ayotem efficiency ie therefore maximum at higher inlet temperature than ie that for Rankine or stirling engines (Bigures 16 and 17). Thie driven the recelver design coward higher recelver temperatures and, therefore, omall receiver apertures (high geometric concentration ratios, Pigure 18), this In turn drives the concentrator design toward higher performance (high reflectance, blocking factor, and intercept factor, and correspondingly low mirror and pointing errore, Pigure 19).

Note that for the examples shown in Pigures 16 and 17 the effectivenesecemperature relationehip of a Brayton engine leade to a receiver temperature for maximum system efficiency, $T_{\max }$, which is 330 to $400^{\circ} \mathrm{C}$ higher than that for an engine with constant effectiveness. The shapes of the peaks are almost identical. In the Brayton oystem, for example, the temperature at which the system efficiency resches 0.99 of the peak efficiency $\left(T_{0.99}\right)$ is $115-125^{\circ} \mathrm{C}$ below the peak temperature $\mathrm{T}_{\max }, \mathrm{T} 0.98$ is $160-170^{\circ} \mathrm{C}$ below $\mathrm{T}_{\max }, \mathrm{T}_{0.95}$ is $270-275^{\circ} \mathrm{C}$ below $\mathrm{T}_{\max }$ and $\mathrm{T}_{0.90}$ is $375-405^{\circ} \mathrm{C}$ below (see Figure 17). The corresponding numbers for constant-effectiveness systems, such as Rankine or Stirling, are 125-130, 185-190, 275-305, and $385-415^{\circ} \mathrm{C}$. For the idealized and baseline systems $\mathrm{T}_{0.90}$ is 345 to $410^{\circ} \mathrm{C}$ higher when the Brayton engine is used than when the engine has an effectiveness versus temperature curve characteristic of a Rankine or stirling cycle. With the concentrators listed, the geometric concentration ratio, optimized at these receiver temperatures, is 3620 (idealized system) or 3250 (baseline aystem) with the Brayton engine; it is 2660 (idealized system) or 2480 (baseline system) with the Rankine or Stirling engines (Figures 16 and 17). An examination of the effect of changing slope error would show that a low concentrator slope error would provide a greater performance improvement with the Brayton engine than with the Rankine or stirling.

In dish collector syatems, the engine inlet temperature of Rankine engines is typically 350 to $600^{\circ} \mathrm{C}$ ( 700 to $1100^{\circ} \mathrm{F}$ ), of stirling engines 700 
to $800^{\circ} \mathrm{C}\left(1300\right.$ to $1300^{\circ}$ : : of Brayton engines 800 to $900^{\circ} \mathrm{C}(1300$ to $1650^{\circ} \mathrm{E}$ ), conelderably higher tamperatures are antelpatef for future Brayton engines (see Reference 28). Recelver comperatures are ellghty higher than engine inlet comperatures the difference to uoually lese then $50^{\circ} \mathrm{C}$ $\left(100^{\circ} \mathrm{F}\right)$.

H. RPFECT OF RECEIVER ABSORPTANCE AND RECEIVER LOB8ES

Recalver radiative, convective, and conductive losees all enter into the collactor enerey balance (Equatione 1 and 2 ) and so affect the reculver aperture optimization (Equatione 18 and 19), w well at the temperaturs at which the aystem efficiency peaks if the eystem output is mechanical or electrical onergy. Thun, the receiver emittance and coefficiente of convection and conduction exter into the optimization. The recelver ahoorptance alo entere into the optimization (Equations 1, 18, and 19).

Note, however, that the aboorptance, $a$, and emittance, 6 , in Equation 1 are the effective quantities for the receiver aperture. A cavity receiver is deaigned to approximate a black-body cavity, and the effective aboorptance and emittance of its aperture tend to be high (typically above 0.95), even if the absorptance and emittance of the internal wall are noi (Figure 20). Also, the absorptance and emittance tend to be coupled: for receiver temperatures of interest for point-focusing systems, it is difficult to find materials with high absorptance and low emittance. (The absorptance and imittance are not identical because they pertain to different wavelengths: the absorptance to the solar spectrum at the Earth's surface, which peaks at about $0.5 \mu \mathrm{m}$, and the emittance to the sectrum emitted by the receiver, which peaks at wavelengtho varying from about $4.7 \mathrm{Am}$ for a receiver temperature of $350^{\circ} \mathrm{C}$ $\left(700^{\circ} \mathrm{F}\right)$ to $1.8 \mu \mathrm{m}$ for peceiver temperature of $1300^{\circ} \mathrm{C}\left(2400^{\circ} \mathrm{F}\right)$. The receiver and solar spectrum overlap, however; hence the difficulty of finding materials with high absorptance for solar radiation and low emittance for receiver radiation.)

Point-focusing systems are occasionally designed with open flat or spherical receivers rather than with cavity receivers. Cavity receivers, however, are almost always used because they have two advantages: 
(1) In a cavity receivar, the exposed aran at rocelver camperatire for outgoing radiation and convection to no groater that the exposed area for incoming wolar radiation (both are the receiver aparture area). This in senerally not true for open racelvere.

(2) The cavity dosign incroases the effective aboorptance as compared to that of an open receiver (ace Figure 20). Thio improves performance (Bquation 1). The effective anitence is alpo increaned by the cavity design, but this is usually leas important because ince the firot torm in Bquation ( 1$)$, involving $a$, is larger than the corm involving in any prectical collector. ( $Q_{\text {c }}$ mint be pooltive).

Because the offective aboorptance and amittance of cavity receivera cond to be cloae to 1.0, differencen encountered in chese quantitios among different cavity receiver deaigna do not have much afect on collector performance optimization (Table 3-4).

Convective loses from a receiver aperture are difficult to mensure and there are no wall-entablished theoretical expreasions for tham. Moreover, thea lonses change as the aligle of the aporture to the horizontal change. during the day and as the wind speed and direction change (see Refarance 11 for recant work on this problam). Table 3-4 given an exanple of the effect of a change in aperture convective loss upon collector optimisation. The effect of closing the receiver aperture with a window will be diacussed in subsequent aection.

Conductive logses from the receiver depend on the dimensions and material of the receiver and can be significantly modifiod by changing the thicknesa and conductivity of the inalation betwas the cavity and the axterior of the raceiver. Exterior characterintica affecting the losege from the oftside of the recoiver to the surroundings are probably lese significant. An example of the effect of a difference in conductive los upon collector performance optimiration appears in Table 3-4.

In the examples of Table 3-4, halving the absorptance of the receiver cavity wall causes a slight dopp in efficiency but has almost no offect on the 
Table 3-4. Effect of heat Iransfer Coeficients Epon Collector Performance Optimization Baseline system except as notec. Receiver aperture optisized at each tempe-ature.

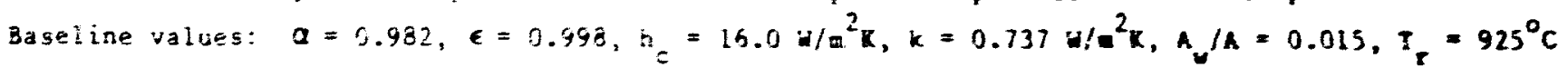

\begin{tabular}{|c|c|c|c|c|c|c|c|c|c|c|c|c|c|c|}
\hline \multirow[t]{2}{*}{ Coeżicients } & \multicolumn{4}{|c|}{$I_{r}=925^{\circ} \mathrm{C}$} & \multicolumn{5}{|c|}{$I_{r}=I_{\max }$} & \multicolumn{5}{|c|}{$T_{r}=I_{0.95}$} \\
\hline & c & $\phi$ & $\eta=011$ & $\eta_{\text {sys }}$ & $\begin{array}{c}I_{\max } \\
{ }^{\circ} \mathrm{C}\end{array}$ & c & $\phi$ & $\eta_{\text {coll }}$ & $\eta_{\text {sys }}$ & $\begin{array}{c}\tau_{0.95} \\
{ }_{0}\end{array}$ & c & $\phi$ & $7 \operatorname{coll}$ & 7 sy: \\
\hline \multicolumn{15}{|l|}{ Baseline } \\
\hline $\begin{array}{l}a_{\text {zall }}=0.59 \\
\epsilon_{\text {vall }}=0.93\end{array}$ & 2410 & 0.981 & 0.805 & 0.255 & 1295 & 3250 & 0.948 & 0.698 & 0.320 & 1025 & 2350 & 0.975 & 0.781 & 0.304 \\
\hline $\begin{aligned} a_{w a 11} & =0.30 \\
a & =0.941\end{aligned}$ & 2440 & 0.930 & 0.758 & 0.252 & 1295 & 3290 & 0.945 & 0.552 & 0.304 & 1015 & 2620 & 0.974 & 0.745 & 0.289 \\
\hline $\begin{aligned} \epsilon \text { dali } & =0.45 \\
\epsilon & =0.970\end{aligned}$ & 2400 & 0.0 & 0.807 & 0.255 & 1300 & 3260 & 0.947 & 0.695 & 0.322 & 1030 & 2500 & 0.975 & 0.782 & 0.303 \\
\hline $\begin{aligned} a_{* a 11} & =0.30 \\
a & =0.941\end{aligned}$ & 2620 & 0.981 & 0.770 & 0.253 & $i 295$ & 3260 & 0.947 & 0.666 & 0.305 & 1015 & 2600 & 0.974 & 0.748 & 0.289 \\
\hline $\begin{aligned} \epsilon \text { all } & =0.45 \\
\epsilon & =0.970\end{aligned}$ & & & & & & & & & & & & & & \\
\hline$n_{c}=32 \pi / m^{2}$ & 2630 & 0.979 & 0.797 & 3.262 & 1295 & 3310 & 0.945 & 0.590 & 0.317 & 1020 & 2650 & $0.97 ?$ & 0.774 & 0.301 \\
\hline$h_{c}=30 \mathrm{w} / \mathrm{m}^{2}$ & 2650 & $r_{j} .973$ & 0.775 & 0.255 & 1295 & 3490 & 0.936 & 0.567 & 0.306 & 1010 & 2820 & 0.967 & 0.755 & 0.291 \\
\hline$k=1.474$ & 2410 & 0.981 & 0.792 & 0.250 & 1295 & 3250 & 0.948 & 0.680 & 0.312 & 1010 & 2580 & 0.976 & 0.771 & 0.297 \\
\hline
\end{tabular}


temperature of maximum system performance $\left(T_{\max }\right)$ or on the cptimum concentration ratio and intercept factor. Halving the emittance of the wall has negligible effect on performance or optimization. Doubling the convection coefficient increases the optimum geometric concentration ratio slightly but has no other appreciable effect on performance or optimization. Increasing the convection coefficient by a factor of 5 produces a further olight increase in optimum geometric concentration ratio and a olight drop in efficiency. Doubling the conduction coefficient causes $a$ slight drop in efficiency with no appreciable effect on optimum temperature, concentration ratio, or intercept factor.

Typical cavity receiver efficiencies in dish collectors range from a low of about 0.6 to a high of 0.95 or greater. Becsuse the receiver losses increase with tempersture, high receiver efficiency is more likely to be attained at low rather than at high receiver temperature. Relatively high receiver efficiency for a given receiver temperature may be considered to indicate high receiver quality.

Typical dish collector efficiencies range from about 0.4 , which would be considered low, to 0.9 , which would be considered very high.

I. EFFECTS OF INSOI.ATION LEVEL AND PART-LOAD PERFORMANCE

The direct insolation, I, varies with site, time of day, time of year, and weather from a low of zero to a high of about $1,100 \mathrm{~W} / \mathrm{m}^{2}$ at the surface of the Earth. (It may occasionally be somewhat higher at high-altitude sites.) Typical insolation design points for dish collectors are 700 to $1,000 \mathrm{~W} / \mathrm{m}^{2}$.

Suppose a dish thermal system is operating at its design point and the insolation then falls, because of a change in weather. After a transient, the power output of the collector must fall to match the insolation. (The transient may be long if thermal storage is included in the collector. Storage is not annsidered here). If the collector is supplying process heat, this heat will usually be needed at a fixed temperature, so the operating strategy will probably be to keep the receiver temperature constant and vary the flow rate of the working fluid to match the insolation. 
Suppose the collector io providing heat to a powar converter. The thermal 108 serms in Equation (3) vary inversely with the insolation, I, whereas the firet term is independent of insoletion. The curve of $\eta_{\text {coll }}$ versus $T_{T}$ will therefore fall and become eteeper as the insolation $I$ decreases (Bigure 21 ). The curve of $\eta_{\text {pc }}$ versus $T_{r}$ remains unchenged, as, to a first approximation dose the value of $\eta_{\mathrm{Pp}}$. The curve of $\eta_{\text {oys }}$ verous $T_{r}$ is the product of the curves for $\eta_{c o 11}$ ' $\eta_{p e}$, and $\eta_{p p}$. When the insolation falle, this curve will peak at a lower temperature than it does for high insolation (see Figure 21). If the oystem was initially operating at or near $T_{\max }$, it will be desirable to drop $T_{r}$ to match the new, lower, $T_{\max }$. If, however, the oyotem was initially running well below $T_{\max }$ (perhaps for ressons of cost), it may be desirable to continue running at this temperature rather than reduce $T_{Y}$ : presumably the $T_{Y}$ selected is satisfactory, and lowering it will only mean operation further from $T_{\max }$ and hence at atill lower $\eta_{8 y 8}$. This means that the mass flow rate of the working fluid should be reduced to match the insolation. Implications in turn depena on the design of the power conversion and power processing subsystems. For example, is the engine speed constrained to a constant multiple of $60 \mathrm{~Hz}$ to maintain synchroniom with the electric grid? If bot's opeed and inlet temperature must be kept constant, what can be varied to change the mass flow rate? In stirling engines it is usually possible to change the operating pressure and hexce the density of the working fluid. Some Brayton engines have guide vares to change the flow impedance. In other engines no suitable operating parameter may be available, and it may be necessary to maintain speed and allow inlet temperature to fall, thus decreasing efficiency. The part-load performance of different engines varies and depends on the parameter used to accomodate load cisiges (temperature, speed, pressure, flow impedance). System opti. in for part-load operation therefore depends heavily upon the power cc: : ing and power processing characteristics. Dish collector power systems may be shut down at direct insolftion lower than 300 to $500 \mathrm{~W} / \mathrm{m}^{2}$ because the power produced is insufficient to: pply system losses (unless the plant is provided with energy storage or can operate off fuel as well as ounlight.)

A dish module is often connected to a power sink that will accept all its output. If this is not so, and there is no provision for energy storage, it may be necessary, when demand is low or insolation high, to ratch the input 
and output by lowering the ayatem efficiency. This may be done by dumping energy from the power conversion or power procesaing oubeystem, by reducing the receiver temperature (if this can be done), by permitting the receiver temperature to rise above $T_{\max }$ (if this is permisaible), by pointing -lightly off-sun (if this does not damage the receiver aperture plate) or, if necessary, by shutting down. If multiple modules are used to supply comon demand, it should be possible to shut down some and keep others running.

\section{J. EFFECTS OF SECONDARY CONCENTRATOR}

Figure 22 gives examples of collector and system efficiencies as functions of receiver temperature, with and without a secondary concentrator. The secondary concentrator provides an increase in geometric concentration ratio and, when the receiver aperture is optimized, an increase in intercept factor. This does not always increase collector efficiency, however. At low receiver temperatures and moderate secondary reflectance, the reflectance loss is greater than the improvement at the receiver aperture, and performance is better without the secondary than with it. At higher temperatures the receiver aperture $10 \mathrm{sses}$ are more important; if the receiver temperature and secondary reflectance are high enough, the secondary concentrator can improve perfornance.

Performance with a secondary concentrator is sensitive to the reflectance or transmittance of the secondary: note the difference between the performances of secondaries with reflectances 0.90 and 0.95 in Figures $22 a$ and $b$, If a secondary is to be of help, it ohould have very high reflectance or transmittance.

The characteristics of the engine also enter into the tradeoff: Figure 21 is for a system that uses an engine whose effectiveness rises with receiver temperature. The performance of such a system tends to optimize at a fairly high receiver temperature, at which a secondary concentrator is likely to be advantageous. If the engine effectiveness did not rise with temperature, system performance would be maximum at a lower temperature, at which the secondary concentrator is less likely to be of use. 
Pigure 22 ouggesto that aecondary concentrator le more likely to be useful at long focal ratios than at short. Pigure 23 compares the effecte of focal ratio upon the performance of a simple and a compound concentrator. The collector efficiency with the olmple paraboloidal mirror peaks at a focal ratio of $0.4-0.6$, and falls markedly at longer focal ratios. With a oecondary concentrator that provides maximum efficiency, the collector efficiency (Duff-Lameiro approsimation) is almost constant over the whole range of $f_{r}=0.4-3.0$. More exact calculations (References 22 and 23) indicate that the performance rises as the focal ratio increases (Figure 5). It may not, rowever, be desirable to go to a long focal length because of conc ntrator weight and cost considerations. These can sometimes be alleviated by using an optical configuration that folda the optical path after it leaves the primary mirror (Reference 12).

The overall geometric concentration ratio, optimized, is higher with the secondary concentrator than without, but the primary geometric concentration ratio of the compound concentrator is lower than that of the concentrator without secondary. The difference is, of course, due to the geometric concentration ratio of the secondary. The secondary concentration ratio optimizes only slightly sbove 1.0 at very short focal lengths (at which use of a concentrating secondary is unlikely to prove efficient). It optimizes at 10 or more at long focal lengths (see Figures 5 and 23 ).

It is of some interest to consider the effect of a secondary concentrator with primaries having various slope errors, specularity spread, or pointing error. As Figure 24 shows, a secondary concentrator is of more help when the accuracy of the primary is poor. In some cases, adding a secondary to a primary with moderate errors can provide performance equivalent to that of a more accurate primary alone.

Another consideration is that the reflectance loss at the secondary concentrator may not actually be a loss to the system. A small secondary, struck by all of the collected sunlight, will tend to heat well above ambient temperature. Depending on the system design, it mav be advantageous to use the secondary concentrator to preheat the working fluid before it enters the receiver (or the recuperator of the power conversion subsystem). This permits 
recovery of the solar energy loet in the secondary and at the same time providee active cooling of the secondary.

Figures 22 through 24 indicate that the use of a secondary concentrator ie likely to improve performence only if the eystem can utilize to advantage a high receiver temperature or if the primary concentrator is oomewhat inaccurate. The high receiver temperature may be used oither to oupply a demand for high-temperature process heat or to drive a heat engine whose performance increases markedly with inlet temperature.

\section{R. EFFECTS OF WIND SCREENS AND INFRA-RED REFLECTORS}

To reduce convective $1088 e s$ out the receiver apecture, a wind screen is sometimes used. The most common form is a portion of a sone (Figure 25a), with a cone angle at least as great as the rim angle of the concentrator. If such a screen does not extend beyond the shadow cast by the receiver and the power conversion equipment mounted with the receiver, it does not increase the blocking and shadowing factor. Quantitative dats on the amount by which ouch a screen reduces convective 108 are scarce.

An alternative is a portion of a sphere centered at the receiver aperture (Figure 25b) and confined to angles greater than the rim angle of the concentrator. This may be less effective aerodynamically than the cone in reducing convective losses, though data on losses from such shapes are almost non-existent. On the other hand, the spherical screen can serve another purpose: reducing radiative losses from the receiver aperture by reflecting some of the emitted radiation back $i$ to the aperture. To do this, the interior of the screen should have high reflectance in the near infrared (wavelengths of a few microns). Because of its spherical shape, if the screen is a perfect reflector, almost all the radiation from the aperture that strikes the screen will be reflected back into the aperture. If the concentrator rim angle is $60^{\circ}$, a screen outside of it will subtend 0.5 of a hemispherical solid angle and so could reflect back almost 0.5 of the emitted radiation. If the rim angle is $45^{\circ}$, the screen solid angle can be 0.7 of a hemisphere and so could reflect back almost 0.7 of the emitted radiation. Because cavity receivers are not black bodies, these limits are only 
epproximate; a more exect calculation would take into eccount the distribution of radiation within the recelver cavity.

The conical wind screen of Figure 25 a to not very uneful as an infrared reflector because the viow angle of the receiver aperture, as seen from ocreen, is poor, and opecular reflection at the ecreen will not return emitted radiation to the receiver. This conical design can, however, double as a secondary concentrator (oee Pigure $4 b$ ).

\section{EPFECTS OF WINDOWS}

In the discussion so far, it has been tacitly assumed that the receiver aperture is open to the air. The aperture may, however, be closed by a window. Sometimes the receiver cavity is designed to contain the working fluid, and it is undesirable to let this fluid escape out the aperture or to let cold ait enter and mix with the working fluid. Another reason for a window is to eliminate convective heat $108 s$ out the receiver aperture. This advantage must then be traded againgt the 1080 of entering sunlight due to reflection and absorption by the window.

This is a difficult trade-off because data and theory for convective loss have not been adequate. The window loss is ordinarily $8 \%$ of the incoming sunlight or more, depending on the thickness and composition of the window. (Anti-reflection treatment may be useful.) A window to prevent convective heat $108 s$ may be justified if the convective 108 sithout the window is higher than the window loss. The window also reduces the loss of outgoing radiation from the receiver, but this is usually a smaller effect. As the receiver temperature is increased, the $108 s$ per unit area of receiver aperature also increases. On the other hand, the receiver aperture size is usually decreased as the temperature rises; this tends to reduce 1088 out the aperture. It seems clear, however, that the usefulness of a window is greater at high receiver temperature than at low.

In the example shown in Figure 26, the collector and system efficiency above $900^{\circ} \mathrm{C}\left(1650^{\circ} \mathrm{F}\right)$ are higher with a window than without. Below $900^{\circ} \mathrm{C}$ efficiency is higher without a window. 
The receiver temperature at which the oyotem affleiency to greateot tends to be higher with a window than without one (wee Pigure 26). The window reduces the effect of comperature on receiver efficiency; the curve of oyotem efficiency versus temperature is then more influenced by the engine efficiency, which tende to rise with engine inlet and receiver temperature.

A window ie more likely to be advantageous when the concentrator errors are high because high concentrator errors lead to ute of a large receiver aperture, and so to high convective lose if the aperture is open. In the example of Figure 27, collector efficiency with alope error of 0.5 mrad is higher without a window than with one, over the entire range of temperatures examined $\left(700^{\circ}\right.$ to $1450^{\circ} \mathrm{C}, 1300$ to $\left.2650^{\circ} \mathrm{P}\right)$; with alope error of $5 \mathrm{mrad}$, the opposite is true.

It would be helpful to tailor the window's spectral characteristics to permit high inward transmisaion of solar radiation but low outward transmission of infra-red radiation from the receiver (Reference 33). Ideally, the window should reflect wavelengths longer than 2 or $3 \mu \mathrm{m}$. So far, no materials have shown to have both these desired spectral characteristics and adequate high temperature properties. Fused silica, though not a good infrared reflector, does absorb a significant fraction of the infrared radiation emitted at receiver temperatures, while transmitting almost all the solar radiation; the infrared absorption improves the performance of fused silica as a reciver window.

M. SYSTEM CONSIDERATIONS

As should be clear from the above, the performance optimization that can be done considering the collector alone is rather limited. We can optimize the focal length for a simple concentrator. We can optimize the receiver aperture if the required temperature for the working fluid is specified for a process heat demand, if the concentrator errors are fixed by manufacturing tolerances, and if the expected insolation is defined. Performance optimization beyond this generally requires that the rest of the solar thermal system be considered. If the system is to produce mechanical or electrical power, the efficiency of the engine as a function of inlet temperature and 
part load will have to be conoldered in optimizing the recelver tomperature and hence the recelver aperture. The pointiny error of the concentrator affecto collector optinisation but is in turn affected by the dealgn and optimiration of the control oubyetem. Clearly, it is dosirable to optimize the performance of the ontire colar thermal eyotem and not of the collector alone.

Coneiderations other than efficiency and initial cost (discussed below) affect dioh collector design. High receiver cemperatures axacerbate problems of lifetime, reliability, maintenance, and the availability of ouitable materiale; the receiver is, therefore, uoually dealgned to operate at a temperature lower than that at which efficiency is maximum. To reduce the heat flux on the lip of the receiver aperture, the aperture size may be increased beyond that at which efficiency is optimuro. The choice of focal length may be influenced not only by efficienc but also by a crade-off befween the additional length and structural weight required for a long focal length and the additional mirror area required for a fixed projected area when the focal length is verv short. The latter is illustrated in Figure 28 for a paraboloidal mirror. Note that at focal ratio 0.6 the ratio of mirror area to projected area is 1.04 , but for incremental area at the rim, the ratio io about 1.08 . At a focal ratio of 0.4 , the ratio of areas is 1.09 , the ratio of incremental areas about 1.18. The corresponding equationa are:

$$
\frac{A_{8}}{A}=\frac{2}{3} \frac{1}{\sin ^{2} \theta}\left(2 \sqrt { 2 } \left(\overline{1+\cos \theta)}-(1+\cos \theta)^{2}\right.\right.
$$

$$
\frac{d A}{d A}=\sqrt{\frac{2}{1+\cos \theta}}
$$

where $A_{s}=$ surface area of the mirror. 
BECTION IV

METHODS POR COBT OPTIMIZATION

Cost optimization is often more important, in principle, than performance optimization. Cost optimization of dioh ooler collectors and of dish solar thermal oyotems tends to be difficult in practice because of the lack of reliable cont deta. Hardly any dish collectore are beyond the prototype etage. Coste or prices in volume production are therefore only estimates coete of operation and maintenance are even more uncertairi. To obtain meaningful information on the coet differential between, for example, a concentrator with a lope error of 2 mrad and a concentrator with a blope error of 4 mrad is almost impossible at present. still more difficult is knowing how this differential varies with the production rate.

In the absence of ureful data on the effect of design variables upon collector costs, this discussion is limited to cost trade-offo in which the collector cost and collector efficiency are assumed to be known. The resulto can be examined in terms of how much the purchaser of a solar thermal system would find it worthwhile to pay for certain desired characteristics.

\section{A. BASIS FOR COST OPTIMIZATION}

There is no point in optimizing on a collector or system cost alone because an inexpensive system that has zero performance is of no use. One may utilize a measure of cost/output ratio, such as mills/kW-h (electrical or thermal), or the invested $\$ / \mathrm{kW}$ of installed capacity. Costs to be considered include not only the price of a purchased concentrator but also such factors as transportation costs, cost of site and installation, costs of operation, maintenance, and replacement over the life of the plant. Energy cost and capacity cost are not the only important cost parameters: for instance, it may be worthwile to increase the availablity of solar power over the year even if the cost per kilowatt-hour and the cost per kilowatt of installed capacity are thereby increased. In this paper, however, I use as a cost parameter for optimization the busbar energy cost (BBEC) in either of two variations. One 
is the levelized bubbar energy cost (abbreviated ab BBC, where the overlining oignifies "lovelized"). This is the measure most commonly used by utility companies to evaluate alternative plant designe, and represente the fixed revenue per kilowatthour that a uility must receive for the energy produced by the plant during ite lifetime in order to just cover the utility's lifetime coste for the plant. $\overline{B B E C}$ assumes revenue is a fixed number of dollar for cents, or mille) despite the inflation that is asoumed to take place in coots. The other variation is real levelized busbar energy cost (BBEC ${ }_{0}$ ), which is the corresponding fixed revenue in reel (non-inflated) dollars, and assumes that the actual number of current-year dollars received will inflate at the general inflation rate. BBEC has some advantages over BBEC (Reference 34), including much less sensitivity to the inflation rate assumed to apply over the lifetime of the plant. The choice of $\overline{B B E C}$ or BBEC has no significant effect on the optimizations discussed in this report, and energy costs in this report are given in terms of both. See Reference 35 for further discussion of busbar energy cost and how to calculate it. Though BBEC is most widely ured for the cost of eiectrical energy, it can be used equally well for the cost of thermal energy.

\section{B. COST CALCULATION AND OPTIMIZATION}

Costs were calculated using the model for utility-owned solar power systems described by Doane, et al, in Reference 35. The quantities calculated were the levelized busbar energy costs, $\overline{B B E C}$ and $B B E C$. The economic assumptions are 1 isted in Appendix A.

To reduce computing time and expense, cost sensitivities derived by Revere (see Reference 24) were used. These sensitivities, together with the baseline system to which they refer, are also described in Appendix A. 
BRCTION $v$

RBBULTS OR COST OPTIMIZATION

A. EPBECT OR COLLBCTOR COST

A. Pigure 29 Indicates, the concentrator coet is expected to be the largeet of produced in quantity. The collector (concentrator plue receiver) cost is typically projected as near $50 \%$ of the total capital coot.

Figure 30 showe eatimated operatione and maintenance (OSM) costs for the same eystem as Pigure 29. Concentrator maintenance is the largest ingle item of O8M, typically projected near $40 \%$ of the total 08M. Nate too that $08 M$ coste are quite oignificants in this example, euch coete are more than $50 \%$ of the cepital costs, over the 30-year design lifetime of the plant. (This is in conotant (real) dollars. In current dollare, with the assumed cost escalation (inflation; see Appendix), O8M would be almost $150 \%$ of the capital noot.)

Bince collector costs represent such a large portion of total plant costs, they have atrong effect upon the cost of the electricity produced. In the example given, a $1 \%$ increase in collector costs raises the cost of the electricity produced by $0.64 \%$ (Figure 31 ).

B. EFFECTS OF COLLECTOR PERPORMANCE

If the output is constant but the collector efficiency is decreased, the concentrator aperture area must be increased to gather more sunlight. This tends to increase the concentrator cost (initial and $08 M$ ) per unit of output. The same is true if the concentrator area is held constant and the output is allowed to fall. Figure 31 gives an example. For the system considered, a $1 \%$ decrease in collector efficiency increases the busbar energy cosc by $2.0 \%$.

The trade-off between collector efficiency and collector unit price can be examined by considering the collector efficiency and unit price for each 
(fired) BBEC. This is clarifled in Blgure 32. For the baceline eyetem illuetrated, with a collector efficiency of 0.80 , the trade-off ios a 18 decrease in collector efflelency requires $0.32 \%$ decrease in collector coet to maintain the same BBEC. At lower collector efficiencies, largar decresece In collector coste are needed for each percent decreses in collector efficiency; below ome finite collnctor efficiency, the BBEC cannot be maintained even if the collector is free.

Figures 33 and 34 show the corresponding effect of optical efficiency alone (rather than collector efficiency), together with the effect of collector price and the correoponding trade-off. Plguree 35 and 36 thow the relatione in terme of lope error, geometric concentration factor, and collector price for the same (baseline) oystem. If the slope error is too large, the BBEC cannot be attained no matter how low the concentrator coet. Pigure 37 illustrates the effects of optical efficiency and of geomitric concentration ratio upon BBEC; Pigure 36 howe the trade-off between them.

\section{EFPECT OF TEMPERATURE}

If the system produces electrical or mechanical power, and the receiver and engine inlet temperatures are changed, both the collector efficiency and the power conversion efficiency are affected, as discussed earlier. The change in collector efficiency changes the required concentrator area and, therefore, the concentrator price; the change in power converaion efficiency changes the required size of concentrator, receiver, and engine. This affects prices for all of these elenents. Furthermore, an increase in operating temperature will often require changes in the design and materials of the receiver and engine that in turn affect their prices. Also, with an engine and receiver of a given type, an increase in operating temperature is likely to lead to increased maintenance costs and perhaps lowered reliability and availability. These last factors are highly dependent upon the design. Because it is difficult to assign them general quantitative values, these factors will not be treated in this report. Some design variables, such as receiver aperture (geometric concentration ratio), will probably not have a significant effect on equipment price or maintenance cost. 
Iiguri 39 illuetrates the effect of geometric concentration ratio and - lope error upon the buabar onergy cout at variouu recelver temperaturee for the baseline ayotem. The effecte of the independent variables upon oubeyotem efficiencies and of these efficiencies upon oyotam coste are modeled, but effects upon cost of decign, matorial and mointenance changes appropriate to the different temperatures are not. Figure 39 ohould therefore be used with caution. For the asoumption made in conotructing this figure, namely, that equipment and maintenance costa are not raloed by low olope error or high receiver temperature, $\overline{B B E C}$ at the optimum temperature falls from $204 \mathrm{millo} / \mathrm{kW}-\mathrm{h}$ at 10-mred slope error to $122 \mathrm{milla} / \mathrm{kW}-\mathrm{h}$ as $5 \mathrm{mrat}$ and about $70 \mathrm{millo}$ at 0.5 mrad; a $\overline{B B E C}$ of $200 \mathrm{mill} / \mathrm{s} / \mathrm{kW}-\mathrm{h}$ cannot be obtained if the elope orror to 10 mrad. The optimum receiver temperature rises from about $700^{\circ} \mathrm{C}\left(1300^{\circ} \mathrm{F}\right)$ at $10 \mathrm{mrad}$ to $925^{\circ} \mathrm{C}\left(1700^{\circ} \mathrm{Y}\right)$ at $5 \mathrm{mrad}$ and $1500^{\circ} \mathrm{C}\left(2730^{\circ} \mathrm{F}\right)$ or more at 0.5 mrad.

D. EFFECT OF MODULE SIZE

The effect of collector aize upon the unit cost of the heat output should be considered. The price of the concentrator drive is not proportional to its size but tends to vary less strongly than the size. The price of controls for the collecior itself is almost independent of collector size. For very small collectors, the price of drive and controls is high relative to the energy output and incresses the cost of this energy. For very large dish collectors, the cost of structure becomes $1 \mathrm{imiting:}$ the area and the energy output increase as the square of the linear dimension; the weight and the cost of strurture increase as the cube. There is accordingly a collector size that minimizes the cost of the thermal energy produced. For designs evaluated so far, this minimum occurs at diameters of 5 to $15 \mathrm{~m}$. It is, however, very flat, so the cost of the thermal output is rather inseusitive to collector size within this range.

To examine the collector alone may, however, lead to sub-optimization; the whole system should be considered. Parabolic dish solar power plants are comprised of modules, each of which consists of a collector, an associated engin:-generator if one is used, and associated power processing equipment, cabling, and contrnls. Decause these plants are so modular, the plant size 
has little effect upon the eclection of collector aise (unlese the plant is so omail that only a oingle omall collector io needed,) Thare are ome economiea of ecale in the central ecation that are common to all the modules and includee elemente of the power proceseing subsyotem (such as owitchgear and central invertera) and of the control oubeyotemi again this does not affact collector optimization. At the module lavel, however, if the plant produces -lectricity or mechanical work, the power conversion subnyotem interacte with collector optimication. If there is a ceparate heat engine for each module, the size of the collector must match the ize of the heat engine. Small heat engines tond to be lose officiont than larger engines and almost always cost more per unit of output. To leseer extent, this is also true for generatora. If one were optimizing the power conversion oubsyotam alone, the optimum would probably be a large unit, perhapo a oingle large unit for the whole plant. If the oise of the power conversion oubsystem is to match that of the collector, it will tend to drive the collector to a size somewhat larger than the optimum for the collector considered alone. The aize optimum is dependent on the efficiencies that can be obtained in engines of 5 to 15 kW; until now there has been little incentive to attain high efficiency in such small engines. The engine price is less important hecause it is typically small compared to the collector cost (Figure 21); engine osm costs may or may not be important. For the baseline system used as an example, a ix increase in power conversion efficiency decroses the bushar energy cost by 17; 1\% increase in price of the power conversion subsystem increases BnEc by $0.11 \%$. 


\section{RERBRENCES}

1. Jaffe, L. D., Dioh Concentratore for Solar Thermal Power Syoteme status and Technological Development, Technical Report 81-43, Jet Propulaion Laboratory, Paeadena, California, January 1, 1981. Aløo, Proprint AIAA-81-2530, 2nd Terrestrial Bnergy Systems Conference, December 1981 , Colorado Springe, Colorado. Accepted for pit:is:inn, Juurnal of Energy.

2. Owen, W., Bank, H., Otch, D., Wright, C., and Hagen, T., "Eirot Resulte of Steam Receiver Testing at JPL'o Parabolic Dish Teat site," Froceedings 1981 Annual Meering. American Section, International Solar Energy Society, Pp. $415-418$.

3. Hanseth, E. J., "Development, Solar Test, and Evaluation of a High-Temperature Air Receiver fur Point-Focusing Parabolic Dish Applications," 2nd Terrectrial Energy Syotems Conference, AIAA, December 1981, Colorado Springs, Colorado.

4. Osborn, D. B., Haskins, H. J., Conway W. A., and Wen, C. C., "Design and Test of a Solar Receiver for an Organic Rankine Cycle Engine," Proceedinga ASME Solar Energy Div., 4th Annual Conference, Albuquerque. New Mexico, April 1981, pp. 449-457.

5. Lof, G. O. G., and iuffie, J. A., "Optimization of Focusing Solar Collector Design," Journal of Engineering for Power. Volume 85, pp. $221-228,1963$.

ט. Selcuk, M. K., and Ward, G. T., "Optimization of Solar Terrestrial Power Production Uaing Heat Engines," Journal of Engineering for Power, Volume 92. pp. $173-181,1970$.

7. Duff, W. S., Lameiro, G. F., and Lof, G. 0. G., "Parametric Performance and Cost Models for Solar Concentrators," Solar Energy, Volume 17, PP. $47-58,1975$. 
8. Howell J. R., and Bannerot, R. B., "Optimum Solar Collector Operation for Maximizing Cycle Work Output," Solar Energy, Volume 19, Pp. 149-153, 1977.

9. Wen, L., "Thermal Performance Trade-offo for Point-Focusing Solar Collectors," Proceedings Intersociety Energy Conversion Engineering Conference, San Diego, California, August 1978.

10. Wen, L., "Effect of Optical Surface Properties on High-Temperature Solar Thermal Energy Conversion," Journal of Energy, Volume 3, pp. 82-89, 1979.

11. Wu, Y. C., and Wen, L. C., "Solar Receiver Performance of Point-Focusing Collector System," ASME Preprint 78-WA/So1-5, American Society of Mechanical Engineers, New York, 1978.

12. Pons, R. L., "Optimization of a Point-Focusing Distributed Receiver Solar Thermal Electric System," ASME Preprint 79-WA/So1-11, American Society of Mechanical Engineers, New York, 1979.

13. Duff, W. S., and Lameiro, G. F., "A Performance Comparison Method for Solar Concentrators," Paper 74-WA/So1-4, ASME Winter Annusl Meeting, New York, November 1974.

14. Zakhodov, R. A., "Calculation of the Energy Distribution in the Radiation Field of Reflector-Type Solar Energy Devices," Geliotekhnika, Volume 1, No. 5, pp. 11-18, 1965.

15. Grilikhes, V. A., and Zakhodov, R. A., "Derivation of the Equation of Irradiance Distribution in the Focal Plane of Parabolodial Solar Concentrators," Geliotekhnika, Volume 7, No. 4, pp. 9-13, 1971.

16. Clark, T. B., "Comparisons and Results of Optical Analysis Techniques," Technical Report SCSE-013, Ford Aerospace \& Communications Corporation, Newport Beach, California, 1978. 
17. Pettit, R. B., "Characterization of the Reflected Beam Profile of Solar Mirror Materiale," Soler Energy, Volume 19, Pp. 733-741, (1977).

18. Wen, L., Huang, L., Poon, P., and Carley, W., "Comparative Study of Solar Optice for Parabolic Concentratore," Journal of Solar Energy Engineering, Volume 102, Pp. 305-315, 1980.

19. Jaffe, L. D., and Poon, P., Secondary and Compound Concentratore for Parabolic Dish Solar Thermal Power Sybten:;, DOE/JPL - 1060-43, 1981.

20. Jaffe, L. D., and Poon, P., "Secondary and Compound Concentratore for Parabolic Dish Solar Thermal Power Syotems," Proceedinge, 16th Interbociety Energy Conversion Engineering Conference, Volume 2, pp. 1752-1758, ASME, New York.

21. Welford W. T., and Winston, R., The Optics of Nonimeging Concentrators, Academic Pres8, New York, 1978.

22. Baranov, V. K., "Paraboloitoric Focone as Secondary Solar Energy Concentrator," Geliotekhnika, Volume 13, No. 5, pp. 18-25 (1977).

23. Welford, W. T., and Winston, R., "Design of Second Stage Nonimaging Concentrators," University of Chicago, Report to JPL (1979).

24. Revere, W., "System Influence Coefficients of Solar Thermal Power Systems," JPL private communication, February 29, 1980.

25. Rosenberg, L., and Revere, W., A Comparative Assessment of Solar Thermal Electric Power Plants in the 1-10 MWe Range, Technical Report 81-53, Jet Propulsion Laboratory, Pasadena, California, June 1981.

26. O'Neill, M. J., and Hudson, S. L., "Optical Analysis of Paraboloidal Solar Concentralors," Proceedings 1978 Annual Meeting, American Section, Internationai Solar Energy Society, Volume 2.1, pr. 855-862. 
27. Schrenk, G. L., in Clark, T. B., "Flux Distributions and Intercept Factors at the Focal Plane of Parabolic Reflectors," Technical Report SP3-010, Ford Aeroepace and Communications Corporation, Newport Beach, California, 1978.

28. Pham, H. Q., and Jaffe, L. D., "Heat Engine Development for Solar Thermal Power Systems," Proceedings, 3rd Annual Conference on Systems Simulation, Economics Analysia/Solar Heating and Cooling Operational Result8, Reno, Nevada, April 27-May 1 1981. ASME, New York, Pp. 654-659.

29. Hauger, J. S., "A Fresnel Collector Process Heat Experiment at Capitol Concrete Producta," Parabolic Dish Solar Thermal Power Annual Program Review Proceedings, DOE/JPL 1060-46, May 1981, pp. 217-221.

30. Heller, J., and Hyland, R. E., NASA Lewis Research Center, personal communication, 1980 .

31. LeQuere, P., Penot, F., and Mirenayat, M., "Experimental Study of Heat Loss Through Natural Convection from an Isothermal Cubic Open Cavity," Proceedings DOE/SERI/SNLL Workshop on Convective Losses from Solar Receivers, Sandia Laboratory Report SAND81-8014, Livermore, California, October 1981, pp. 165-174. Also, Clausing, A. M., "An Analysis of Convective Losses from Cavity Solar Central Receivers," Solar Energy, Vol. 17, pp. 295-300, 1981 .

32. Sanders Associates, Parabolic Dish Module Program Review \#2, Doc. 82-LMK-011, Merrimack, New Hampshire, March 1982.

33. Jarvinen, P. K., "Heat Mirrored Solar Energy Receivers," AIAA Preprint 77-728, American Institute of Aeronautics and Astronautics, New York, 1977.

34. Chamberlain, R. G., internal communication, JPL, September, 1980. 
35. Doane, J. W., O'Toole, R. P., Chamberlain, R. G., Bos P. B., and Maycock, P. D., The Cost of Energy from Utility-Ouned Solar Electric Systeme, A Required Revenue Methodology for ERDA/EPRI Evaluatione, ERDA/ JPL 1012-76/3, JPL Jechnical Report 5040-29, Jet Propulsion Laboratory, California Institute of Technology, Pasadena, California, June 1976.

36. Revere, W., JPL, private communication, 1981. 
APPBNDIX A

\section{AS8URPTIONS POR COST CALCULATIONS}

Cost calculatione were baind on those of Rosenberg and Revere (see Reference 25) and of Revere (Ref. (4). The economic aseumptione were (eee Reference 25):

Ownership
Plant lifetime
Cost of capital (discount rate)
General escalation (inflation)
rate
Capital cost escalation rate
Operating and maintenance cost
escalation rate
Effective income tax rate
(Miocellaneous tax rate)/
(capital investment)
(Insurance premiums)/
(capital investment)
Base year
Year of commercial operation
Plant construction period

- Investor-owned utility

$8 \quad 30$ yr

: $0.086 / y r$
i $\quad 0.060 / y x$
: $\quad 0.060 / y r$

: $\quad 0.070 / y r$

: $\quad 0.40 / \mathrm{yr}$

$: \quad 0.020 / y r$

: $\quad 0.0025 / y r$

: $\quad 1978$

: $\quad 1989-1990$

: $\quad 2$ years (2/3 1988; $1 / 3$ 1989)

Revere (see Reference 24) derived cost sensitivities for the following baseline system:

$\begin{array}{ll}\text { Type of system: } & \begin{array}{l}\text { Parabolic dish concentrator } \\ \text { Brayton power conversion } \\ \text { Output: electricity }\end{array} \\ \text { Plant size: } & 5 \mathrm{MW} \text { electric } \\ \text { Storage: } & \text { None } \\ \eta_{\text {coll }}= & 0.74 \text { (annual average) } \\ \eta_{p c}= & 0.28 \text { (annual average) } \\ \eta_{\mathrm{PP}}= & 0.95\end{array}$


The costs acoumed for this beseline syotem, in $1978 \mathrm{~s} / \mathrm{m}^{2}$ of concentrator aperture area, were (see Reference 25);

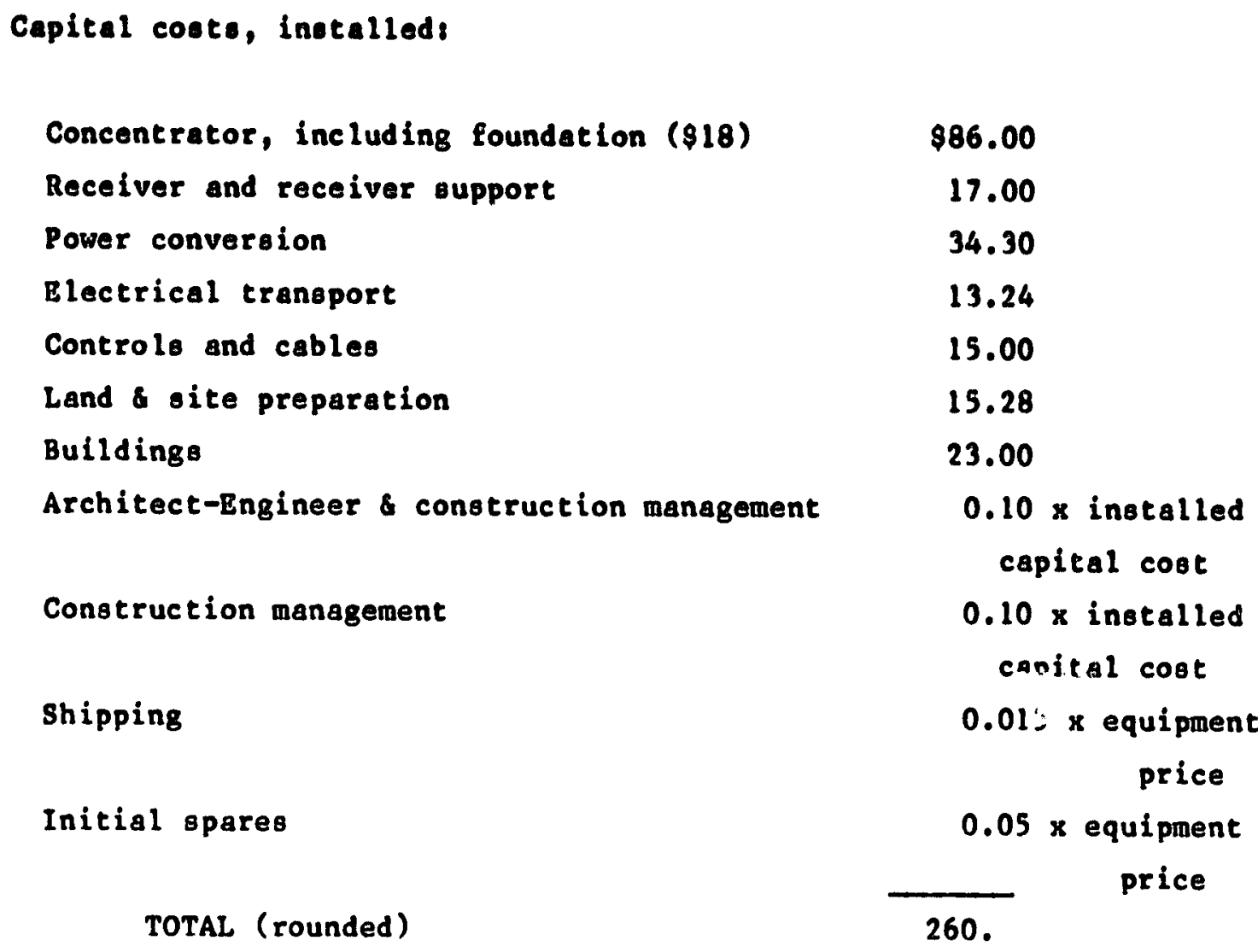

Operating and maintenance

Operation

$\$ 0.35 / \mathrm{yr}$

Concentrator maintenance

1.81

Power conversion maintenance

1.09

Controls maintenance

0.28

Buildings \& ground maintenance

0.90

TOTAL

4.43 
The BबEC calculated (ace Reforence 25) for this baeline oyotem was $89 \mathrm{mill} / \mathrm{kW}-\mathrm{h}$ (in $1978 \mathrm{\$}$ ). This is at a cabacity factor of 0.31 , which was found to be optimum for the plant. (Capacity factor - lelectrical energy produced per year)/(electrical energy produced if operating continuously at rated power for one year).] The corresponding BBEC is $45 \mathrm{mills} / \mathrm{kW}-\mathrm{h}$ (1978\$).

Revere (see References 24 and 36 ) derived the following influence coefficients for deviation from the baseline system:

Concentrator or receiver cost delta of $\$ 1.804 / \mathrm{m}^{2}$ increases BBEC by $1 \mathrm{mill} / \mathrm{kW}-\mathrm{h}$.

Delta in average coliector efficiency of $0.566 \%$ decreases $\overline{B B E C}$ by $1 \mathrm{mill} / \mathrm{kW}-\mathrm{h}$ (1978 \$).

Power conversion cost delta of $\$ 3.53 / \mathrm{m}^{2}$ increases $\overline{\mathrm{BBEC}}$ by $1 \mathrm{mil1} / \mathrm{kW}-\mathrm{h}$.

Delta in average power conversion efficiency of $0.360 \%$ decreases $\overline{\mathrm{BBEC}}$ by $1 \mathrm{mill} / \mathrm{kW}-\mathrm{h}(1978 \mathrm{~s})$.

For this work, all costs were conver. I to 1980 s, using a factor of 1.185 for escalation from 1978 to 1980 .

Also, the effect of a change in efficiency upon BBEC is more appropriately expressed as a multiplicative rather than an additive change:

$$
\begin{aligned}
& \frac{\mathrm{BBEC}_{2} / \mathrm{BBEC}_{1}}{\eta_{\mathrm{co} 11,1} / \eta_{\mathrm{co} 11,2}}=\frac{88 / 89}{0.74 / 0.74566}=0.996=1.00 \\
& \frac{\mathrm{BBEC}_{2 /} \mathrm{BBEC}_{1}}{\eta_{\mathrm{pC}, 1} / \eta_{\mathrm{pC}, 2}}=\frac{88 / 89}{0.28 / 0.2836}=1.001=1.00
\end{aligned}
$$

The ratio $\mathrm{BBEC}_{\mathrm{O}} / \overline{\mathrm{BBEC}}$ for the stated economic assumptions is 0.506 . 
APPENDIX B

PIGURES

B-1 


\section{migura Captiong}

Elg. 1 Dish woler collectors geometry.

18. 2 Size of focal opot ve. Ilm angle and focal ratio.

Compare Duff-Lameiro (Raf, 13) and Aparlel (Refe. 14, 15)

approximatione for parabololdal mirrore. Aloo ohown lo Duff-Lamelro approximation for plenar concentratora. All are for cavity or flat roseivers.

P18. 3 beometric concentration ratio ettainable for parabololdal mirrore a function of elope error or size of focal pot and intercept factor.

Pocal ratio $f_{r}-0.5$. Angular epread of incoming direct ounlight, $\sigma_{\text {sun }}$ taken a $2.3 \mathrm{mrad}$. Specularity opread, $\sigma_{\omega}$, and pointing error, $\sigma_{p}$, taken as 0.0 . Thuo

$$
8^{2}-\left(2 \sigma_{.10 p}\right)^{2}+2.3^{2} \operatorname{mrad}^{2}
$$

Bocal epot relative eize, $\sigma_{f}$, given by tuff-Lamiero approximation (Eq. 7).

Pig. 4 Exampleo of oecondary concentratore to improve optical performance.
a) Presnel lens
b) Conical (truncated, Axicon)
2) Compound elliptic concentrator
d) Hyperbolic trumpet

Fig. 5 Effect of fockl ratio upon attainable geometric concentration ratio of single sind compound concentrators.

Rectangular distribution of slope errors. Intercept factor $=1.0$.

Adapted from Baranov (Ref. 22).

Fig. 6 Effect of optical performance upon collector efficiency.

Intercept factor constant for each system.
a) Idealized system, except as noted
b) Baseline system, except as noted

Fig. 7 Receiver aperture optimization.
a) Idealized system
b) Baseline system

$$
\therefore, B-2
$$


Rig. 8 Effect of concentrator olope errore upon collector efficioncy and intercept factor. Dotted IInes recelver aperture optimised.
a) Idealized eyotem
b) Baseline syotar.

Pig. 9 Effect of opecularity epread upon collector efficlency and intercept factor. Dotted linei recelver aperture optimized.
a) Idealized syotem

b) Baceline oystem

Pig. 10 Effect of focal ratio or rim angle upon collector efficiency.

Receiver aperture optimized for each focal ratio (or riro angle). Duff-Lameiro approximation. Idealized oyotem.

Pig. 1i Rffect of rim angle and geometric concentration ratio upon intercept factor.

Flat solar disk profile, diameter 32 arc minutes. Paraboloidel mirror, reflectance 1.0 , slope error 3 arc minutes, no other errors.

After $0^{\prime}$ Neill and Hudson (Ref, 26).

Fig. 12 Effect of receiver temperature and geometric concentration ratio upon collector, power conversion and system efficiency.

Idealized system, except as noted; constant intercept factor ( $\phi$ 0.98 ), constant power conversion effectiveness.

a) Collector efficiency

b) Power conversion and system efficiency

Fig. 13 Effect of receiver temperature on collector efficiency, with and without optimization of receiver aperture at each temperature.

Idealized system except as noted.

Fig. 14 Effect of receiver temperature on collector, power converaion, and system efficiency.

Receiver aperture optimized at each temperature. Idealized system except as noted. Constant power conversion effectiveness.

Fig. 15 Effect of receiver temperature and concentrator slope error upon efficiency.

Idealized system except as noted. Receiver aperture optimized at each temperature. Constant power conversion effectiveness.

a) Collector efficiency

b) Power conversion and system efficiency 
Big. 16 Bffect of receiver temperature on power converaion and eyetem - fflciency with angines of differing charecterietice.

Idealized eyetem, except at noted. Recelver aperture optimized at each tamperature.

Constent power conversion eftectivenese is characterletic of Rankine and stirling syotems. The numerical value of the effectivenese (here caken a $v=0.3$ ) depende on the perticular engine.

Brayton eyoteme characteriotically hove en engine effectivenese that incresses with engine inlet temperature. Brayton power conversion efficiencies thown here are based on engine efficiencies from Ref. 30 and alternator plue rectifier efficiency of 0.92 .

a) Collector, power converoion, and jyotem efficiencies.

b) System: "iciency a fraction of masimum oyetem efficiencys geometri, concentration ratios and intercept factor.

Fig. 17 Effect of receiver temperature on collector, power converoion, and eystem efficiencies with engines of differing characterietics.

Baseline oyatem, except as noted. Other characteriotica as in Fig. 16.

a) Collector, power conversion, and system efficiencies.

b) Syatem efficiency as a fraction of maximum sotem efficiency; geometric concentration ratios and intercept factor.

Fig. 18 Effect of receiver temperature and geometric concentration ratio upon collector and syotem efficiency.

Fixad intercept factor. Baseline gotem except as noted. Brayton power conversion effectiveness as in Fig. 16.

a) Collector efficiency

b) Power conversion and system efficiency

Fig. 19 Effect of receiver temperature and concentrator olope error upon efficiency.

Receiver aperture optimized at each temperature. Baseline system except as noted. Brayton power conversion efficiencies as in Fig. 16 .

a) Coilector efficiency

b) Power conversion and oystem efficiency

Fig. 20 Effective absorptance or emittance of receiver aperture vo. absorptance or emittance of interior wall for a cavity receiver. (Holraum approximation: aperture ares small compared to tot\&l surface of cavity.) 
Big. 21 Bffect of incolation level upon optimizacion of raceiver temperature. Receiver aperturo optimized at each temperature. Idealized eystam.

Fig. 22 Eefect of secondary concentrator on collector and oyotem performance. Baseline byet,s except as noted. Pocal ratioe 0.6 and 1.0 .

Secondary concentrator reflectences 0.90 and 0.95 . Exit aperture of secondary concentrator coincident with receiver snorture. Secondary geometric concentration ratio maximized at each focal ratio of the primary concentrator $\left(1.96\right.$ at $f_{r}=0.6 ; 4.13$ at $\left.f_{r}=1.0\right)$.

Receiver aperture ( - oecondary concentrator exit aperture) optimized at each temperature for each design.

a) Collector efficiency

b) Syotem efficiency

c) Overall geometric concentration ratio

d) Intercept factor.

Fig. 23 Effect of focal ratio upon performance of aimple and compound concentrators.

Based on Duff-Lameiro approximation for primary (Ref. 13). Idealized system except as noted.

Secondary concentrator reflectance 0.95 . Exit aperture of secondary concentrator coincident with receiver aperture. Secondaxy geometric concentration ratio maximized at each focal ratio of the primary concentration.

Receiver aperture optimized for each design. Receiver temperature $1350^{\circ} \mathrm{C}\left(2460^{\circ} \mathrm{F}\right)$.

a) Collector efficiency.

b) Geometric concentration ratio and intercept factor.

Fig. 24 Effect of secondary concentrator on performance with primary concentrators of various accuracy.

Collector characteristics as for Fig. 23. Focal ratio 0.6 .

a) Collector efficiency.

b) Geometric concentration ratio and intercept factor.

Fig. 25 Wind screens and infrared reflector.

a) Conical wind screen. Can also serve as secondary concentrator: compare Fig. $4 \mathrm{~b}$.

b) Spherical section wind screen. Can also serve as infrared reflector to return emitted radiation to receiver. 
Pig. 26 Bffect of window on collector performance at varioue concentrator slope erroro and recelver cemperatures.

Recolver aperture optimised. Beecline eyotan, except as noted. With window, effective receiver abeorptance 0.92 (due to reflection), convection coefficient 0.0 , effective emittance 0.236 , $0.245,0.261,0.288,0.305,0.322,0.339,0.356$ at $704,760,871$, $982,1093,1204,1316,1427^{\circ} \mathrm{C}$ reepectively (based on date of Ref. 32.)

Fig. 27 Effect of receiver temperature on collector and eyotem performance with and without a window.

Receiver aperture optimized. Baseline syotem except os noted. Receiver lose coefficiente with window same as for Fig. 26. Brayton power converoion effectiveness as in Fig. 16.

Fig. 28 Effect of focal racio upon ratio of concentrator area to projected concentrator area.

Projection paralle to oun line. Paraboloidal reflector.

Fig. 29 Distribution of capital costs for solar thermal power pleni. (Projected.)

System type: dish-Brayton electric. Production rate: 25,000 modules per jear. Plant aize: 5 MWe.

Based on data of Ref. 25 .

Fig. 30 Distribution of operations and maintenance costs for solar thermal power plant se percent of total cost in constant dollars. (Projected.)

Same plant as Fig. 29. Plant lifetime 30 years.

Based on data of Ref. 25 .

Fig. 31 Effect of collector price and efficiency upon cost of electricity produced. (Projected.)

Baseline system except as noted.

Fig. 32 Trade-off of collector p: ice vs. collector efficiency at constant cost of electricity produced. (Projected.)

$\overline{B B E C}=97 \mathrm{mills} / \mathrm{kW}-\mathrm{h}$. Baseline system, except as noted.

Fig. 33 Effect of optical efficiency and collector price upon cost of electricitv produced. (Projected.)

Baseline system except as nowd. 
Pig. 34 Trade-off of collector price ve. optical afficiancy, at conetant coet of elactricity produced. (Projocted.)

Babeline oyatem except as notad.

Fig. 35 Effect of olope arror, geometric concentration ratio, anc collector price upon coet of alectricity produced (Projacted,)

Baseline syatem except a noted. Receiver aperture optimised for each elope error. (For collector efficiencied, wee Pig. Bb.)

Pig. 36 Trade-off of collector price vs. slope orror and geometric concentration ratio, at conetant cost of electricity produced. (Projected)

$\overline{B B E C}$ - $97 \mathrm{mills} / \mathrm{kW}-\mathrm{h}$. Baseline aystem except as noted, Receiver aperture optimized for each olope error.

Fig. 37 Effect of optical performance upon cost of electricity produced. (Projected.)

Baseline system except as noted. (For collector efficiencies, bee Fig. 5.)

Fig. 38 Trade-off of optical efficiency ve. geometric concentration ratio at conatant cost of electricity produced. (Projected.)

Baseline system except as noted.

Fig. 39 Bfect of slope error upon cost of electricity produced at various receiver temperatures. (Projected.)

Baseline sustem except as noted. Receiver aperture optimized. Plant cost assumed to depend on efficiencies but to be otherwise independent of temperature. (For collector efficiencies, see Fig. 19; for power conver ion efficiencies, see Fig. 17a.) 


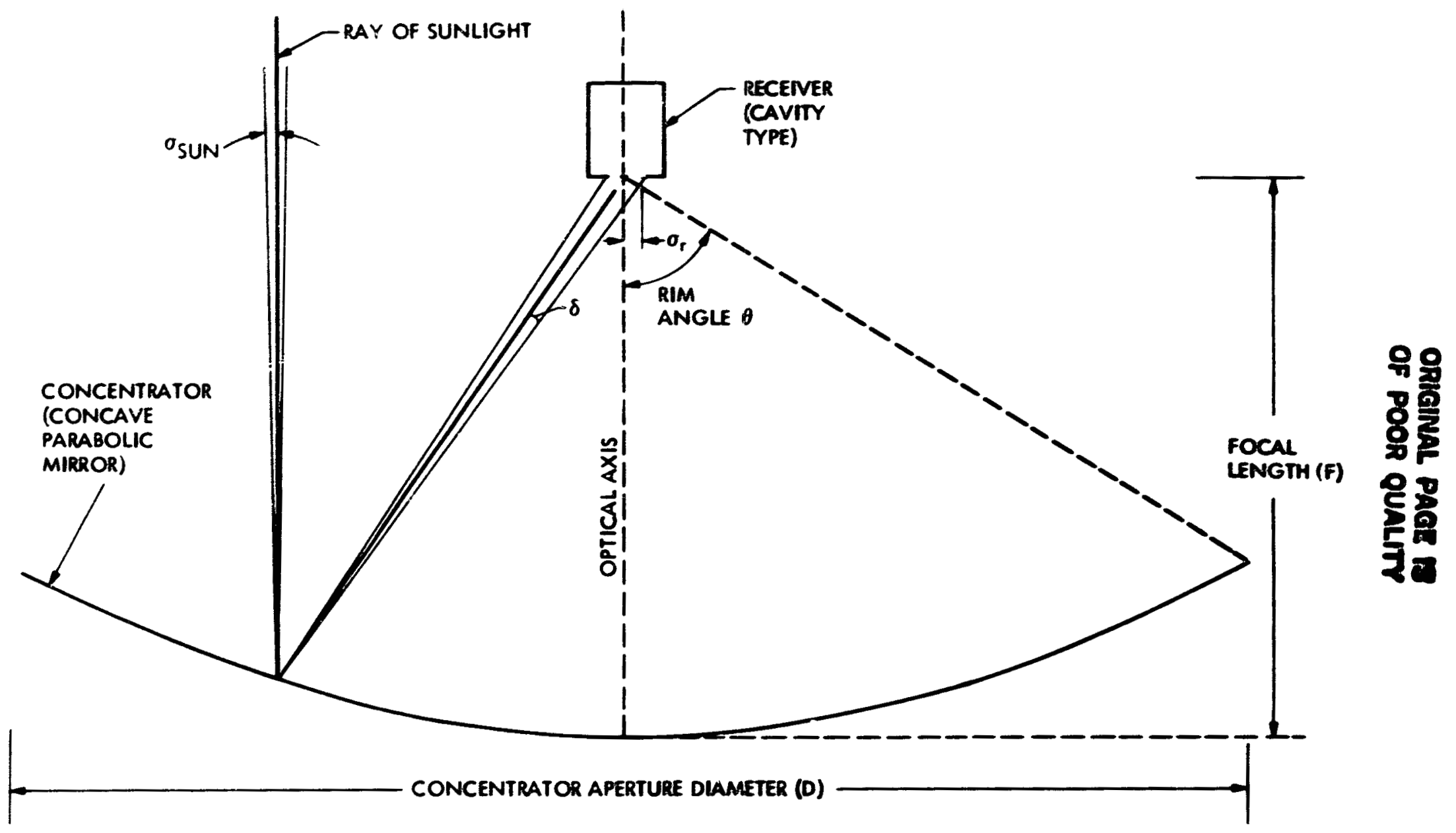

Figure 1. Dish Solar Coilector: Geometry. 
FOCAL RATIO, FLAT MIRROR OR LENS

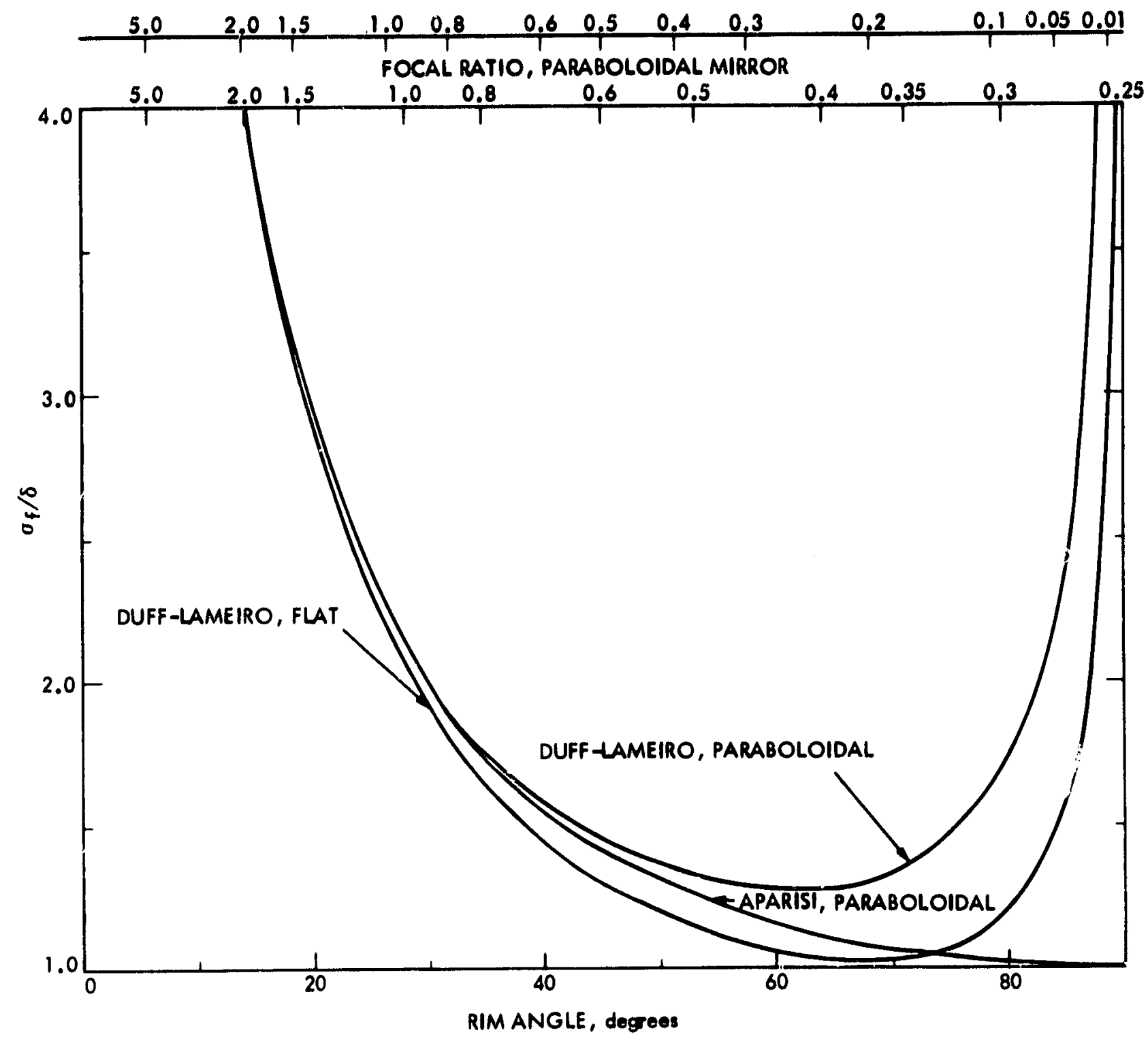

Figure 2. Size of Focal Spot Versus Rim Angle and Focal Ratio. Compare Duff-Lameiro (Ref. 13) and Aparisi (Refs. 14, 15) approximations for paraboloidal mirrors. Also shown is DuffLamelro approximation for planar concentrators. All are for cavity receivers. 


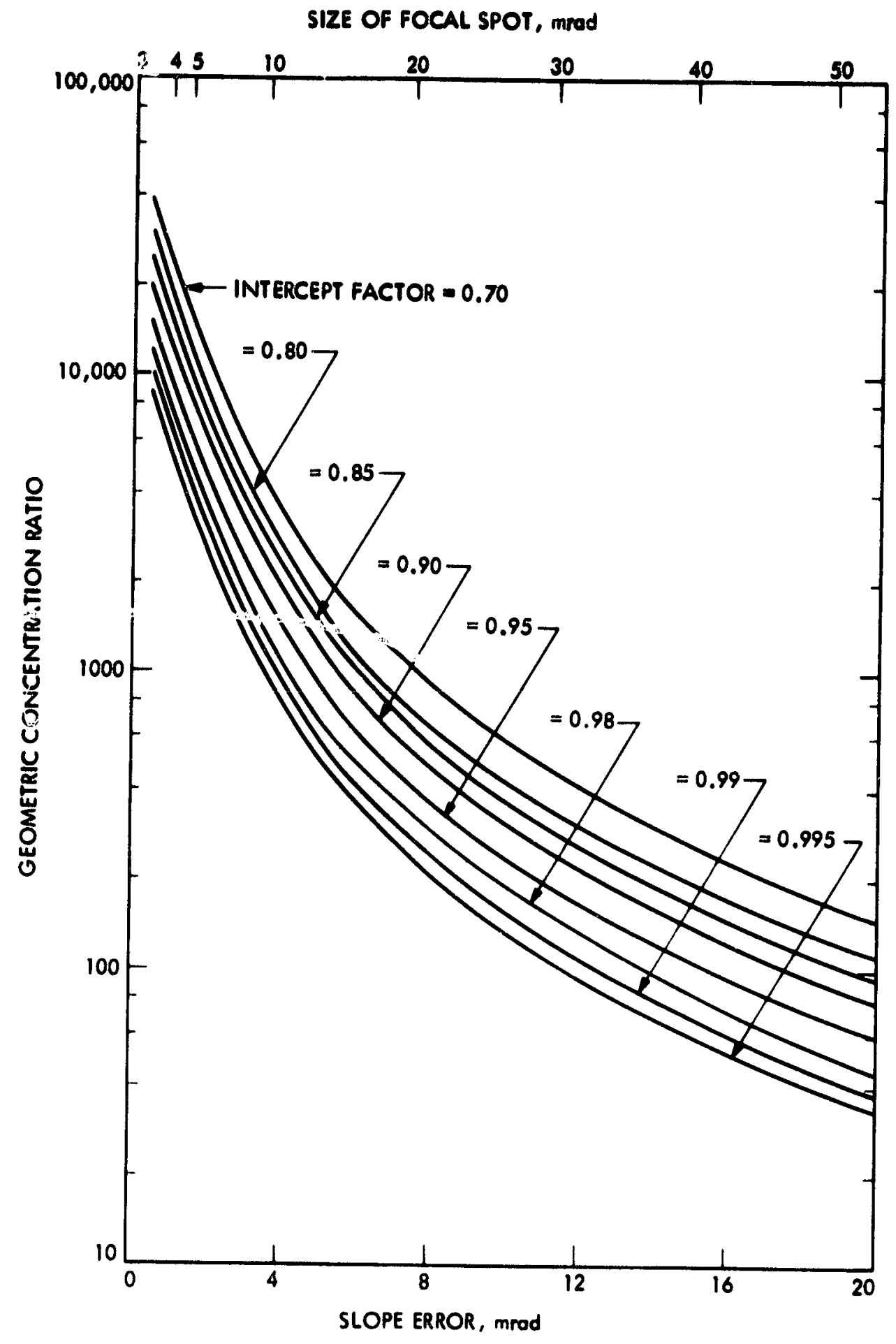

Figure 3. Geometric Concentration Ratio Attainable for Parabololdal Mirrors As a Function of Slope Error or Size of Focal Spot and Intercept Factor.

Focal ratio $\mathrm{F}_{\mathrm{r}}=0.5$. Angular spread of inconing direct sunlight, $\sigma_{\text {sun }}$, taken as $2.3 \mathrm{mrad}$. Specularity spread, $\sigma_{\omega}$, and pointing error, $\sigma_{p}$, taken as 0.0 . Thus, $\delta^{2}=\left(2 \sigma_{\text {slope }}\right)^{2}+2.3^{2} \mathrm{mrad}^{2}$.

Focal spot relative slze, $\sigma_{f}$, given by Duff-Lamelro approximation (Eq. 7 ). 


\section{ORIGINAL PAGE IS \\ OF POOR QUALTT}

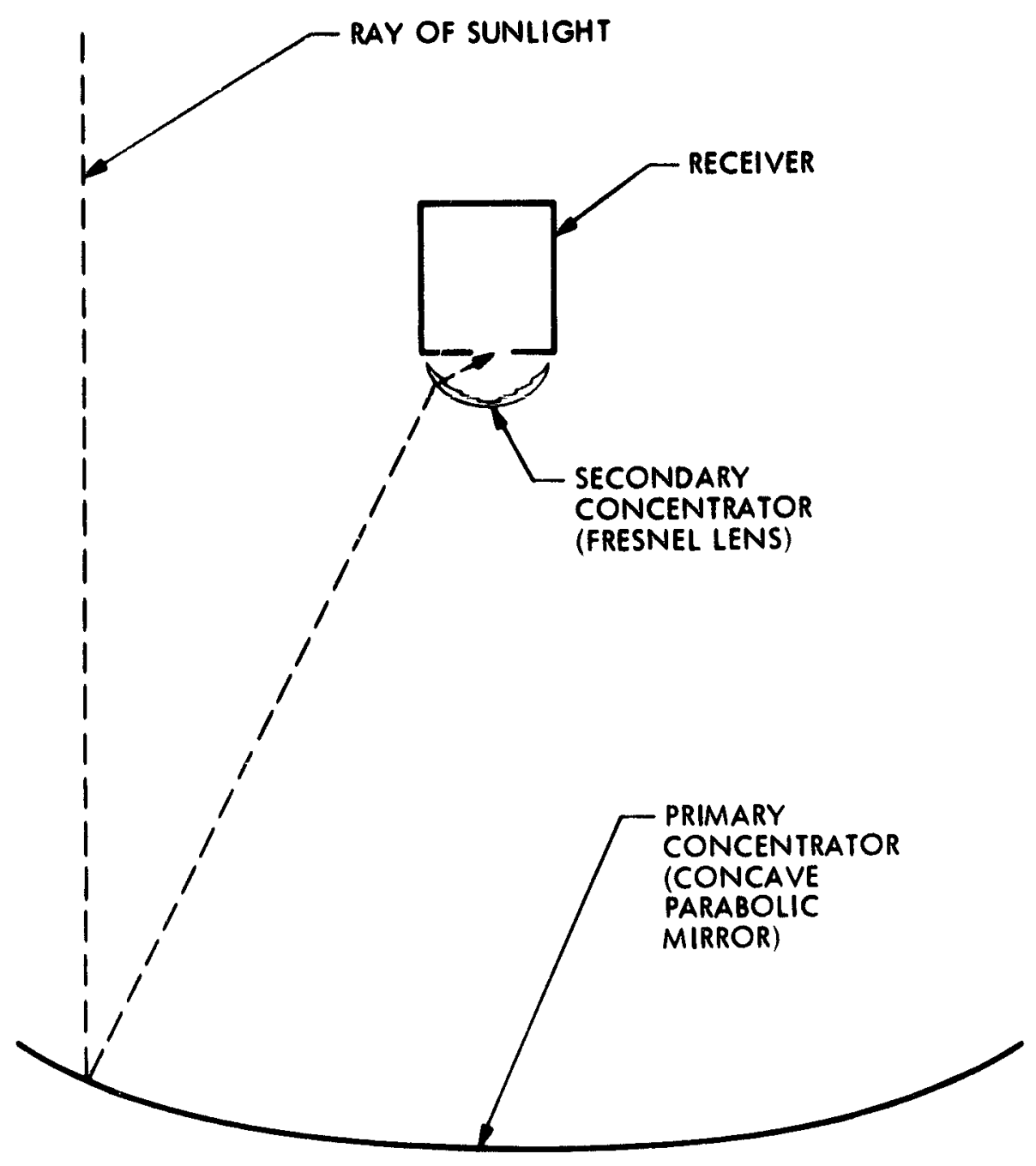

Figure 4 a . Example of Secondary Concentrator to Improve Optical Performance: Fresnel Lens. 


\section{ORIGINAL PAGE Do \\ OF POOR QUALTY}

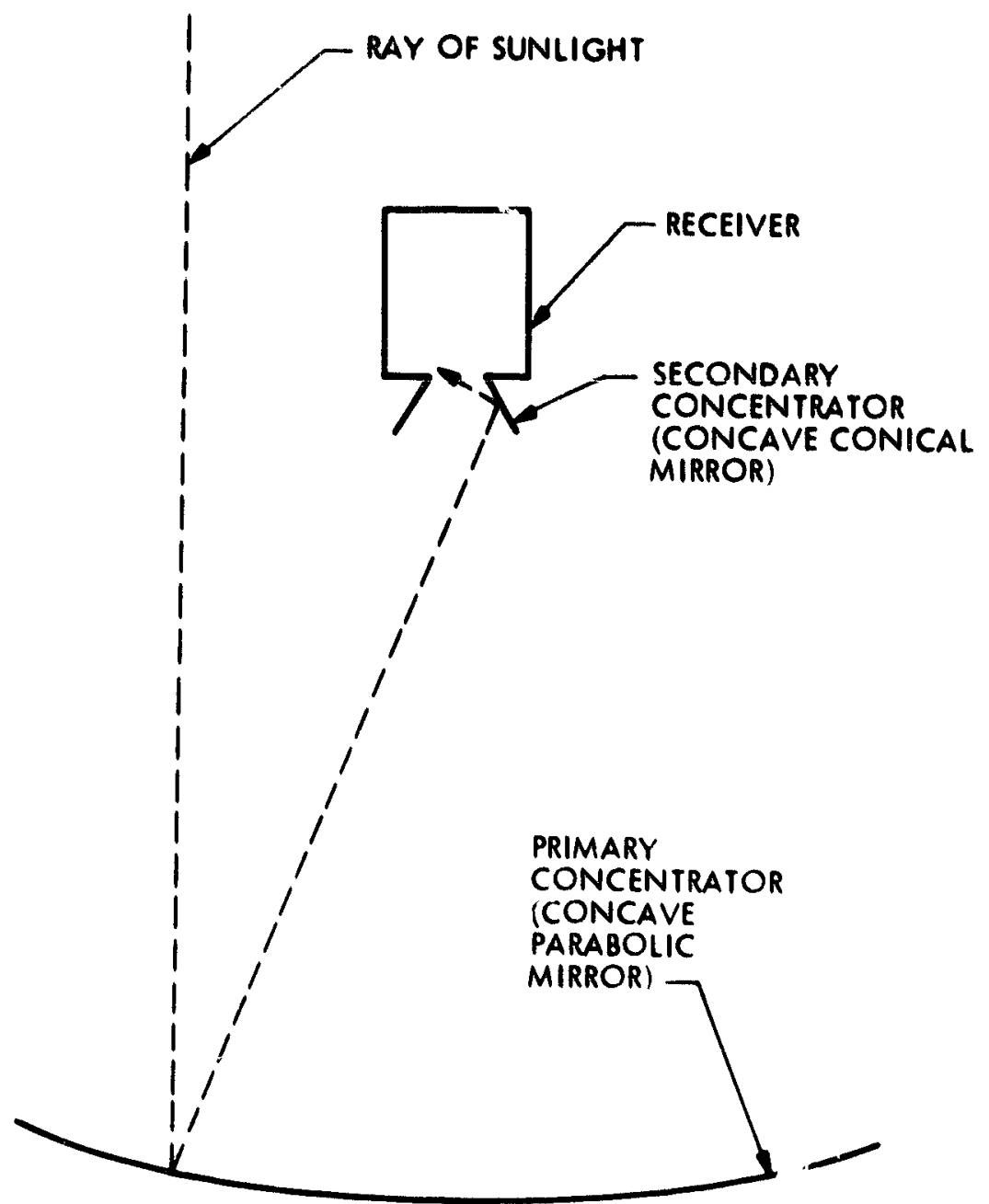

Figure ab. Example af Secondary concentrator to improve Opteal performance: Contcal (Trumbated, Axloun). 


\section{CAICINAL PAGE 18 \\ OF POOR QUALT'}

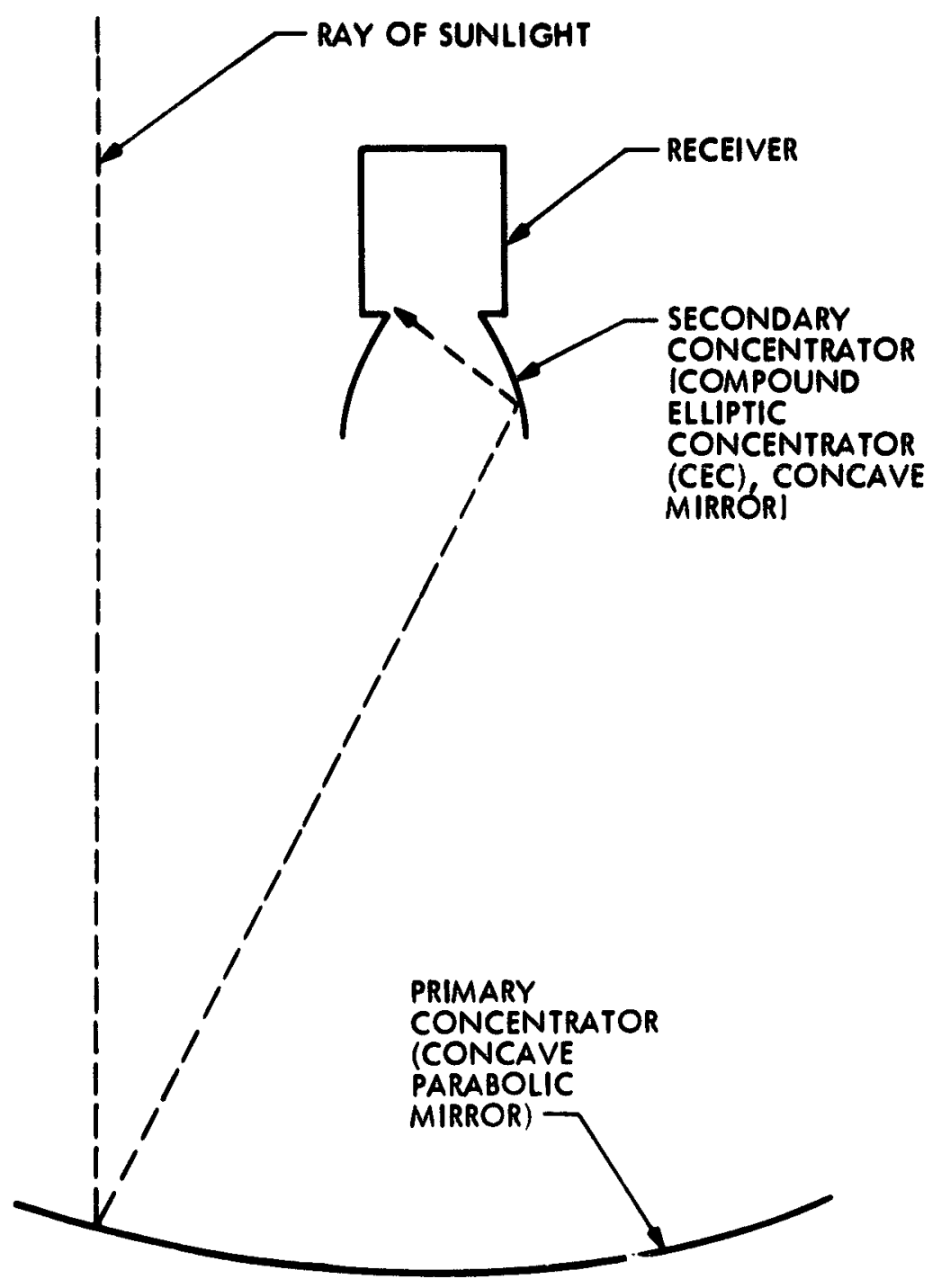

Figure 4c. Example of Secondary Concentrator to Improve Optical Performance: Compound Elliptic Concentrator. 


\section{ORIGINAL PAGE IJ \\ OF POOR QUALITY}

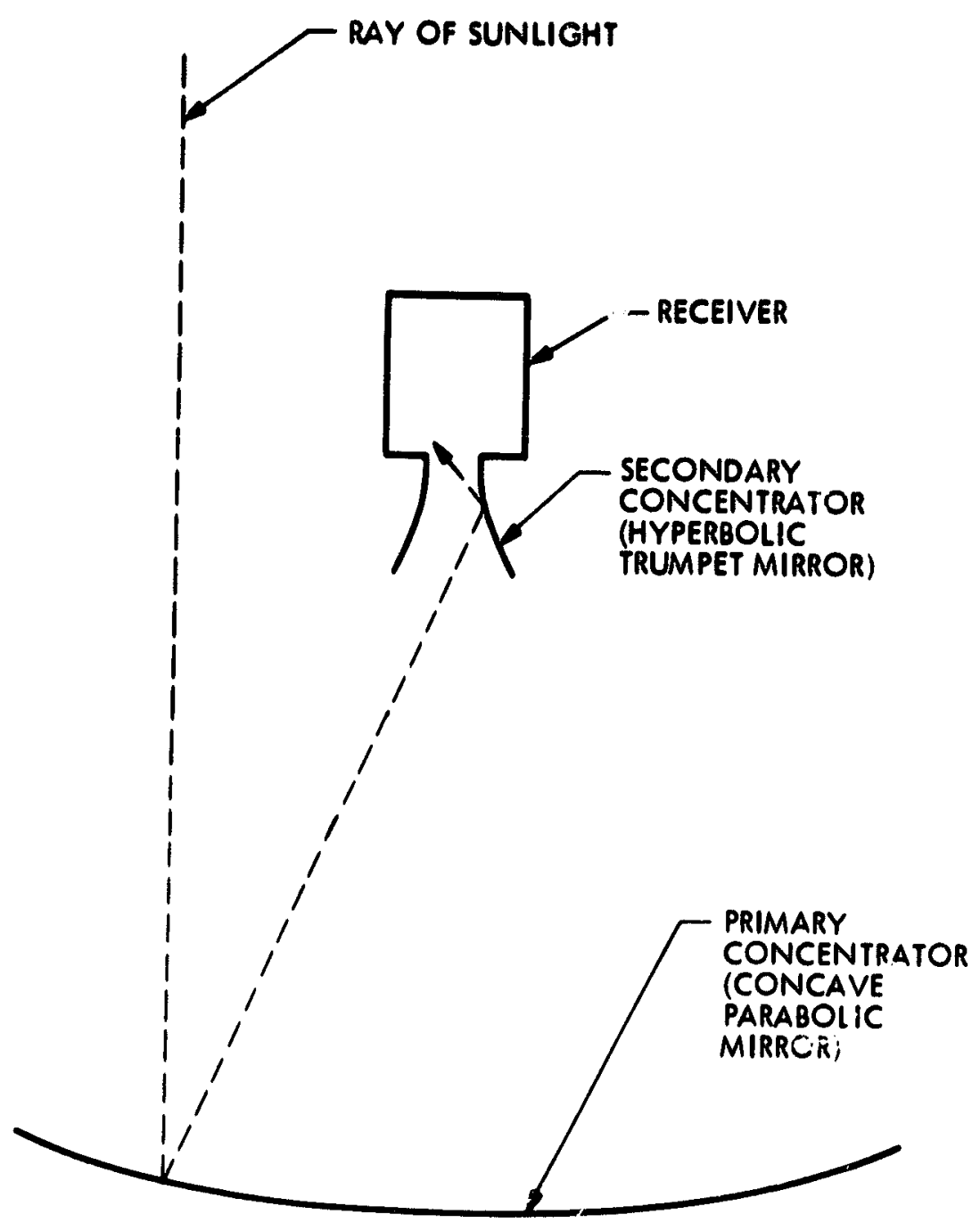

Figure 4d. Example of Secondary Concentrator to Improve Optical Performance: Hyperbolic Trumpet. 


\section{OruaninaL PAOE IS
OF POOR QUAI.ITY}

PRIMARY FOCAL RATIO

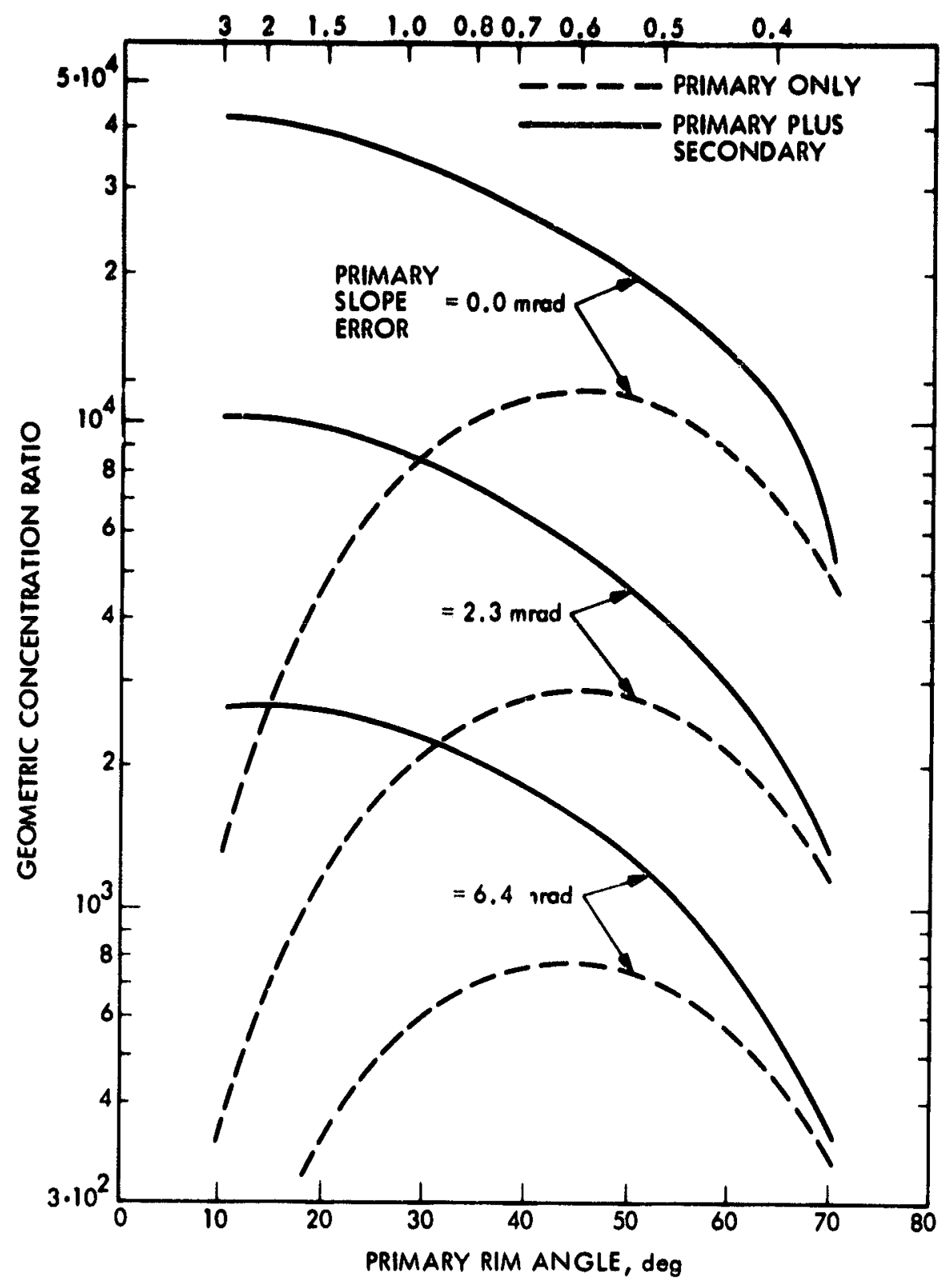

Figure 5. Effect of Focal Ratio upon Attainable Geometric Concentration Ratio of Single and Compound Concentrators.

Rectingular distribution of slope errors. Intercept factor $=3.0$. Adapted from Baranov (Ref. 22). 


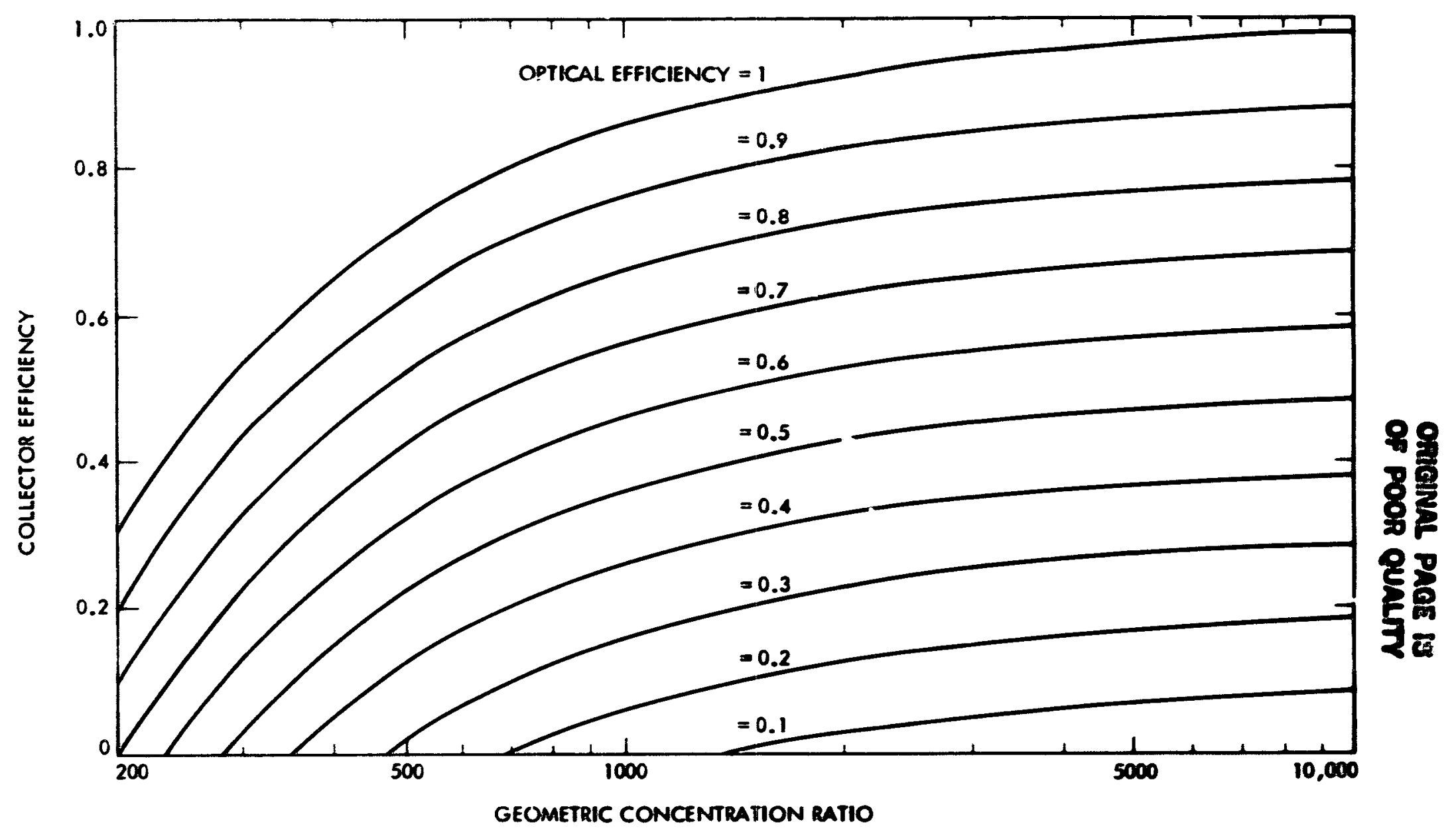

Figure 6a. Effert of Optical Performance upon Collector Efficiency: Idealized System. (Except as noted.)

Intercept factor constant. 


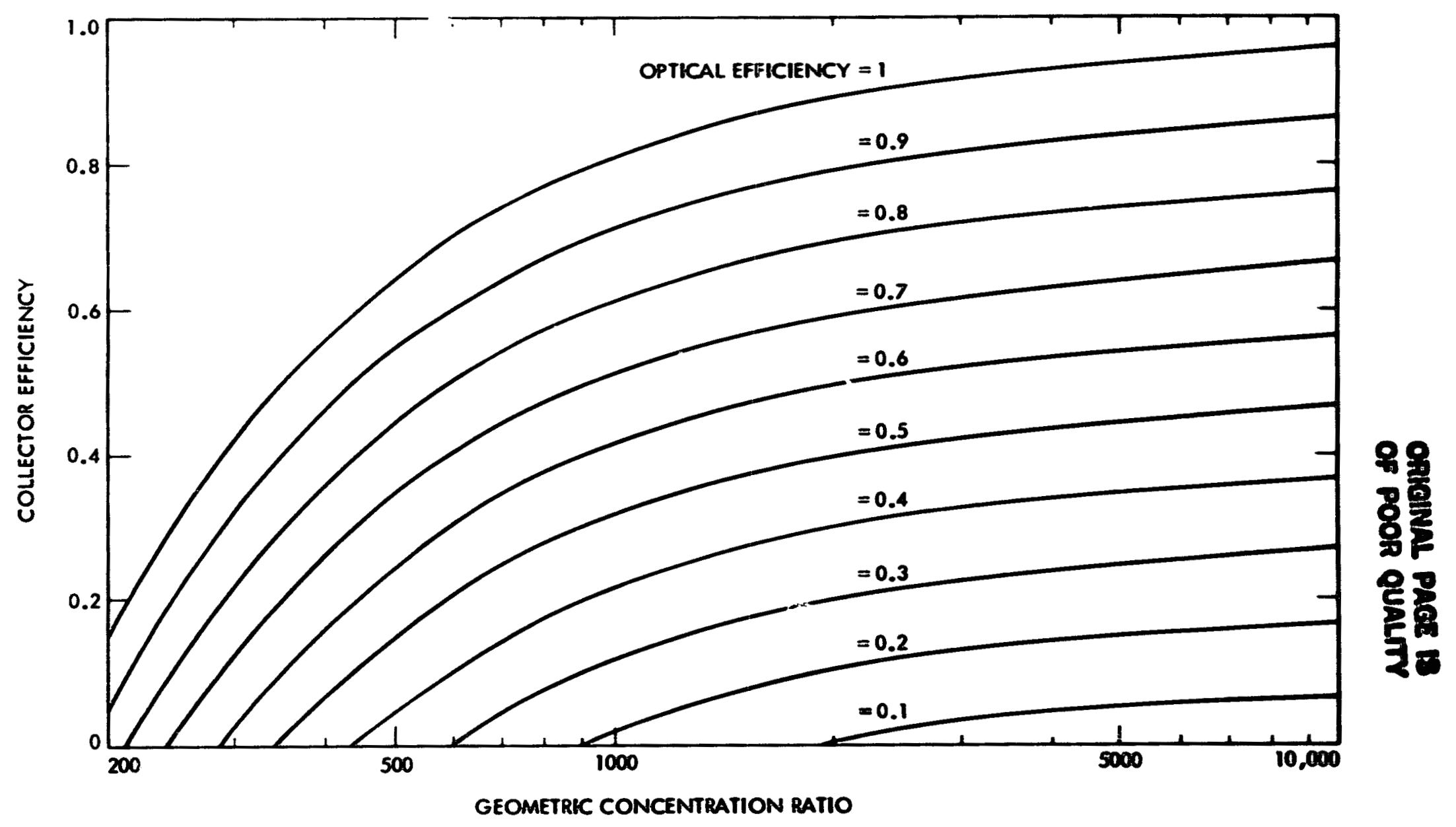

Figure 6b. Effect of Optical Performance upon Collector Efficiency: Baseline Systea. (Except as noted.)

Intercept factor constant. 


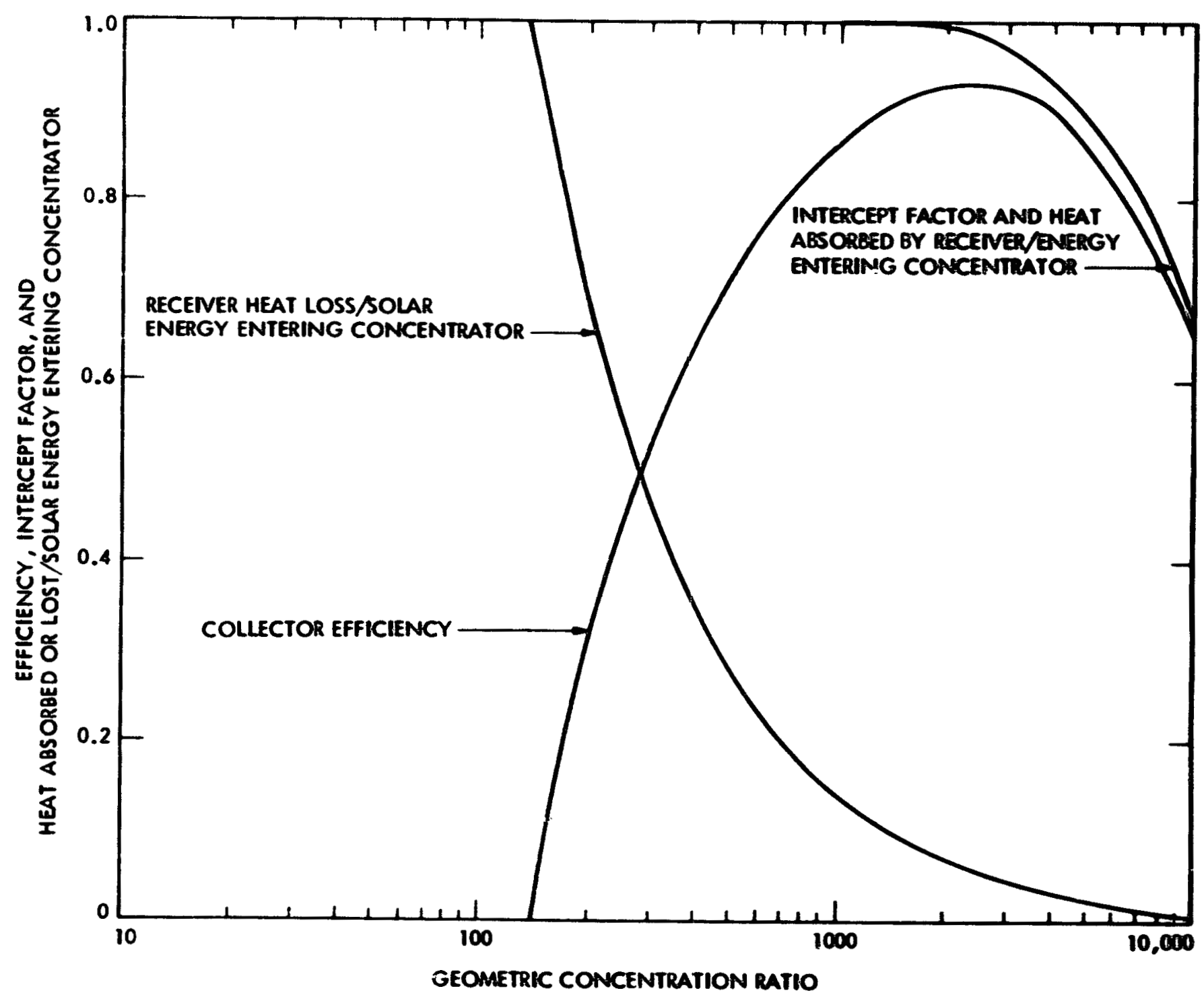

Figure 7a: Receiver Aperture Optimization: Idoalized System. 


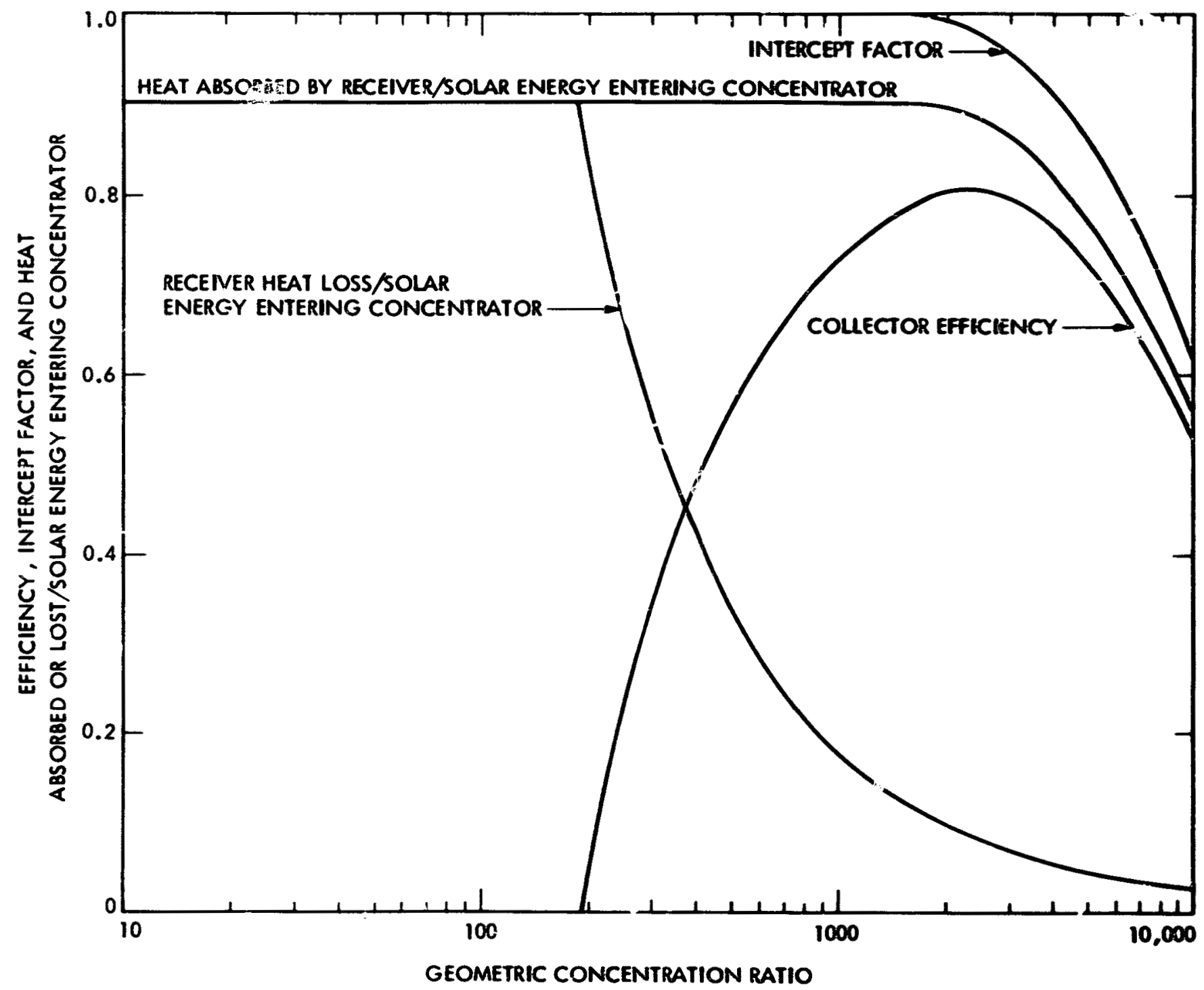

Figure 7b. Receiver Aperture Optimization: Baseline System. 


\section{ORIENAL PAGE IS \\ OF POOR QUALITY}

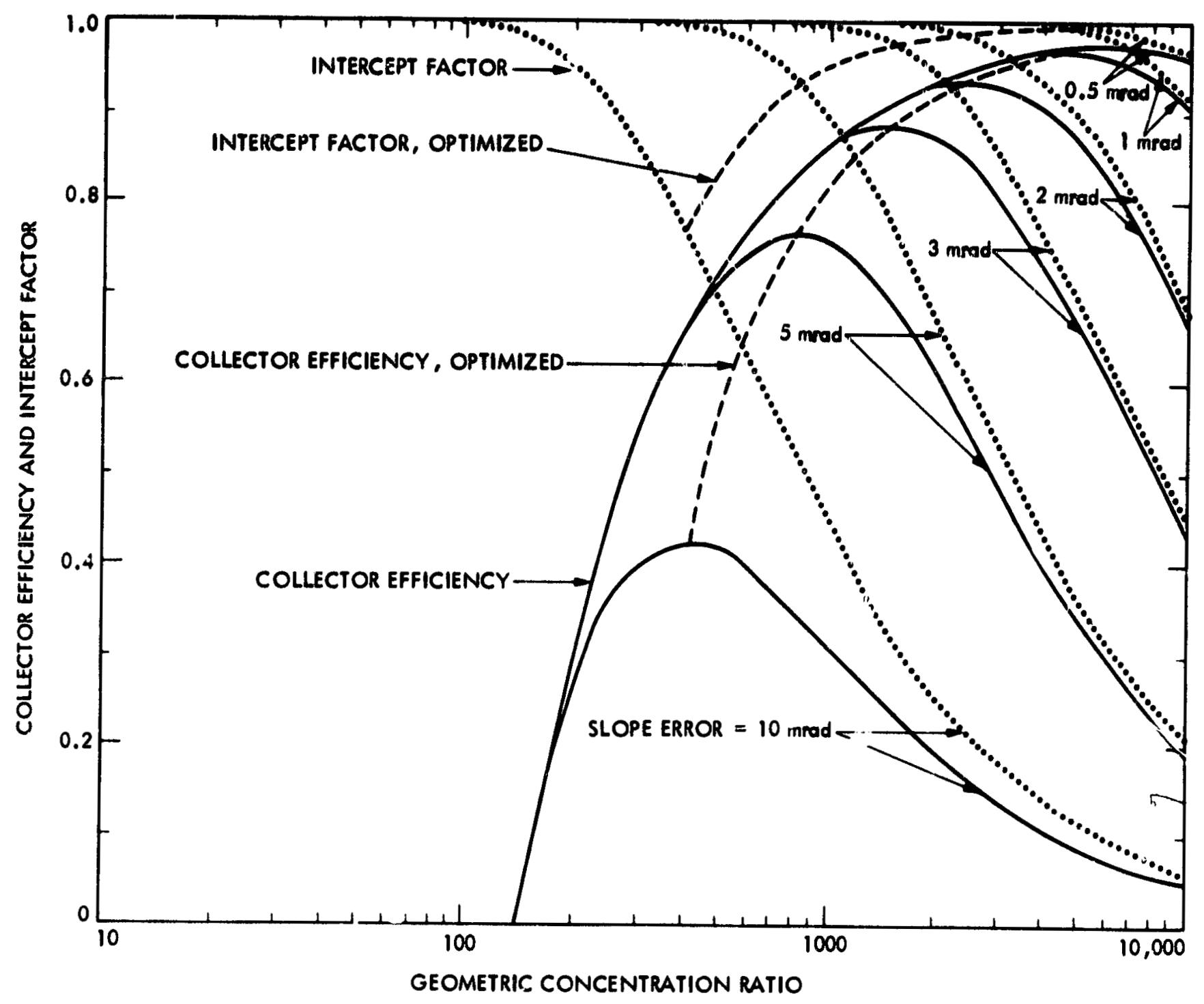

Fífure 8a. Effect of Concentrator Slope Errors upon Collector Efficiency and Intercept Factor: Idealized System.

Dotted line: Receiver aperture optimized. 


\section{original PACE 18 \\ OF POOR QUALITY}

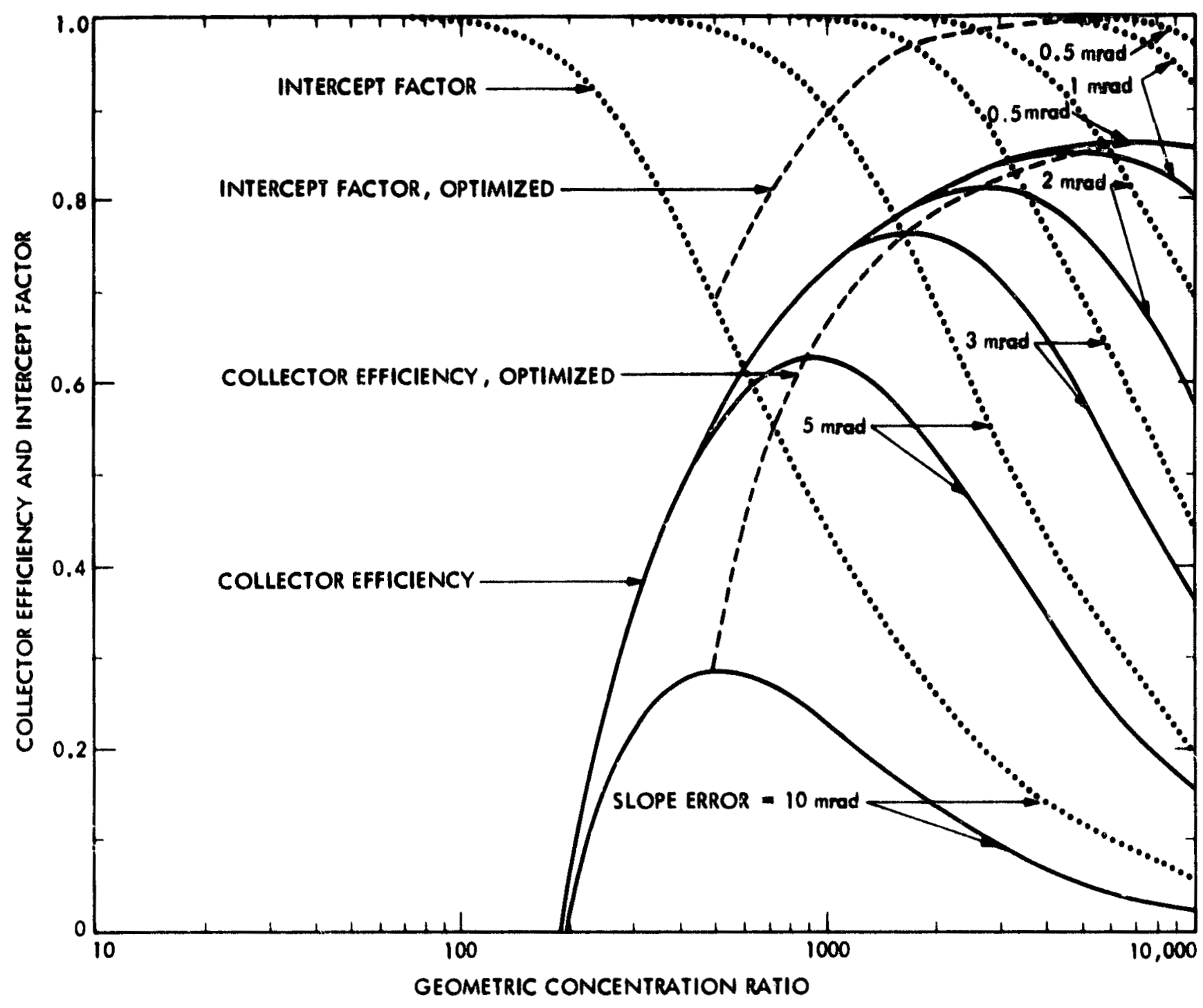

Eigure 8b. Effect of Concentrator Slope Errors upon Collector Ffficiency and Intercept factor: Baseline System.

Dothed line: Recelver aperture optimlzed. 


\section{ORIGINAL PAGR R
OF POOR QUALITY}

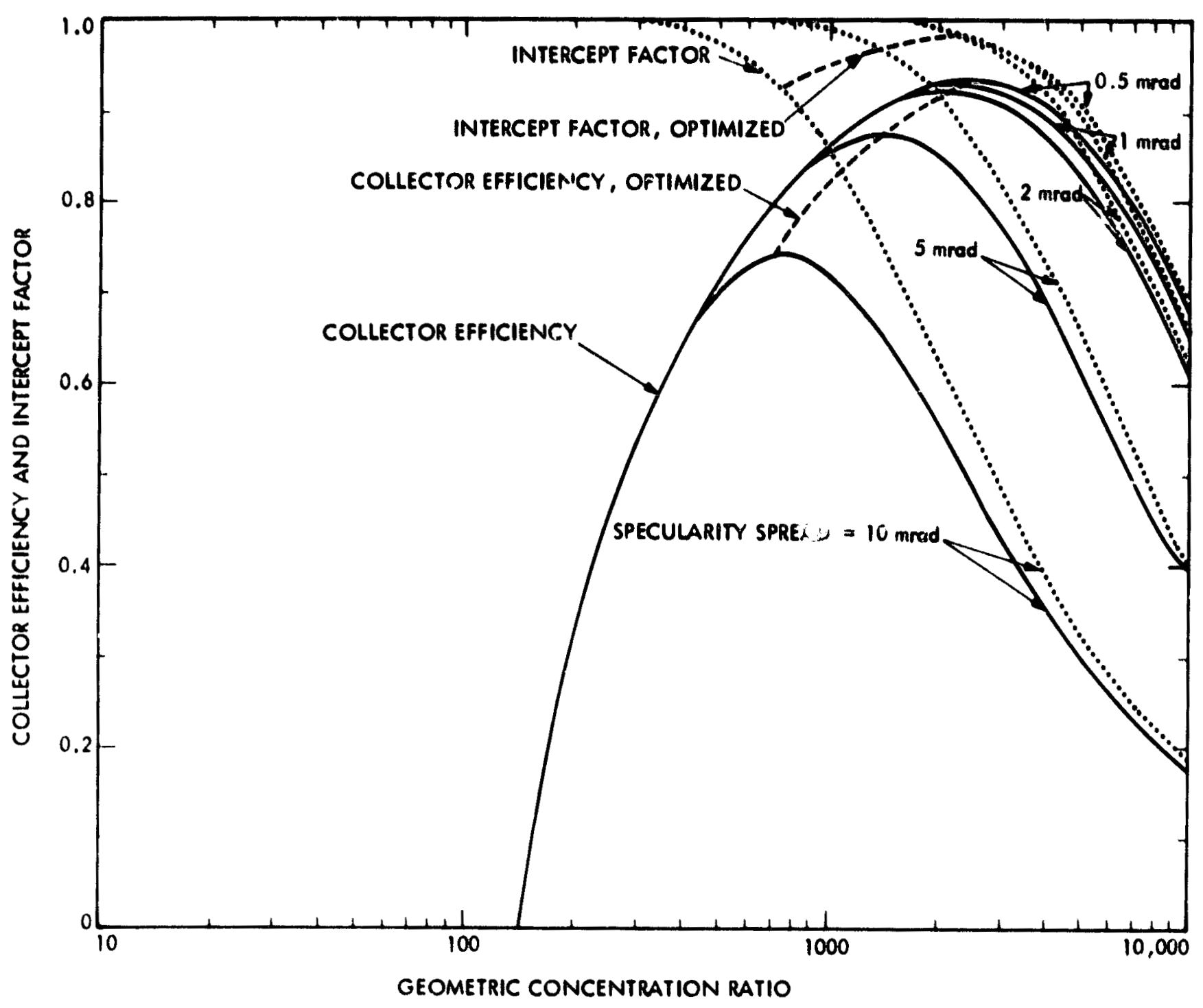

Figure 9a. Effect of Specularity spread upon collector Effictency and Intercept factor: ldoalized system.

boted line: Receiver aperture optimized. 


\section{original pace lo

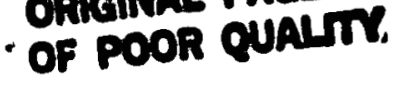

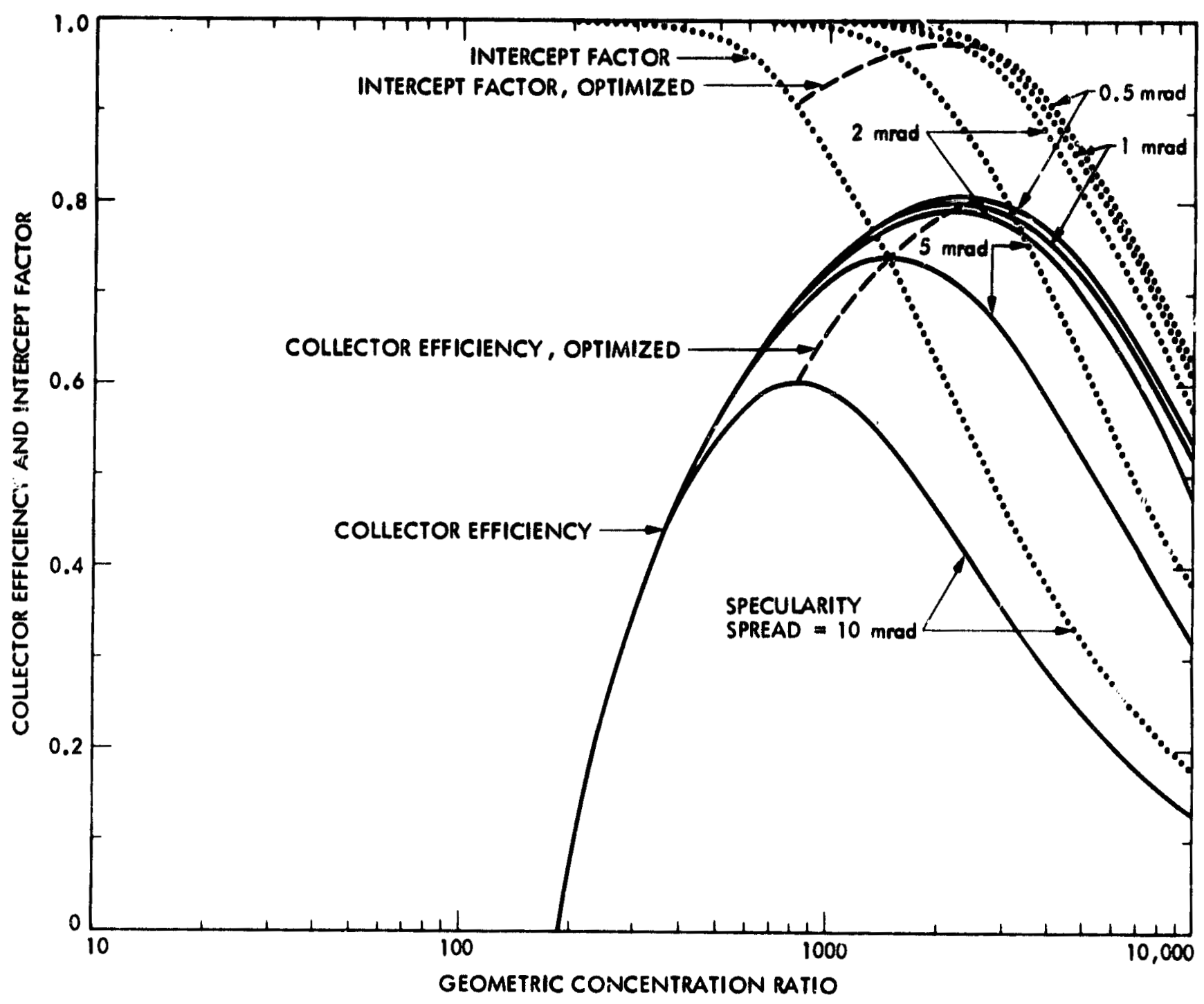

Figure 9b. Effect of Specularity Spread upon Collector Efficiency and Intercept Factor: Baseline System.

Dotted 11ne: Receiver aperture optimized. 


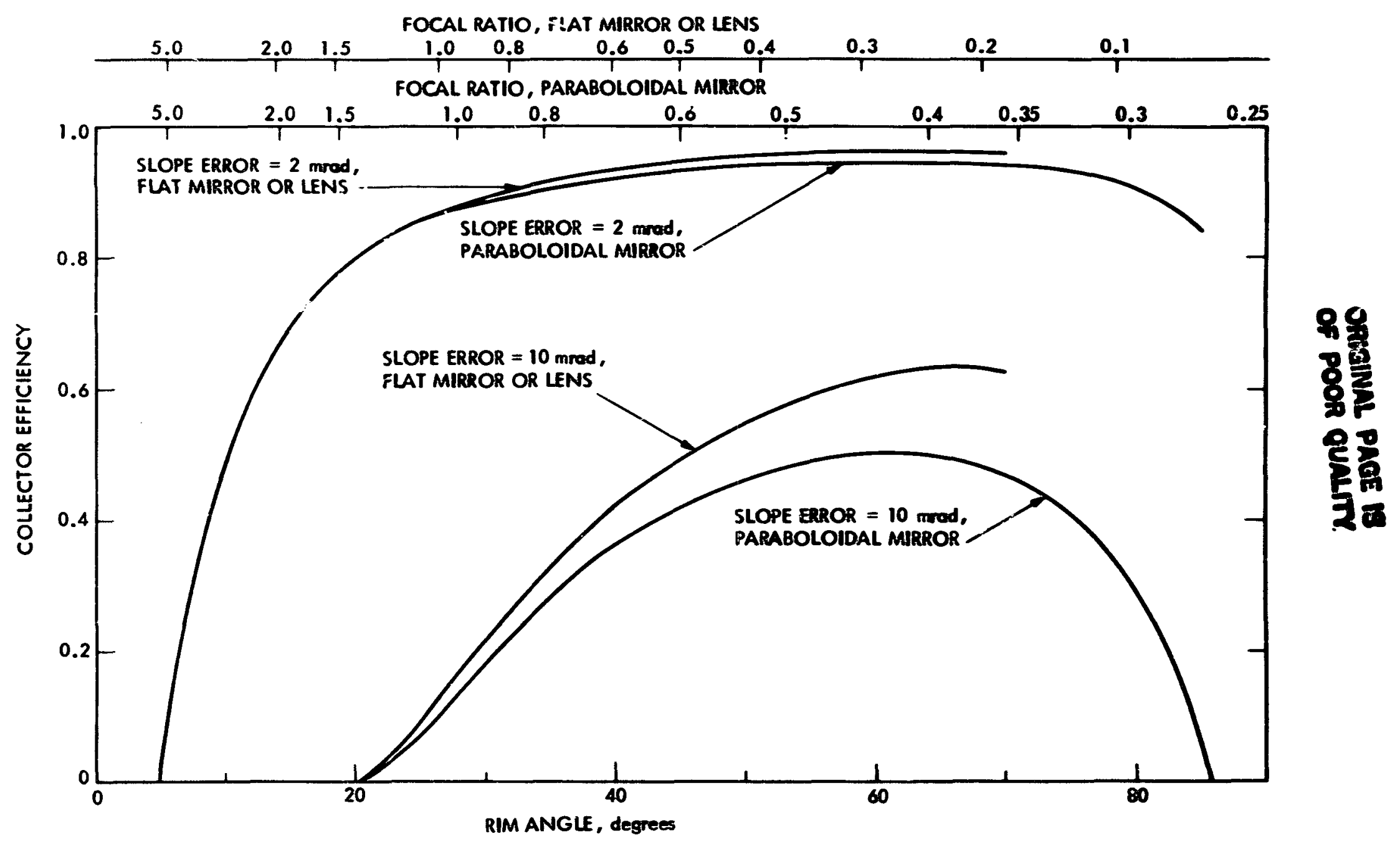

Figure 10. Effect of Focal Ratio or Rim Angle upon Collector Efficiency. Receiver aperture optimized for each focal ratio (or rim angle). DuffLameiro approximation. Idealized System. 


\section{coiscinal para 18 \\ Or pOOR QUALITY}

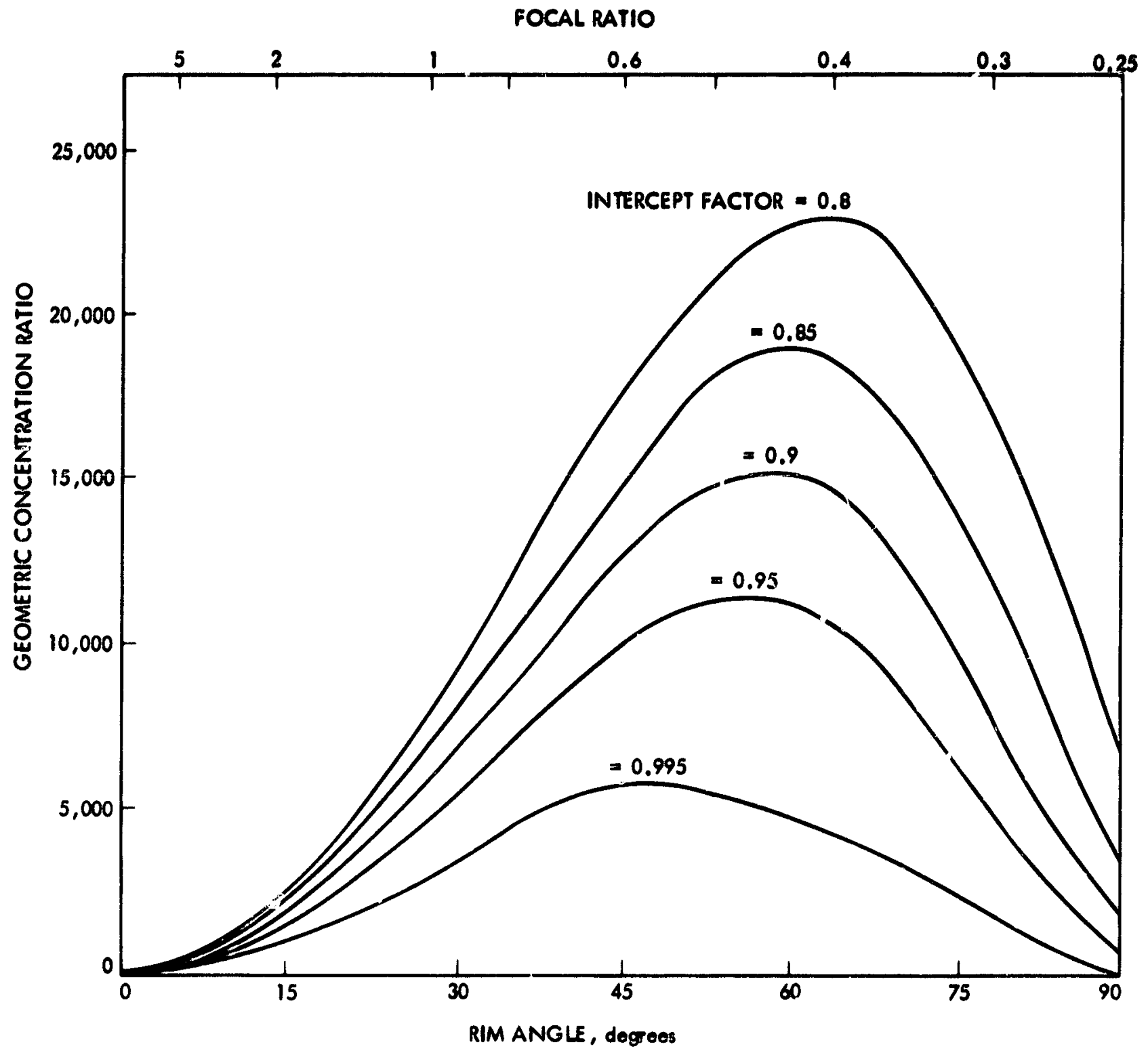

Figure 11. Effect of Rim Angle and Geometric Concentration Ratio upon Intercept Factor.

Flat solar disk profile, diameter 32 arc minutes. Parabololdal mirror, reflectance 1.0 , slope error 3 arc minutes, no other errors. After $0^{\prime}$ Neill and Hudson (Ref. 26). 
RECEIVER TEMPERATURE, ${ }^{\circ} \mathrm{F}$

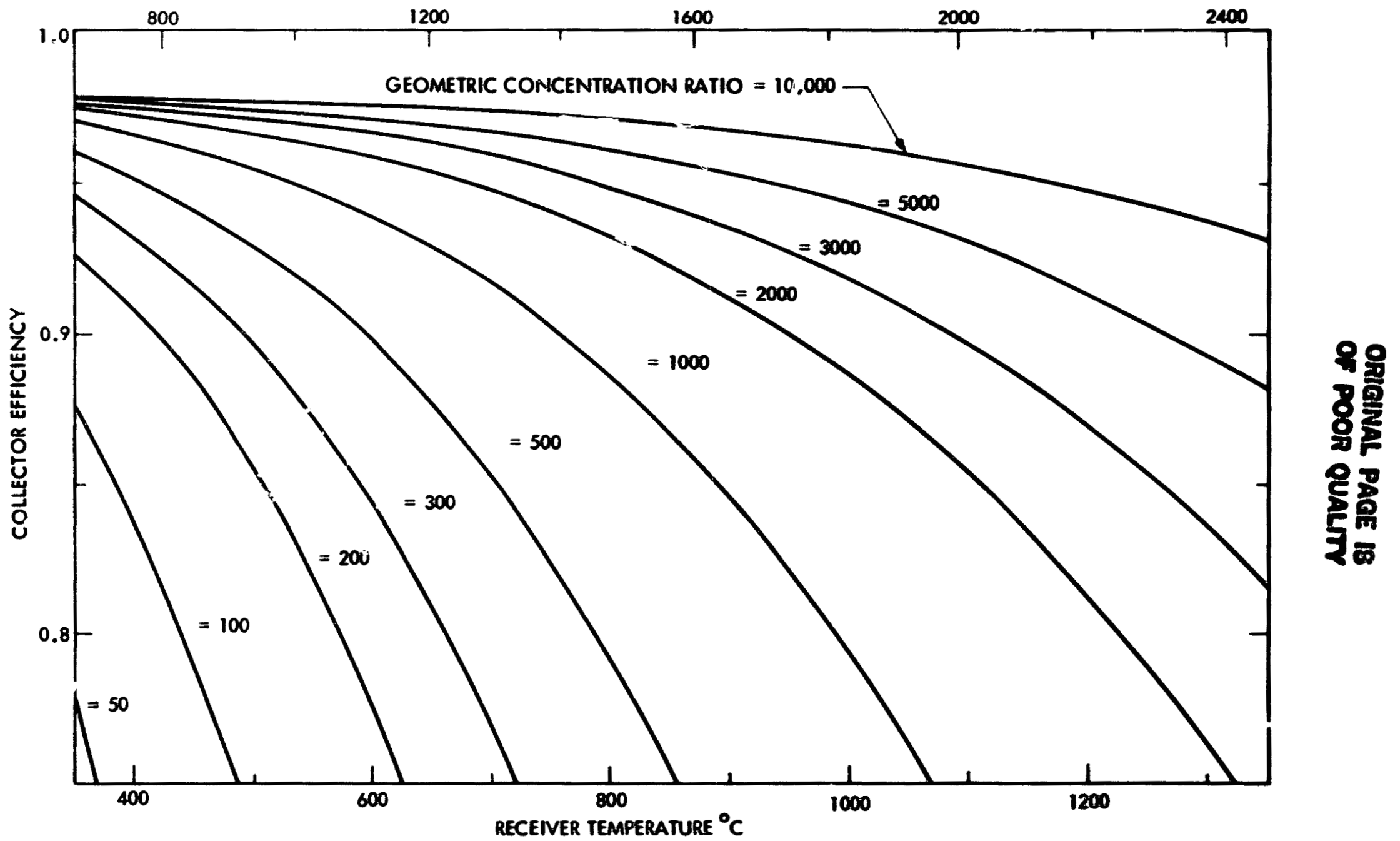

Figure 12a Effect of Receiver Temperature and Geometric Concentration Ratio upon Collector Efficiency.

Idealized system, except as noted; constant intercept factor $(\phi=0.98)$. 


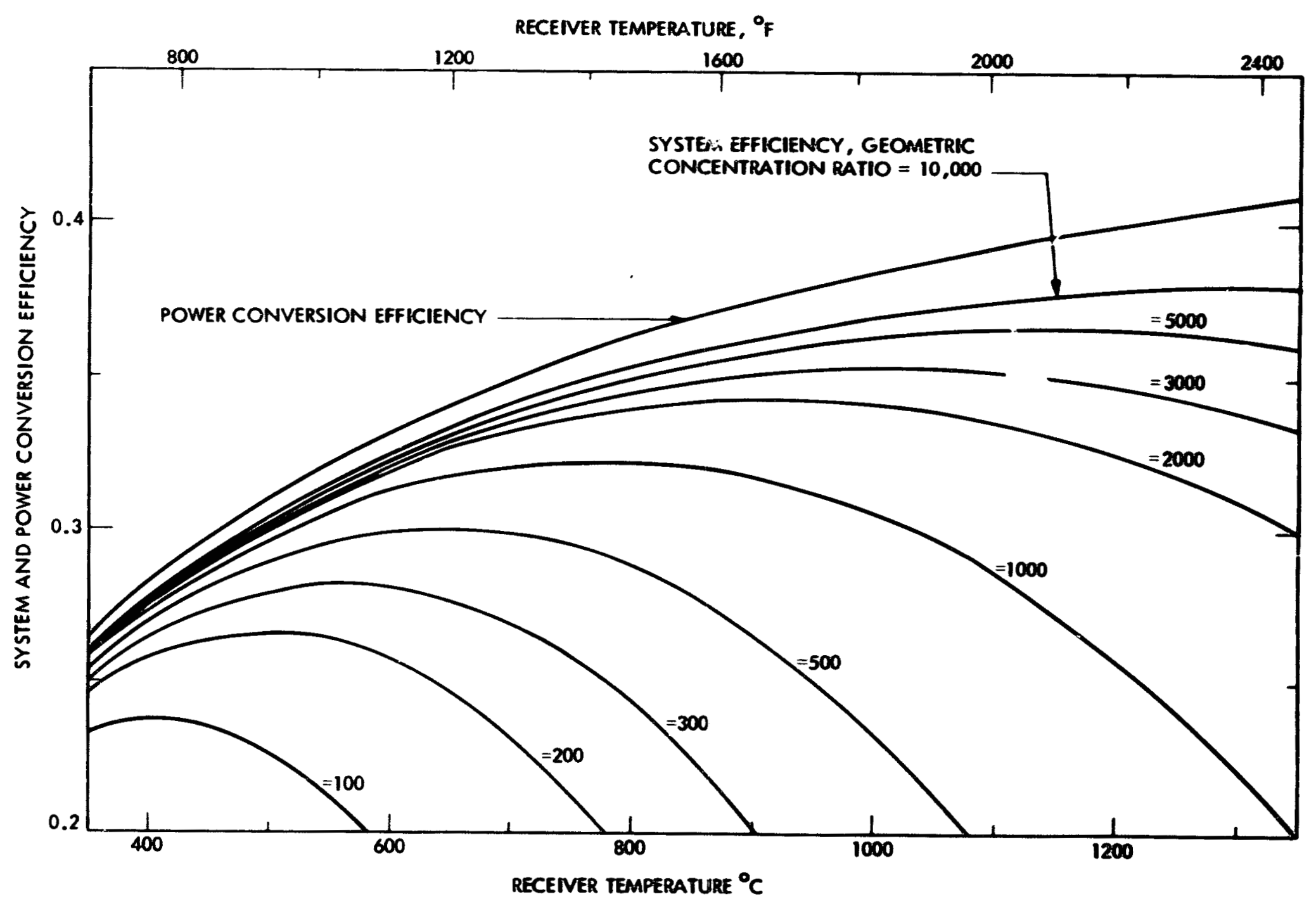

Figure 12b. Effect of Receiver Temperzture and Geometric Concentration Ratio upon Power Conversion and System Efficiency.

Idealized system, e:sept as noted; constant intercept factor $(=0.98)$, constant power conversion effectiveness. 


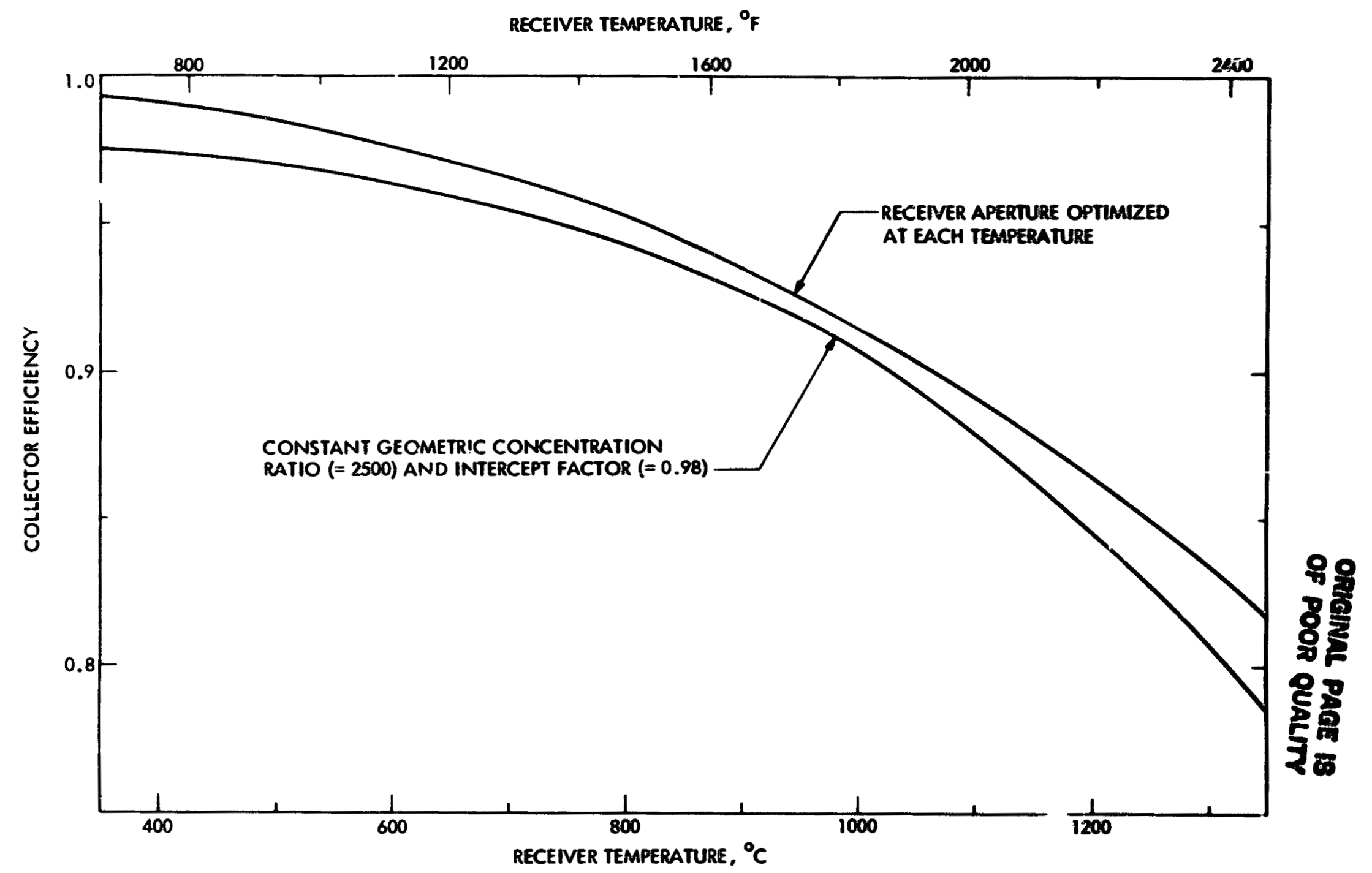

Figure 13. Effect of Receiver Temperature on Collector Ẽficiency With and Without Optimization of Receiver iperture at Each Temperature.

Idealized system except as noted. 


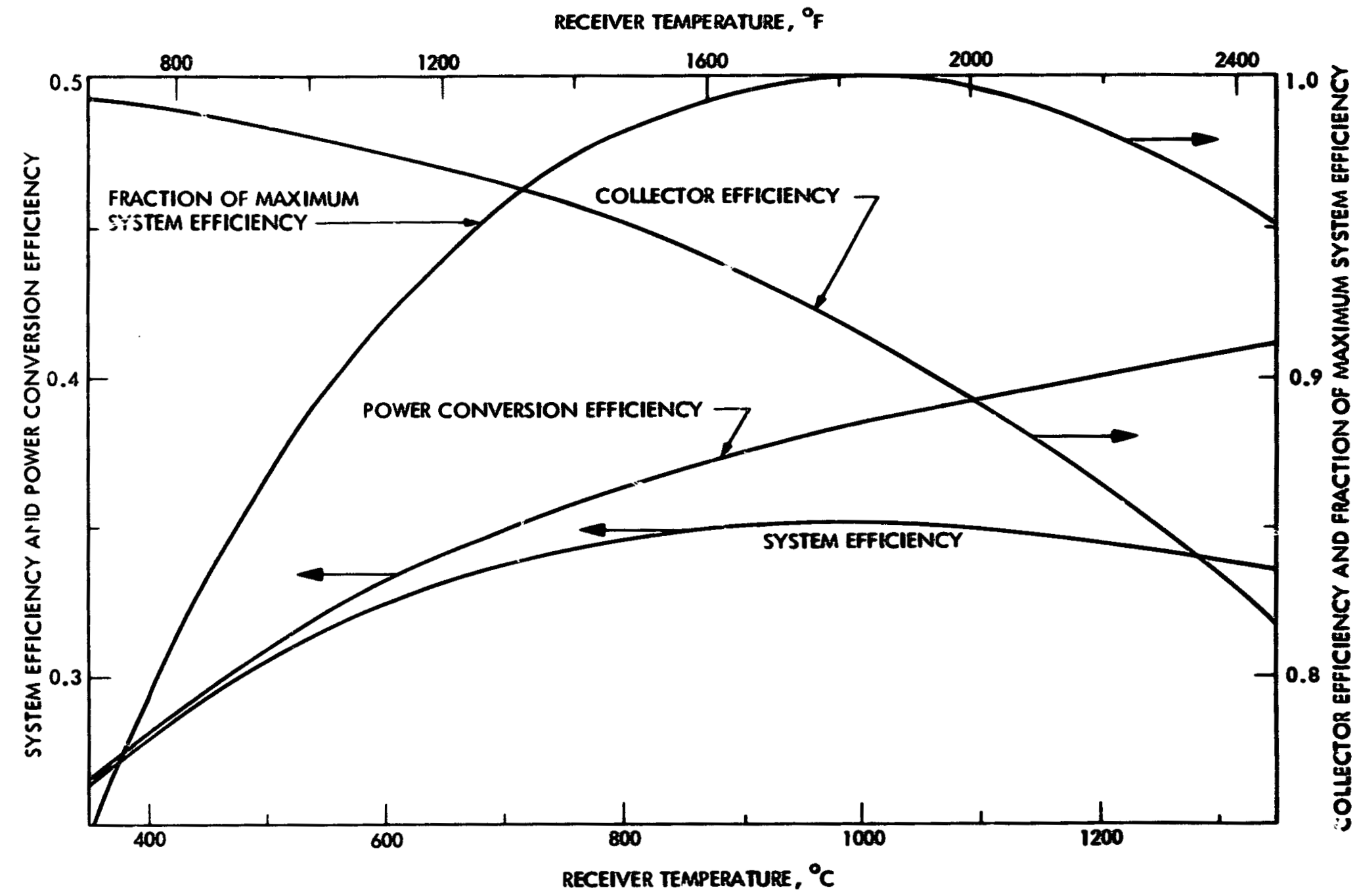

Figure 14. Effect of Receiver Temperature on Collector, Power Conversion, and System Efficiency.

Receiver aperture optimized at each temperature. Idealized system except as roted. Constant power conversion effectiveness. 


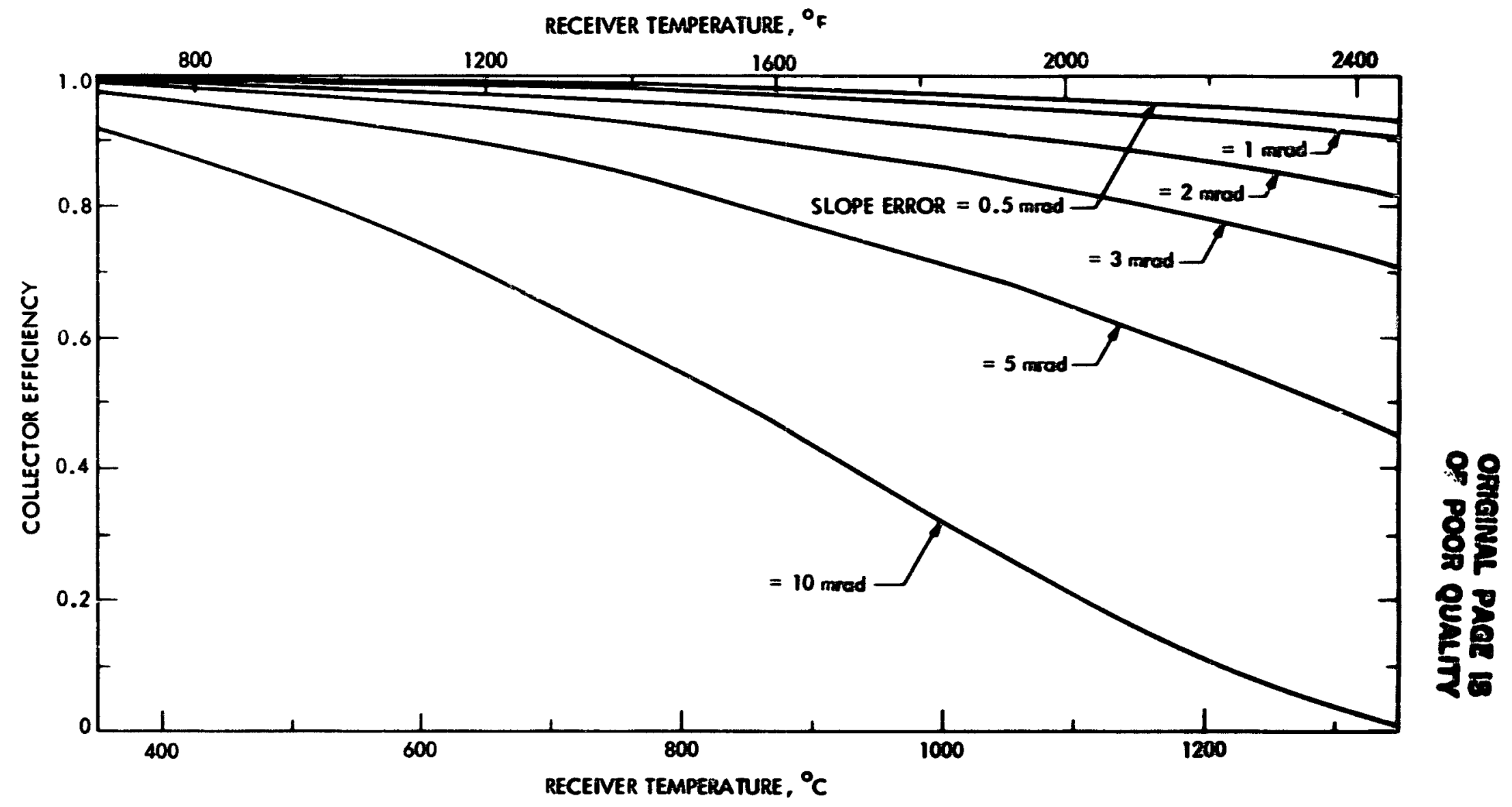

Figure 15a. Effect of Receiver Temperature and Concentrator Slope Error upon Collector Efficiency.

Idealized system except as noced. Recelver aperture optimized at each temperature. 


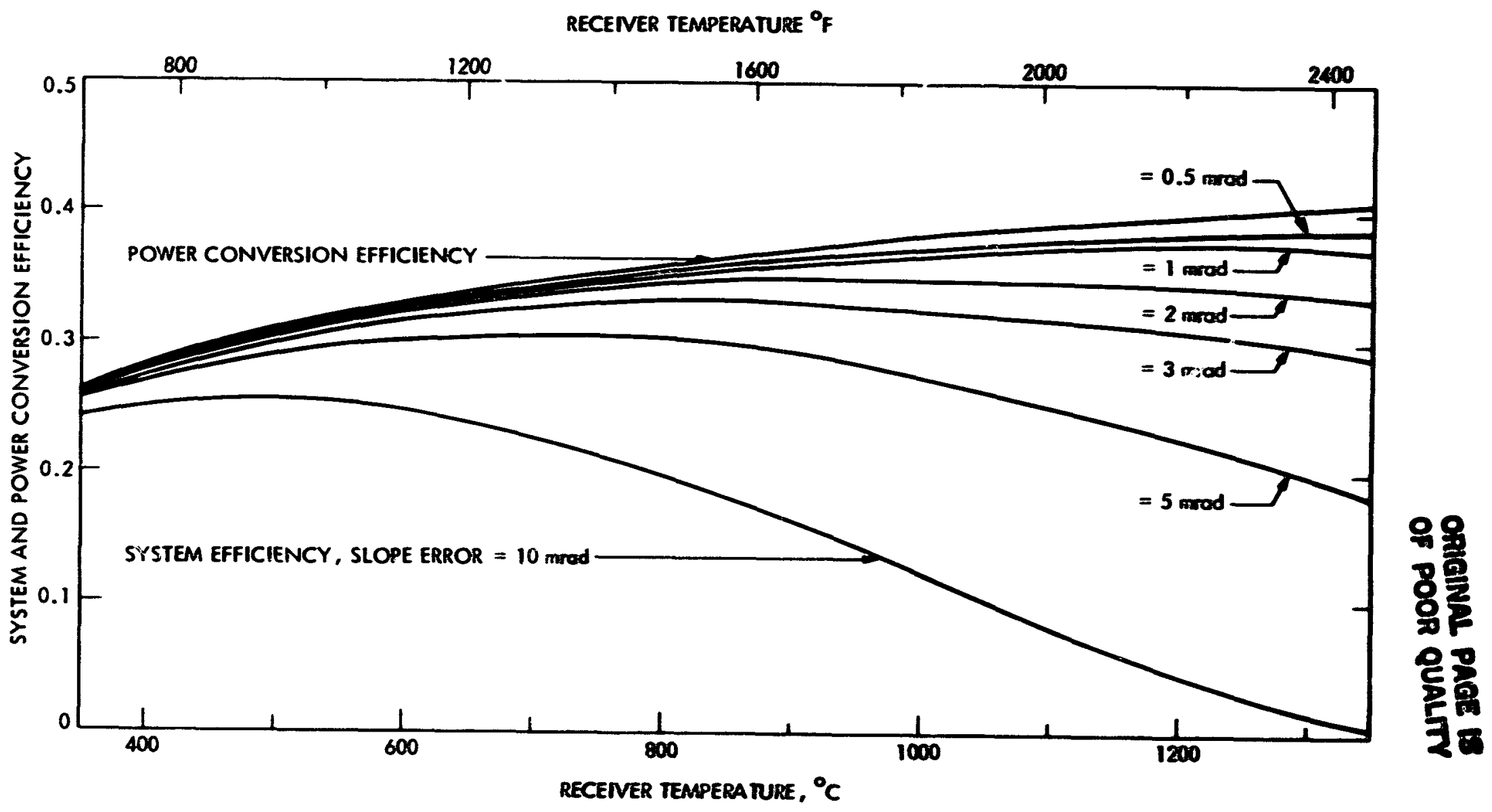

Figure 15b. Effect of Receiver Temperature and Concentrator Slope Error upon Power Conversion and System Efficiency.

Idealized system except as noted. Receiver aperture optinized at each temperature. Constant power conversion ef fectiveness. 


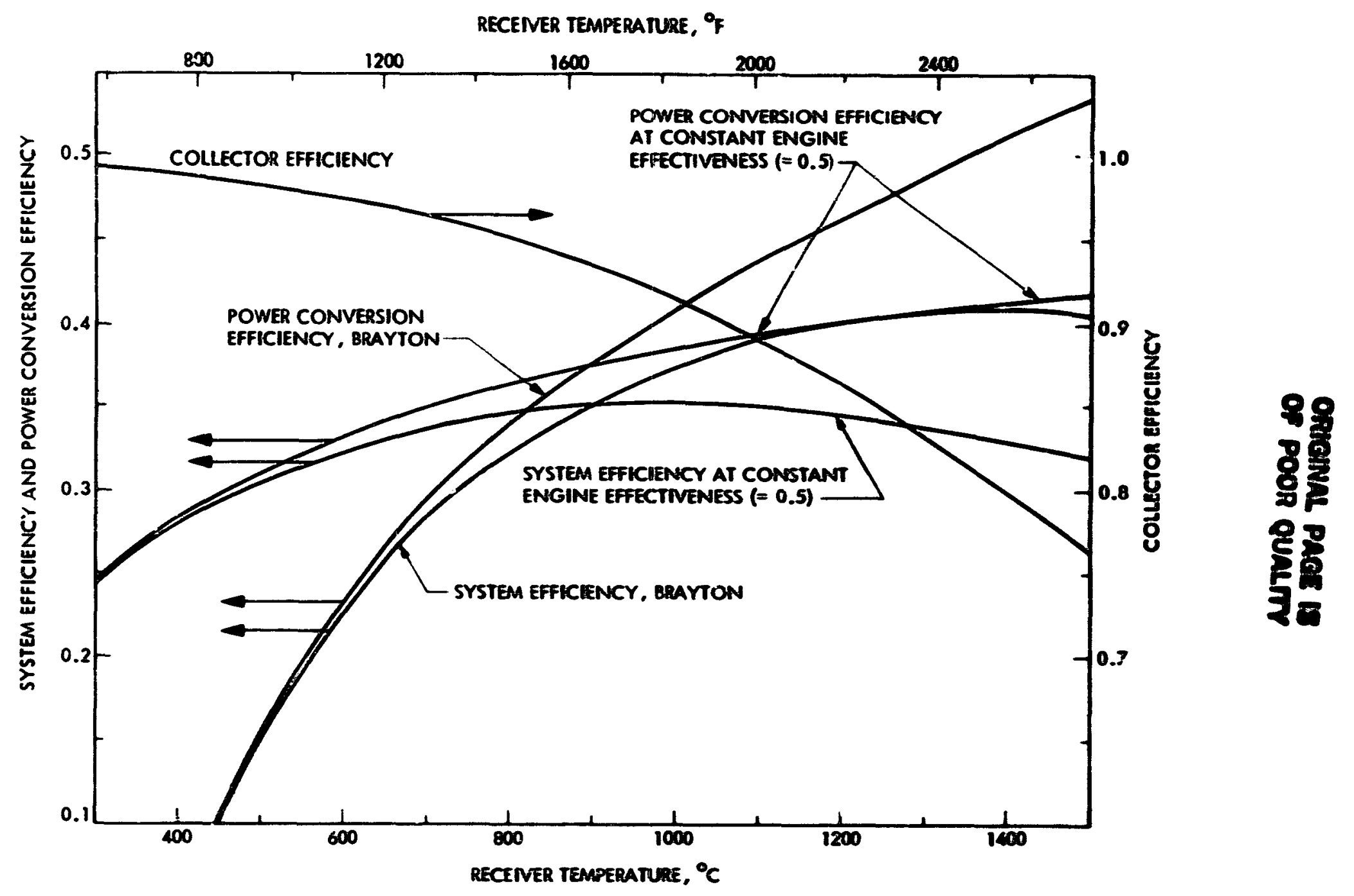

Figure 16a. Effect of Receiver Temperature on Power Conversion and System Efficiency with Engines of Differing Characteristics: Collector, Power Conversion, and Systen Etfieiencies. (Ideallzed systen, except as noted. Receiver aperture optimized at each temperature.)

Constant power conversion effectiveness is characteristic of Rankine and Stirling systens. The numerical value of the effectiveness (here taken as $v=0.5$ ) depends on the particular engine.

Brayton systems characteristically have an engine effectiveness that increases with engine inlet temperature. Brayton power conversion efficiencies shown here are based on engine efficiencies from Refet nce 30 and alternator plus rectifier efficiency of 0.92 . 


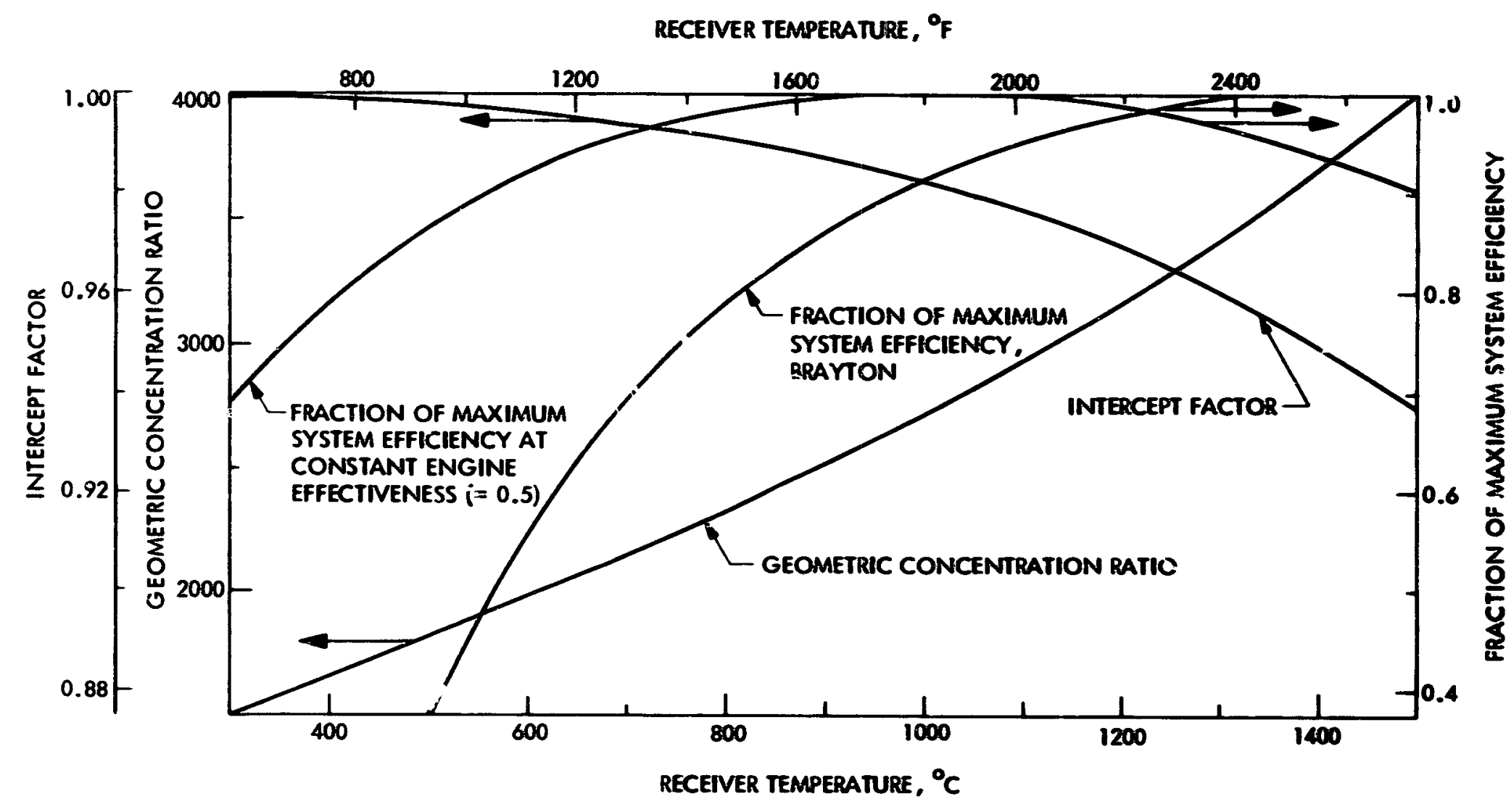

Figure 16b. Effect of Receiver Temperature on Power Conversion and System Efficiency with Engines of Differint Characteristics: System Efficiency As Function of Maximum System Efficieacy, Geometric Concentration Ratio, and Intercept Factor. (Idealized system, except as noted. Receiver aperture optimized at each temperature.)

Constant power conversion effectiveness is characteristic of Rankine and Stirling systens. The numerical value of the effectiveness (here taken as $v=0.5$ ) depends on the particular engine.

Brayton systems characteristically have an engine effectiveness that increases with engine inlet temperature. Brayton power conversion efficiencies shown here are based on engine efficiencies from Reference 30 and alternator plus rectifier efficiency of 0.92 . 


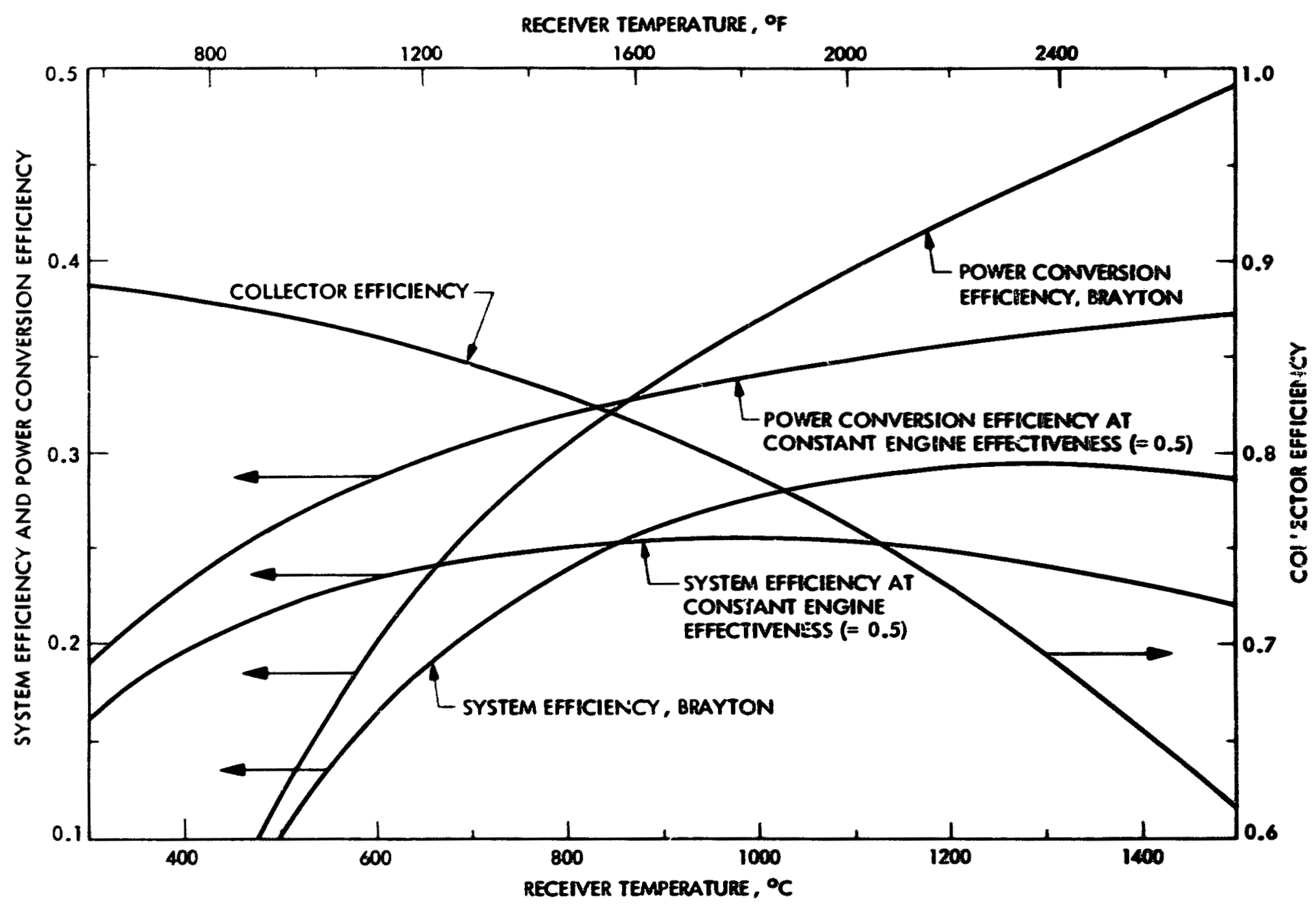

Figure 17a. Effect of Receiver Temperature on Power Conversion and System Efficiency with Engines of Differinis Characteristics: Collector, Power Conversion, and System Efficiencies.

Baseline system, except as noted. Other characteristics as in Figure 16. 


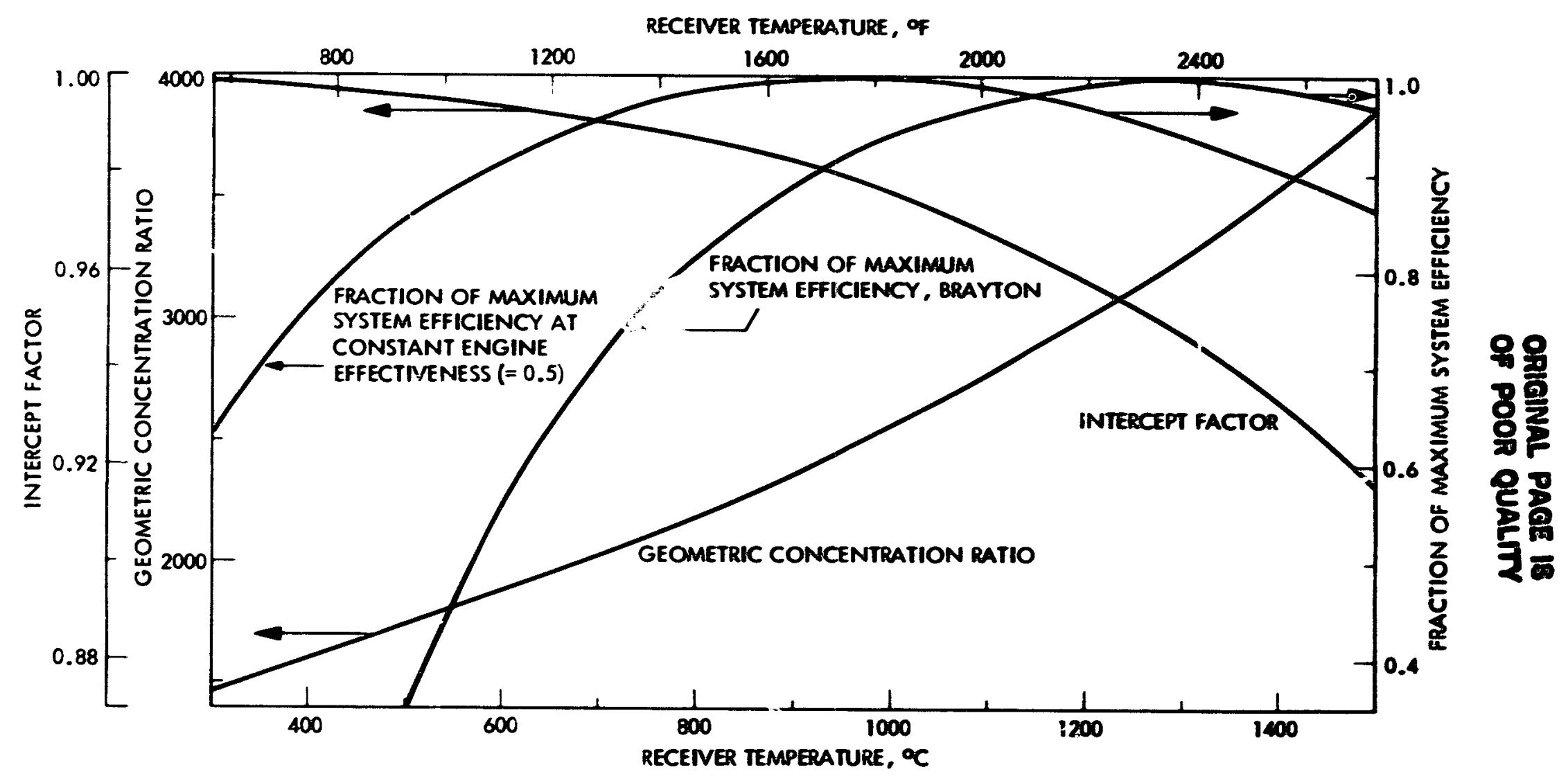

Figure 17b. Effect of Receiver Temperature on Power Conversion and System Efficiency with Engines of Differing Characteristics: System Efficiency As Function of Maximum System Efficiency, Geometric Concentration Ratio, and Intercept Pactor.

Bas 2 ine system, except as noted. Other characteristics as in Figure 16. 


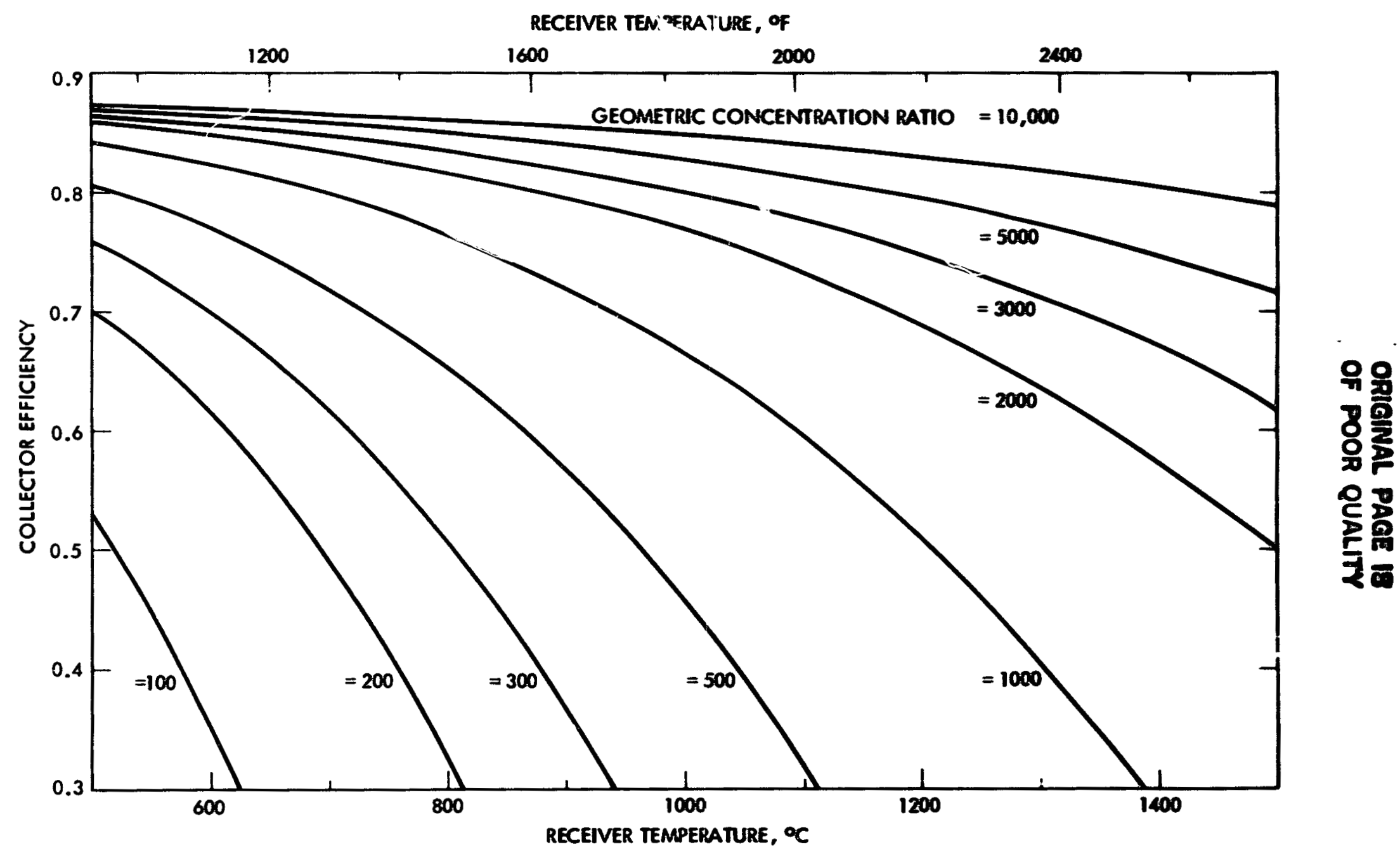

Figure 18a. Effect of Receiver Te $\therefore$ - ure and Geometric Concentration Ratio upon Collector Efficiency.

Fixed intercept factor. Baseline system except as noted. Brayton power conversion effectiveness as in Figure 16. 


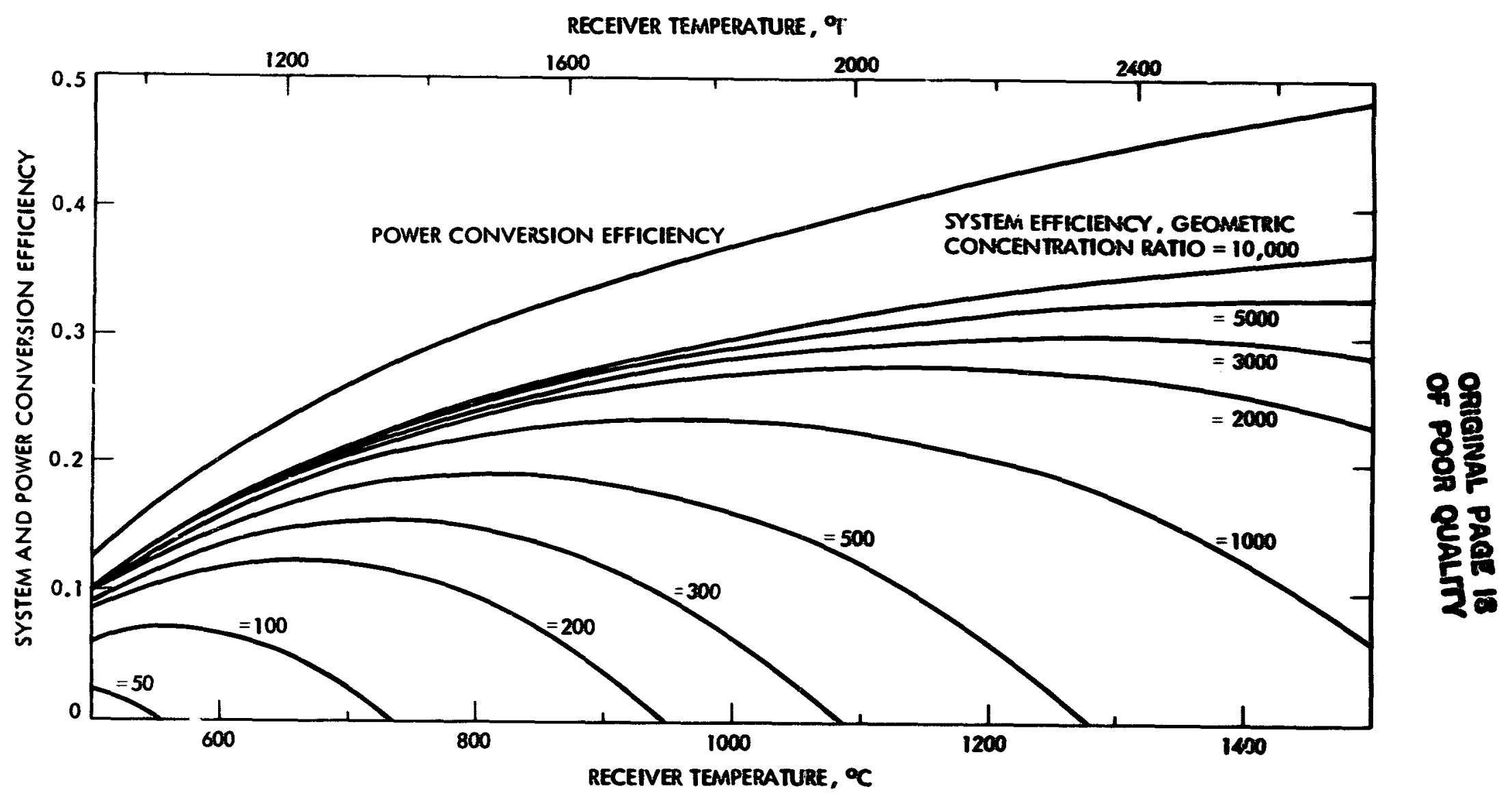

Figure 18b. Effect of Receiver Temperature and Geometric Concentration Ratio upon Power Conversion and System Efficiency.

Fixed intercept factor. Baseline system except as noted. Brayton power conversion effectiveness as in Figure 16. 


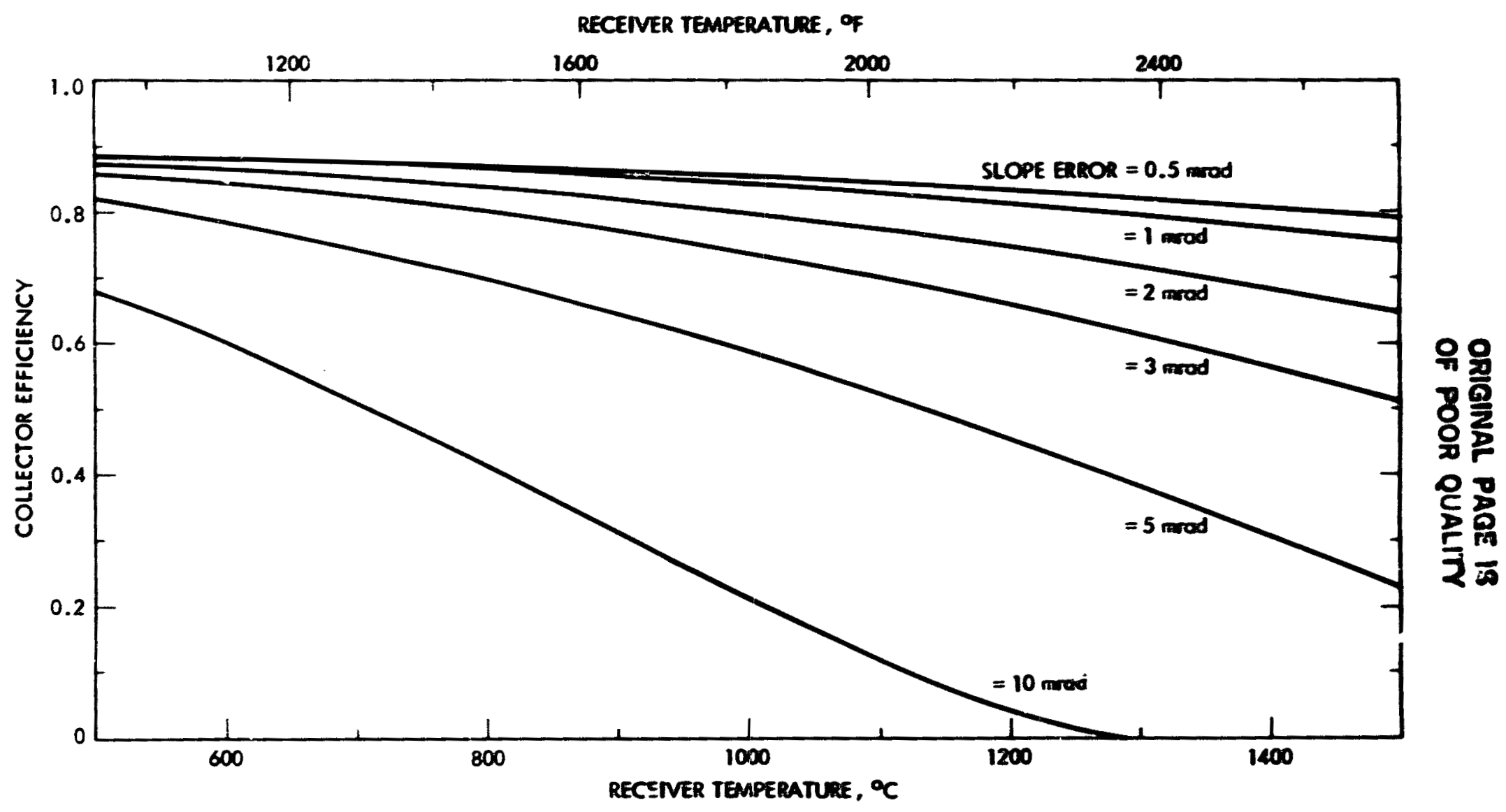

Figure 19a. Effect of Receiver Temperature and Concentrator Slope Error upon Collector Efficiency.

Receiver aperture optimized at each temperature. Baseline system except as noted. Brayton power conversion efficiencies as in Figure 16. 


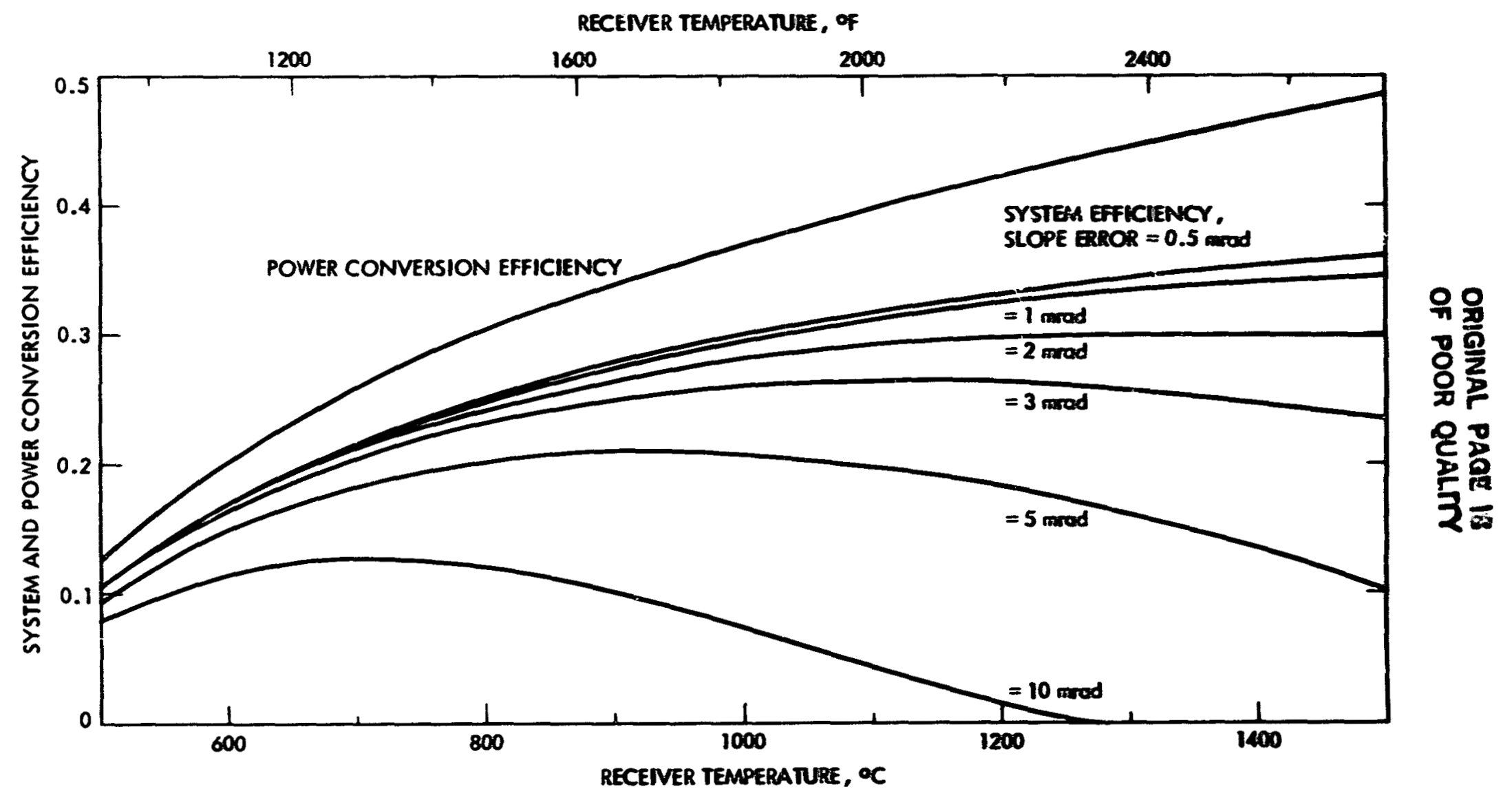

Figure 19b. Effect of Receiver Temperature and Concentrator Slope Error upon Power Conversion and System Efficiency.

Receiver aperture optinized at each temperature. Baseline systen except as noted. Brayton power conversion efficiencies as in Figure 16. 


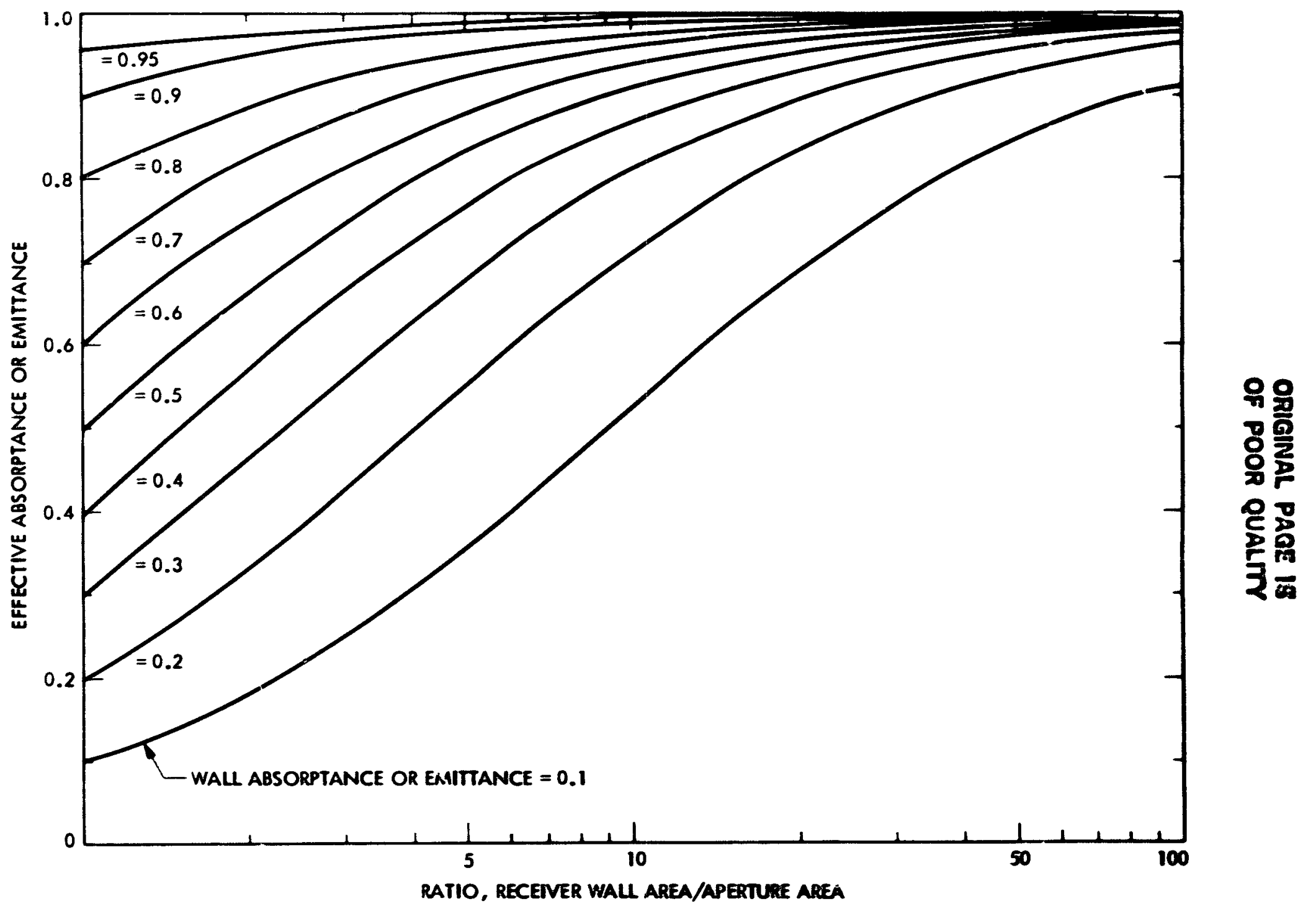

Figure 20. Effective Absorptance or Enittance of Receiver Aperture Versus Ibsorptance or Emittance of Interior Wall for a Cavity Receiver. (Holraum approximation: Aperture area small compared to total surface of cavity.) 


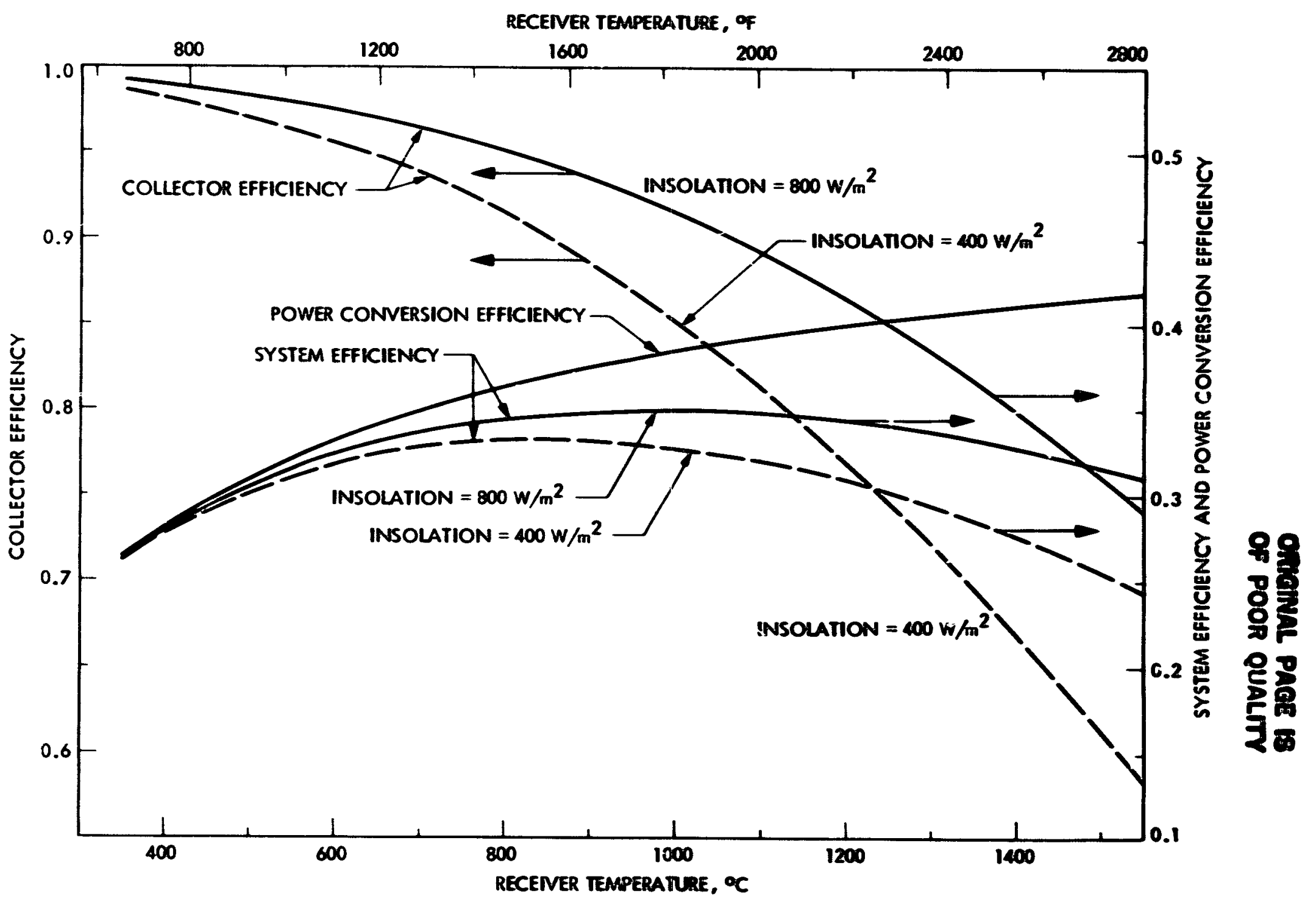

Figure 21. Effect of Insolation Level upon Optimization of Receiver Temperature. Receiver aperture optimized at each temperature. Ideaiized System. 


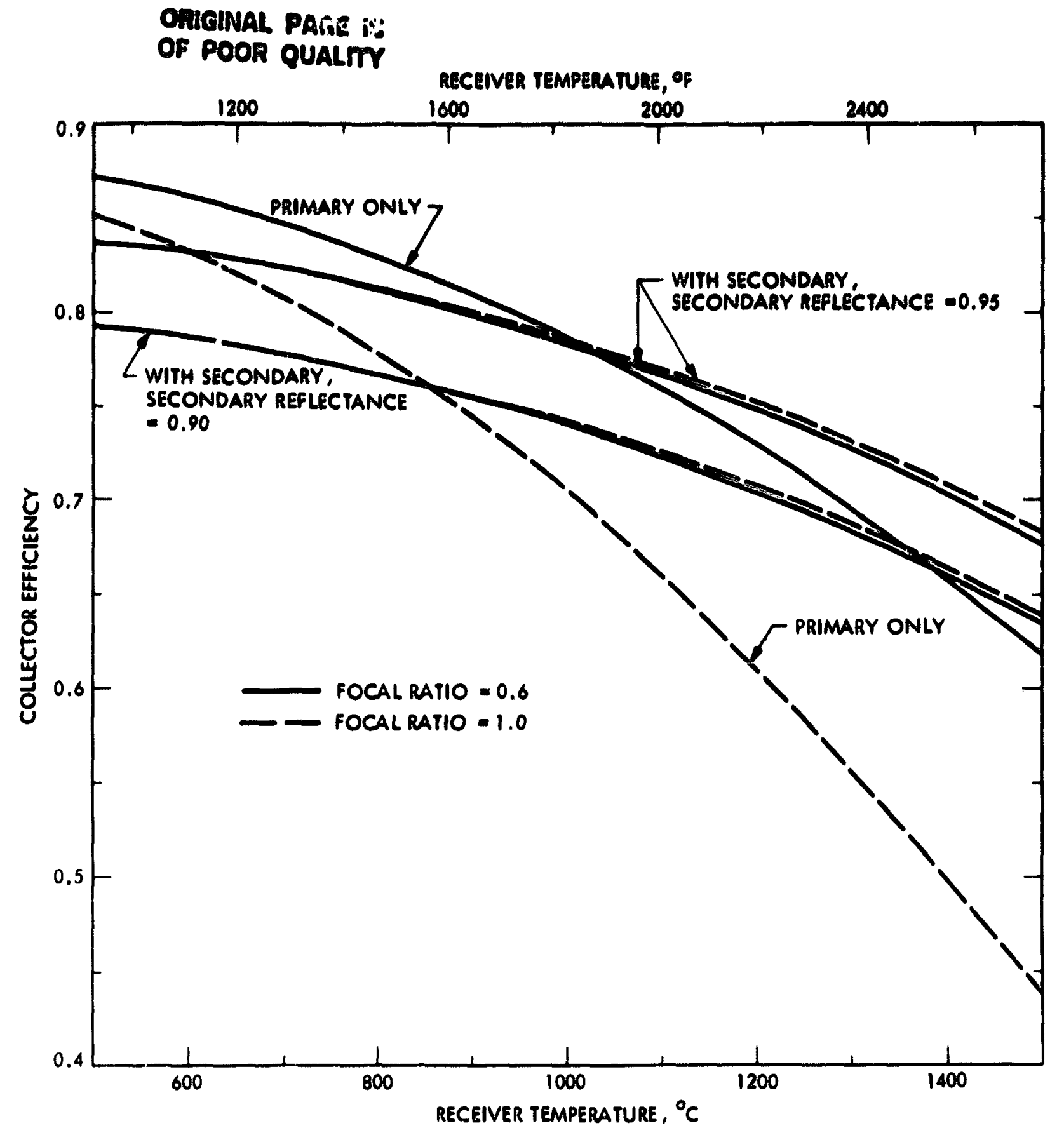

Figure 22a. Effect of Secondary Concentrator on Collector Efficiency. (Baseline system except as noted. Focal ratios 0.6 and 1.0.)

Secondary concentrator reflectances 0.90 and 0.95 . Exit aperturs of secondary concentrator coincldent with recelver aperture. Secondary geometric concentration ratio maximized at each focal ratio of the primary concentrator $\left(1.96\right.$ at $\mathrm{f}_{\mathrm{r}}=0.6 ; 4.43$ at $\left.\mathrm{f}_{\mathrm{r}}=1.0\right)$.

Recelver aperture (= secondary concentrator exit aperture) opt1ilized at each timperature for each design. 


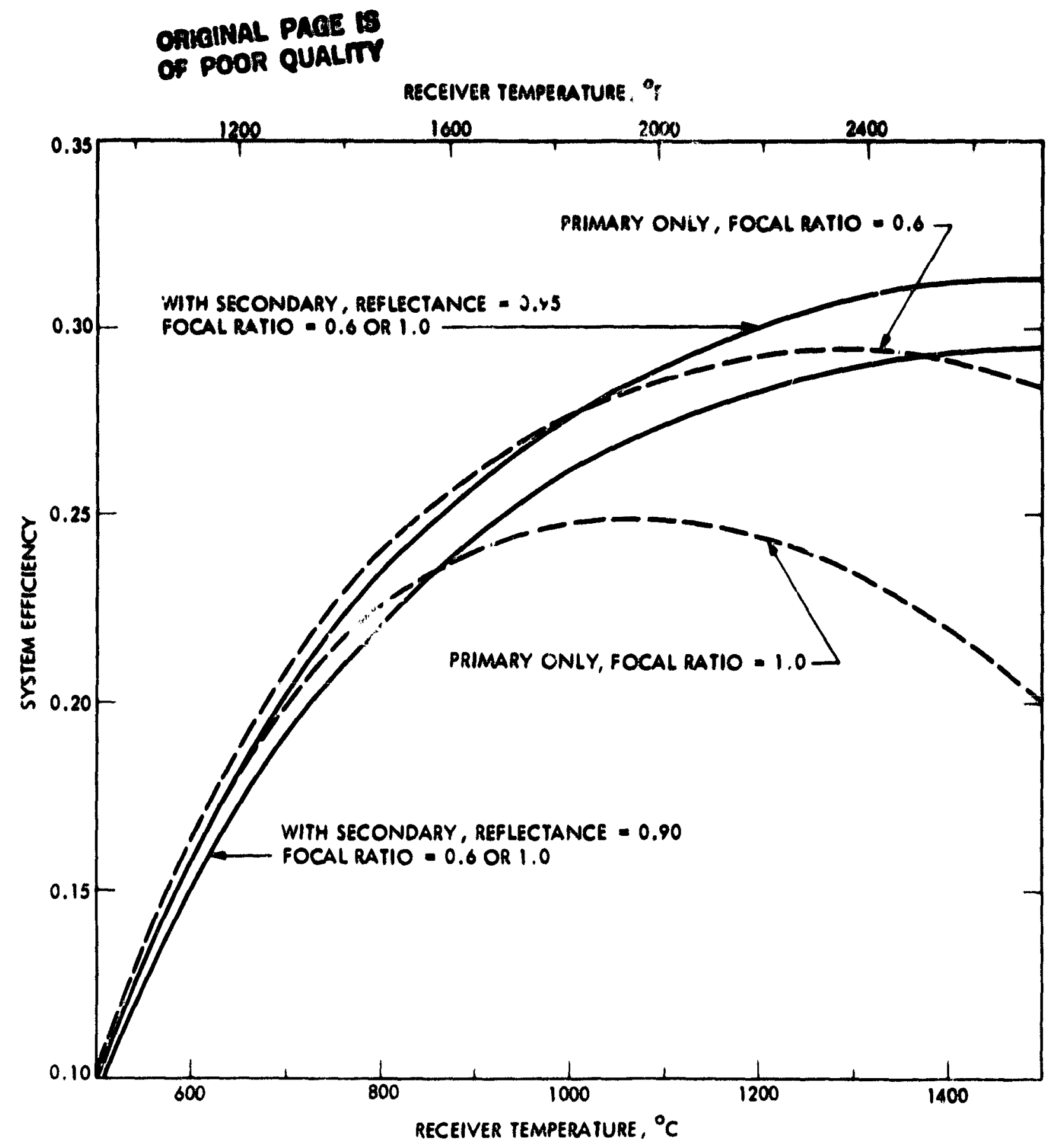

Figure 22b. Effect of Secondary concentrator an system Efficlency. (Baseline system except as noted. Focal rat toe 0.6 and 1.0.)

Secondary concentrator reflectances 0.90 and 0.95 . Exit apercure of secondary concentrator colneldent whth recelver aperture. Secondary geometric concentration ratio maximtzed at each focal ratio of the primary concentrator $\left(1.96\right.$ at $f_{r}=0.6 ; 4.43$ at $\left.f_{r}=1.0\right)$.

Receiver aperture ( = secondary concentrator exit aperture) optemized at cach temperature for each design. 


\section{Oniginal pace 18 \\ OF MODR QUALITY}

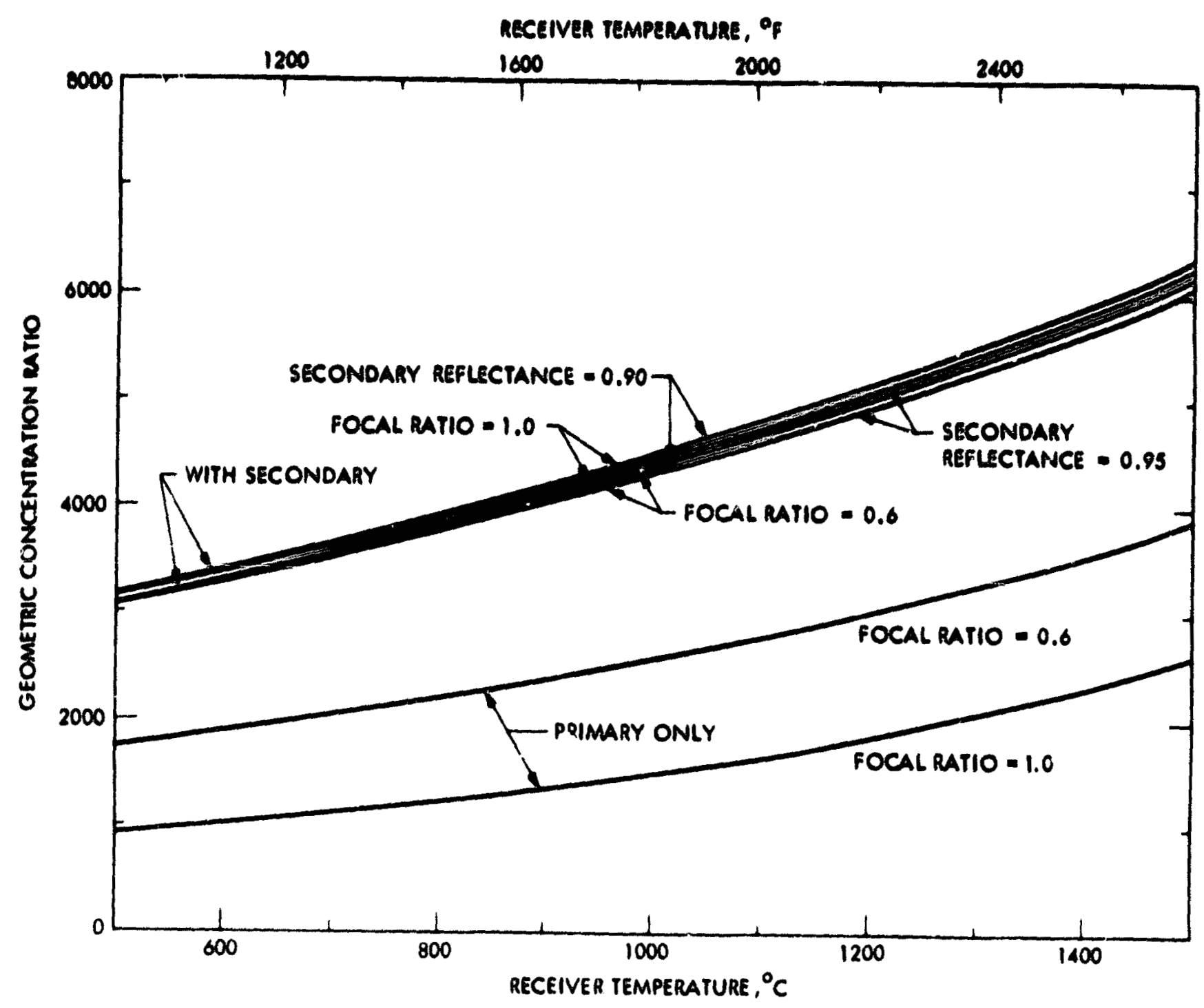

Figure 22c. Effect of Secondary Concentrator on overall cieometric Concentration Ratlo. (Baseline system except as noted. Focal ratilos 0.6 and 1.0.)

Secondary concencrator reflectances 0.90 and 0.95 . Ex1t aperture of secondary concentrator colncident with recelver aperture. Secondary geometric concentration ratio maximized at each focal rato of the primary concentrator $\left(1.96\right.$ at $f_{r}=0.6 ; 4.43$ at $\left.f_{r}=1.0\right)$.

Recelver aperture ( secondary concentrator exit aperture) opt1inlzed at each temperature for cach design. 


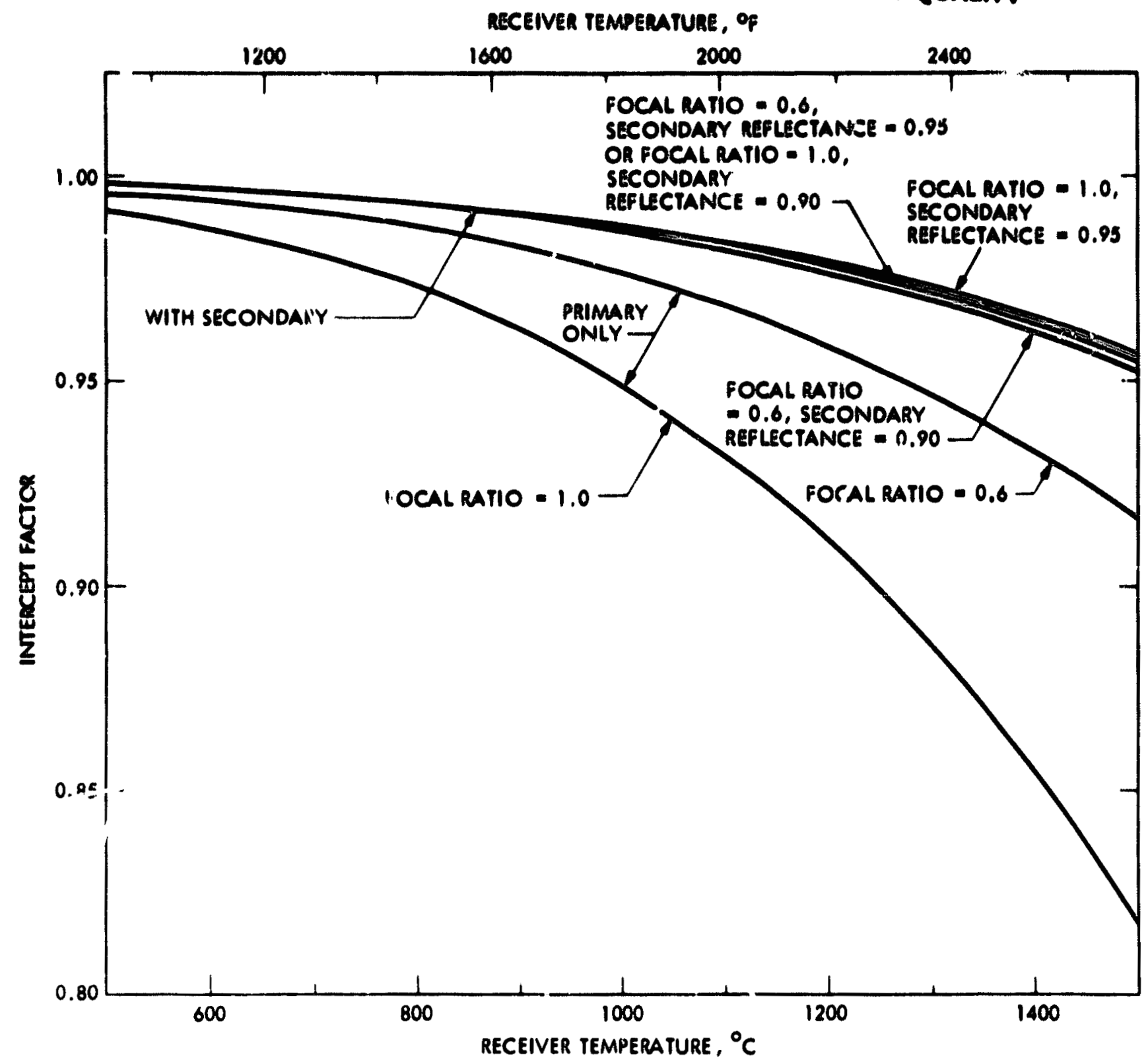

Flgure 22d. Effect of Secondary Concentrator on Intercept Fartor. (Baseline system except as noted. Focal ratios 0.6 and 1.0.$)$

secondary concentrator reflectances 0.90 and 0.95 . Fxit aperture of secondary concentrator coincident with recelver aperture. Secondary geometric concentration ratio maximlzed at each focal rat lo of the prinary concentrator $\left(1.96\right.$ at $f_{r}=0.6 ; 4.43$ at $\left.f_{r}=i .0\right)$. Recelver aperture (m secondary concentrator exit aperture) of tmlaed at each temperature for each design. 


\section{FOCAL RATIO}

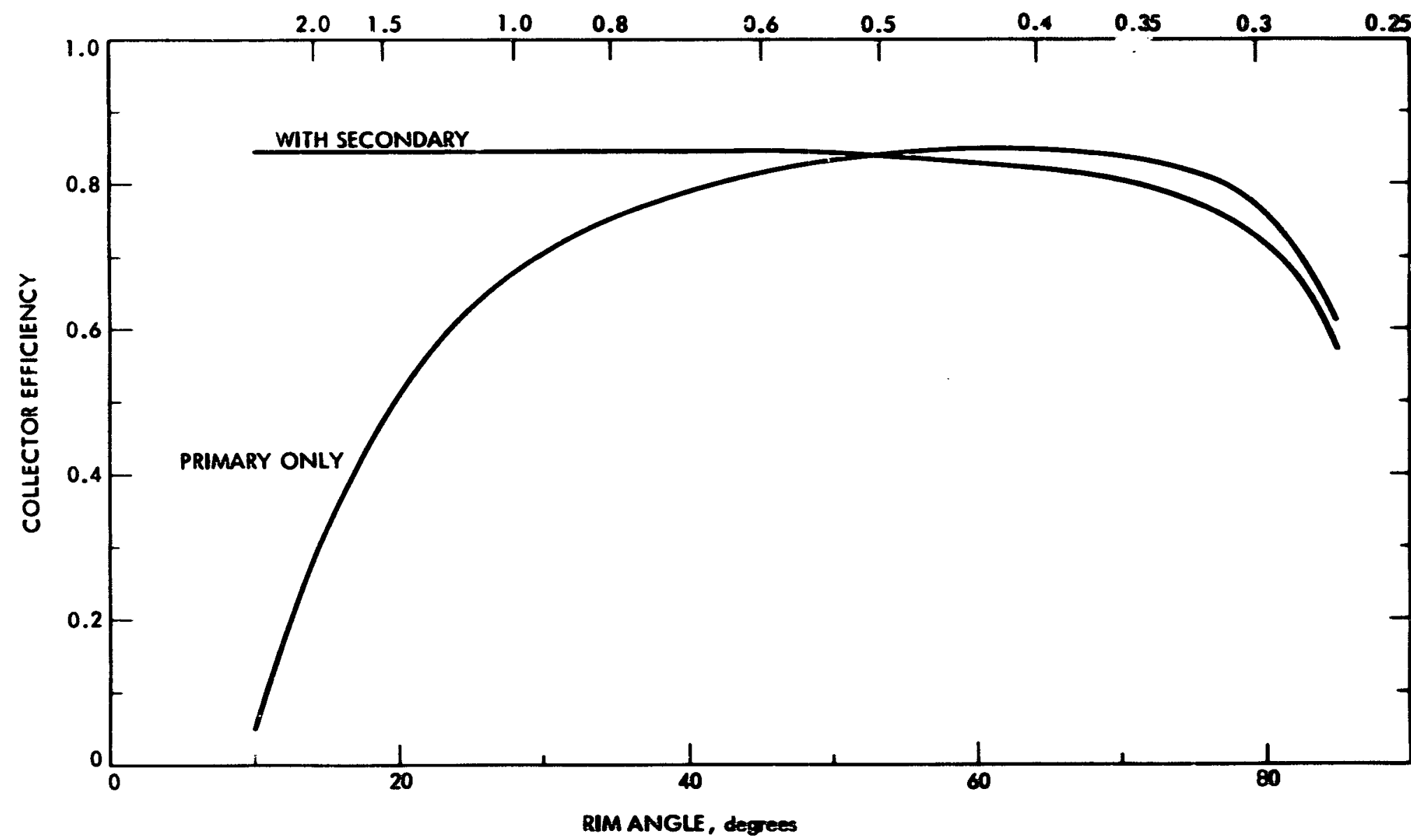

Figure 23a. Effect of Focal Ratio upon Collector Efficiency of Simple and Compoind Concentrators. (Based on Duff-Lameiro approximation for primary (Ref.13). Idealized system except as noted.)

Secondary concentrator reflectance 0.95. Exit aperture of secondary concentrator coincident with receiver aperture. Secondary geometric concentration ratio maximized at each focal ratio of the primary concentrator.

Receiver aperture optimized for each design. Receiver temperature $1350^{\circ} \mathrm{C}\left(2460^{\circ} \mathrm{F}\right)$. 


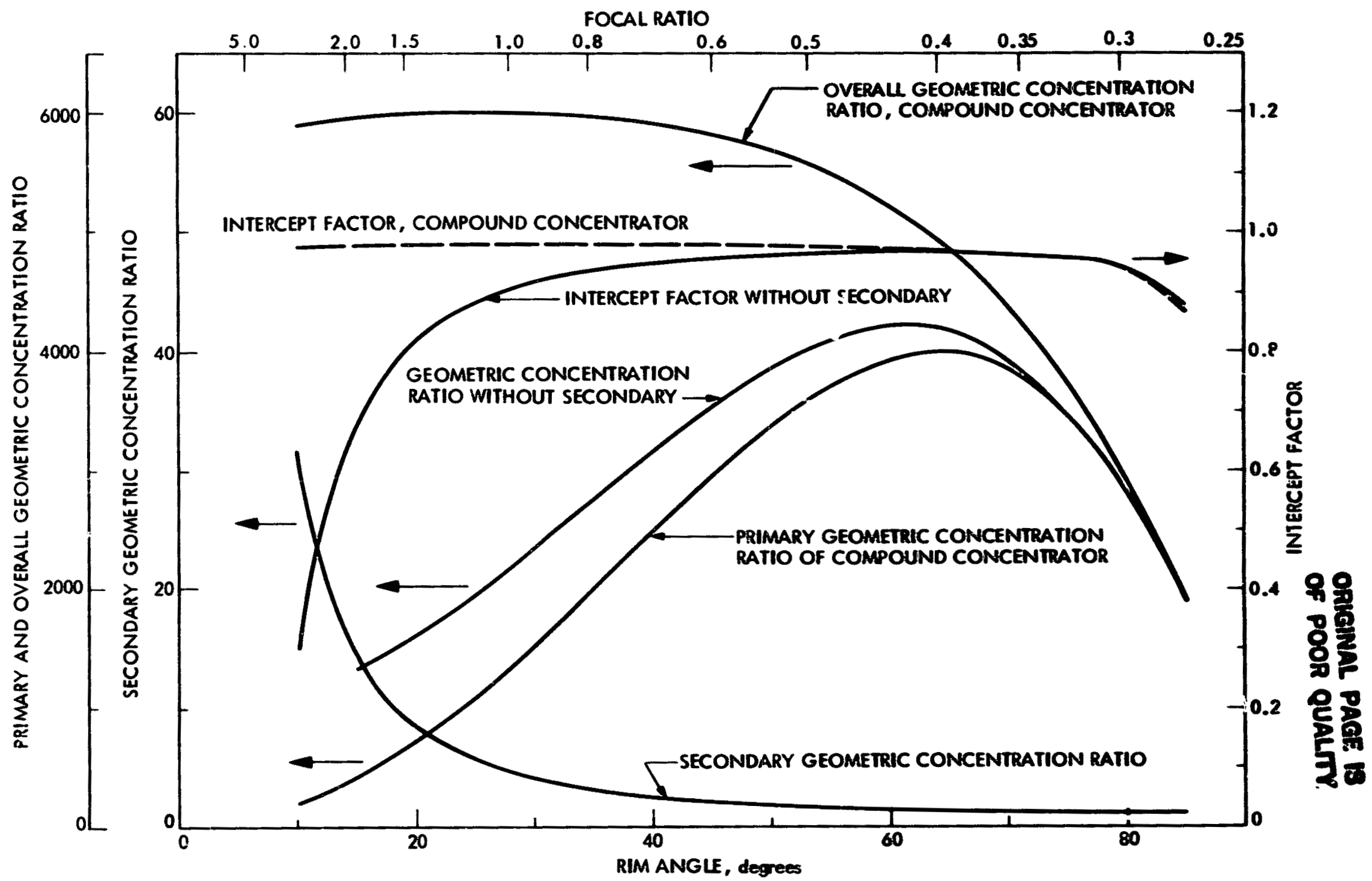

Figure 23b. Effect of Focal Ratio upon Geometric Concentration Ratio and Intercept Factor of Simple and Compound Concentrators. (Based on Duff-Lameiro approximation for primary (Ref. 13 ). Idealized system except as noted.)

Secondary concentrator reflectance 0.95 . Exit aperture of secondary concentrator coincident with receiver aperture. Secondary geometric concentration ratio maximized at each focal ratio of the primary concentrator.

Receiver aperture optimized for each design. Receiver temperature $1350^{\circ} \mathrm{C}\left(2460^{\circ} \mathrm{F}\right)$. 


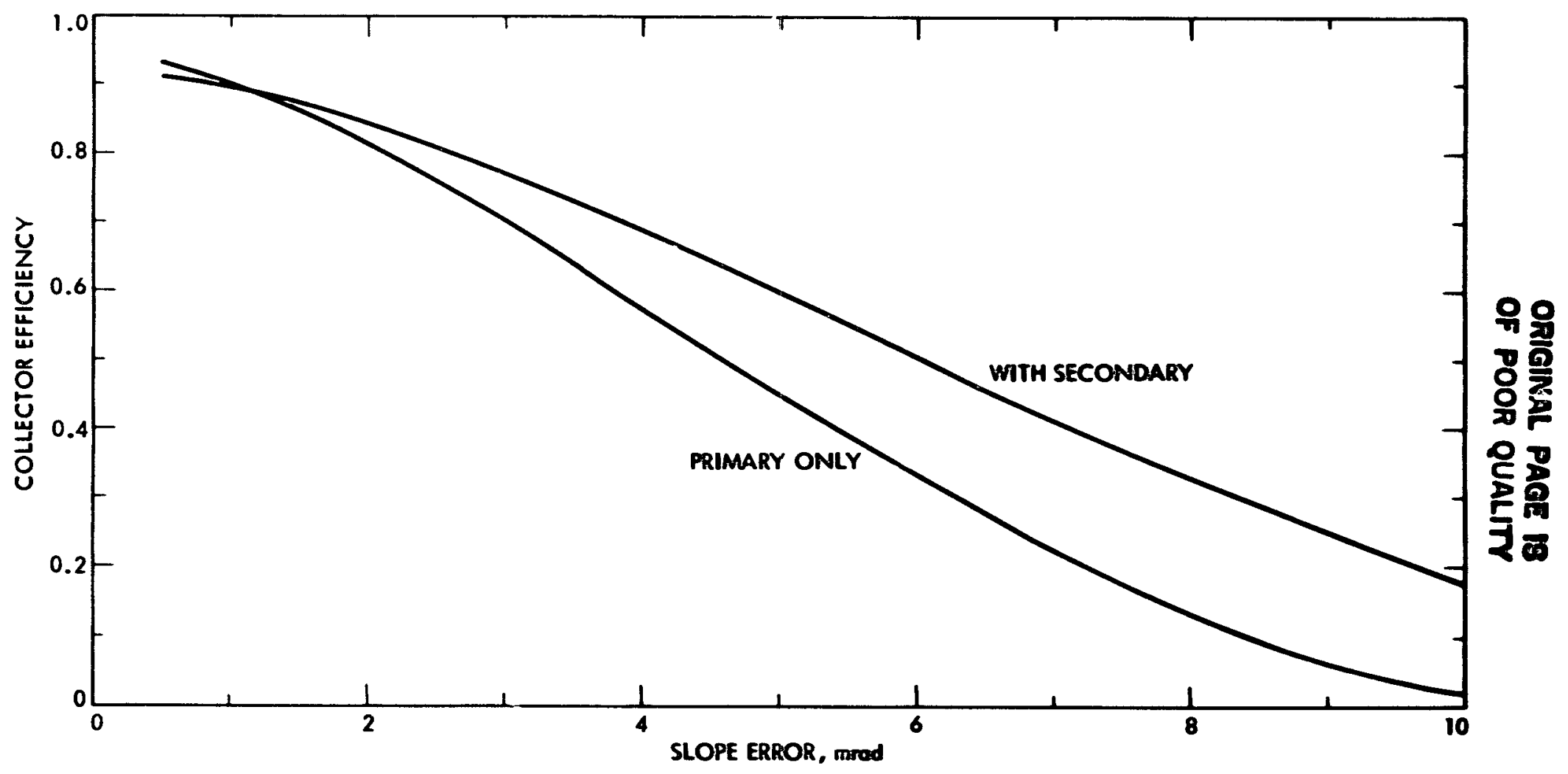

Figure 24a. Effect of Secondary Concentrator on Collector Efficiency with Primary Concentrators of Various Accuracies.

Collector characteristics as for Figure 23. Focal ratio 0.6. 


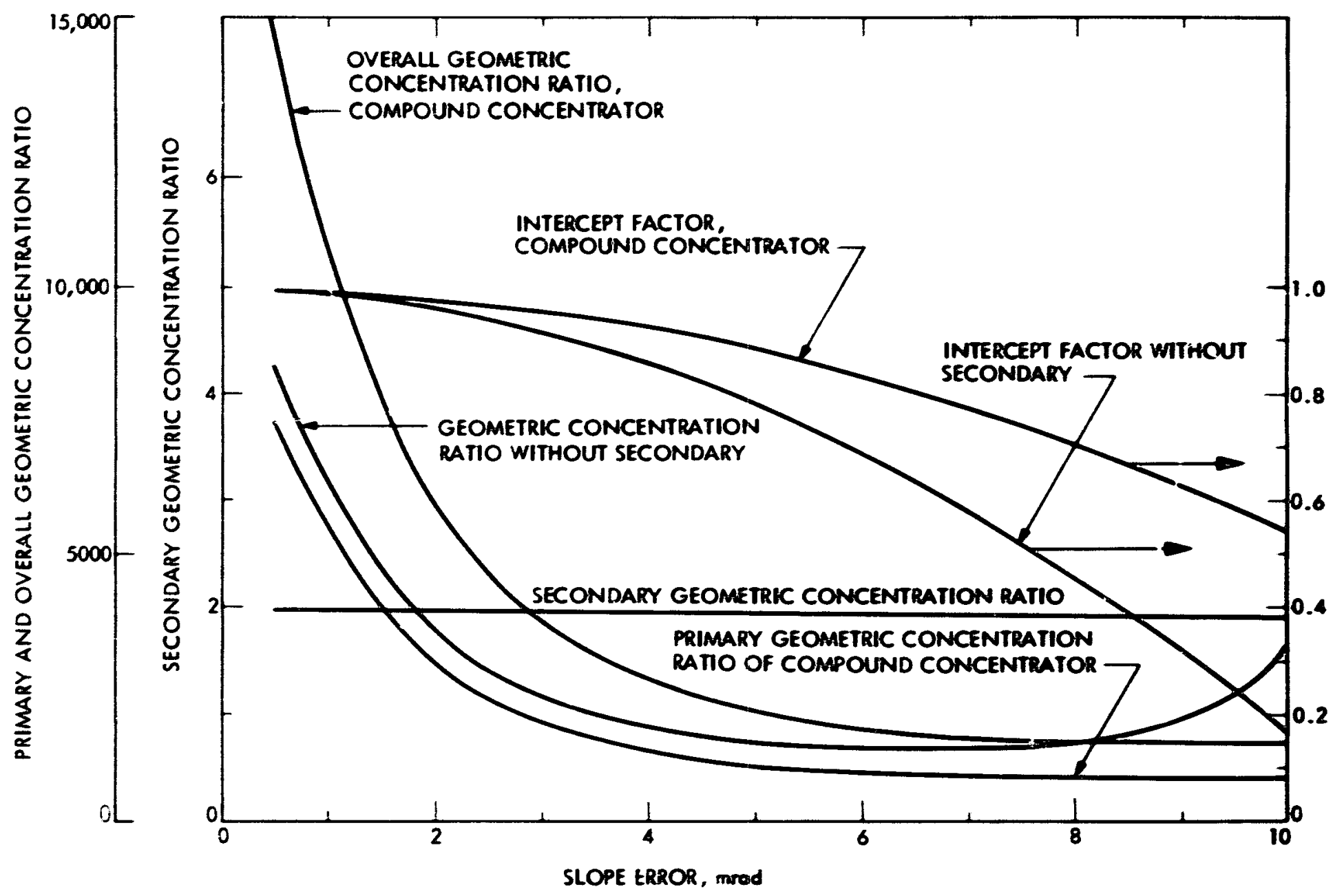

Figure 24b. Effect of Secondary Concentrator on Geometric Concentration Ratio and Intercept Factor with Primary Concentrators of Various Accuracies.

Collector characteristics as for Figure 23. Focal ratio 0.6 . 

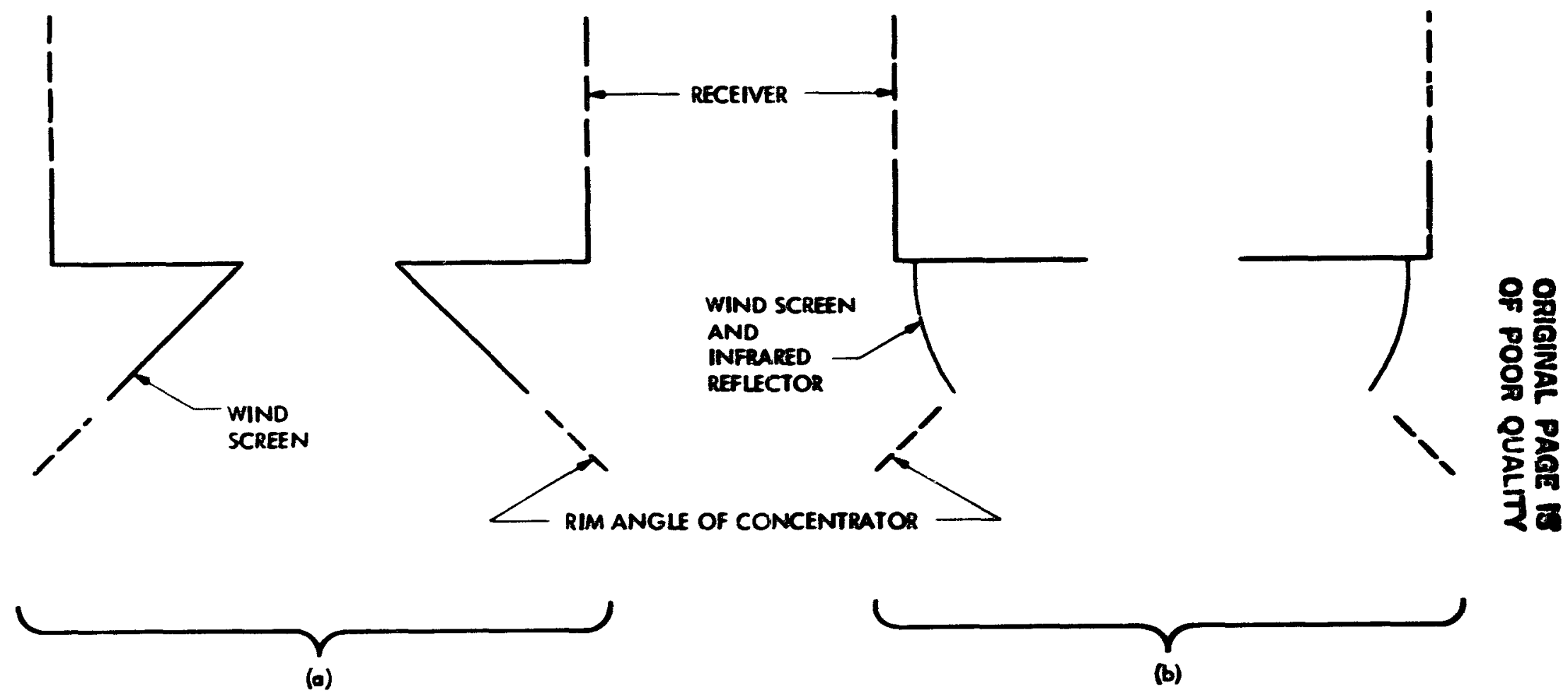

Figure 25. Wind Screens and Infrared Reflector.

a) Conical wind screen. Can also serve as secondary concentrator; compare Figure $4 \mathrm{~b}$.

b) Spherical section wind screen. Can also serve as infrared reflector to return emitted radiation to receiver. 


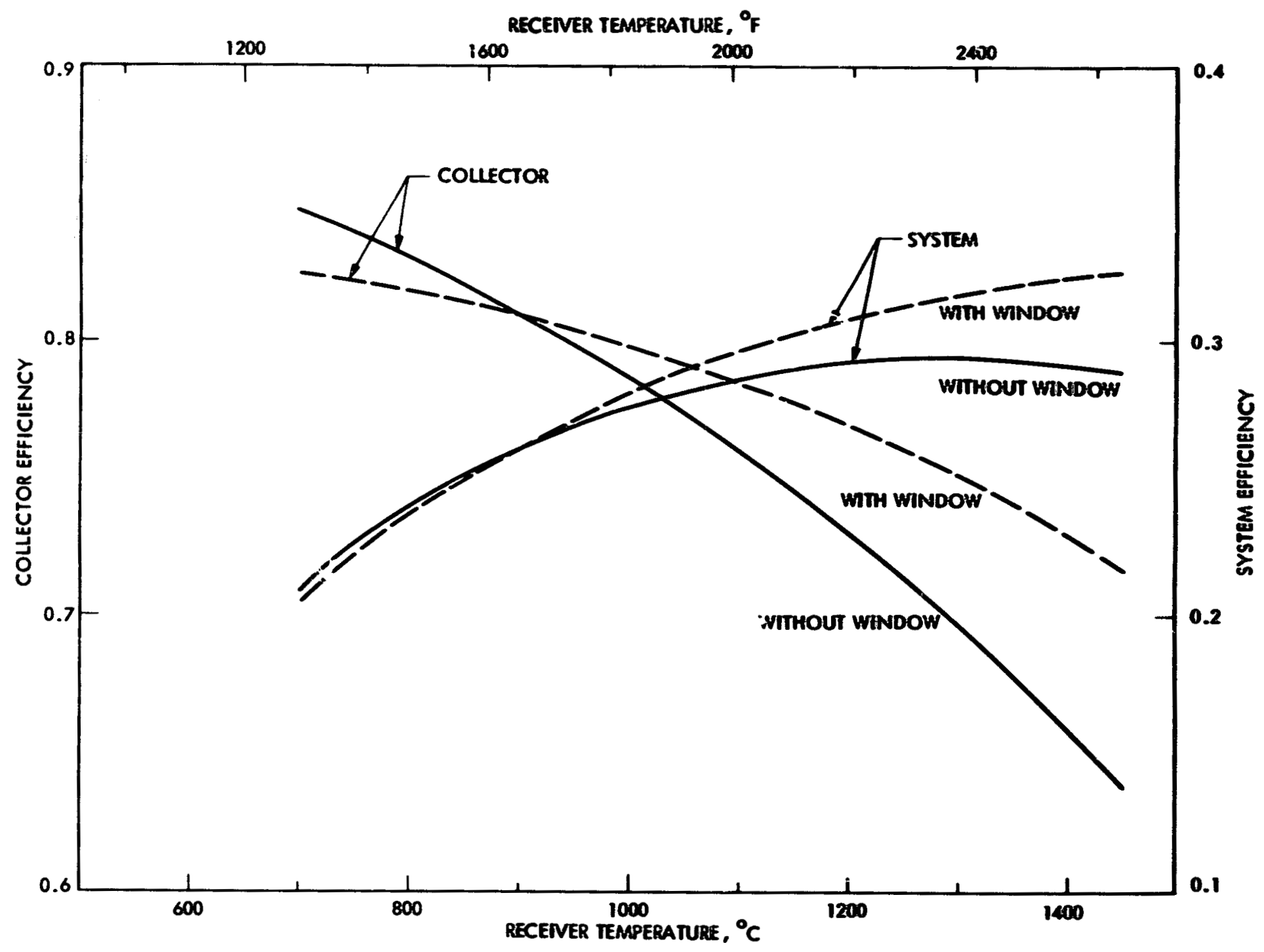

Figure 26. Effect of Receiver Temperature on Collector and System Efficiency With and Without a Window.

Receiver aperture optimized. Baseline system, except as noted. Hith window, effective receiver absorptance 0.92 (due to reflection), convection coefficient 0.0 , effective emittance $0.236,0.245,0.261,0.288,0.305,0.322,0.339,0.356$ at $704,760,871,982,1093,1204,1316,1427^{\circ} \mathrm{C}$, respectively (based on data of Ref. 32). Brayton power conversion effectivess as in Figure 16. 


\section{ORIGNAL PAGE IS
OF POOR QUALITY}

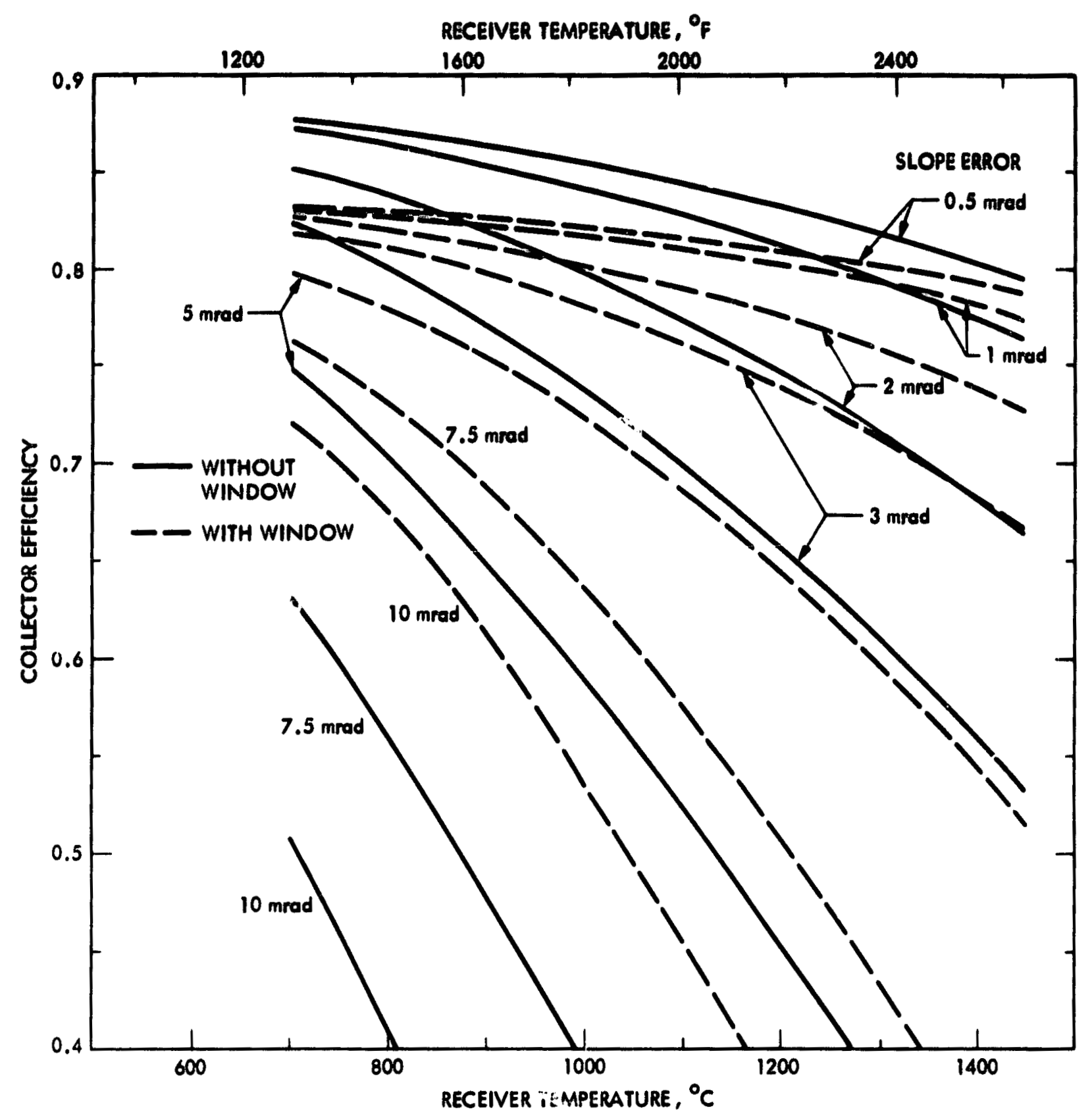

Figure 27. Effect of Window on Collector Performance at Varlous Concentrator Slope Errors and Receiver Temperatures.

Receiver aperture optimized. Baseline system except as noted. Receiver loss coefficients with window: same as for Figure $2 b$. 


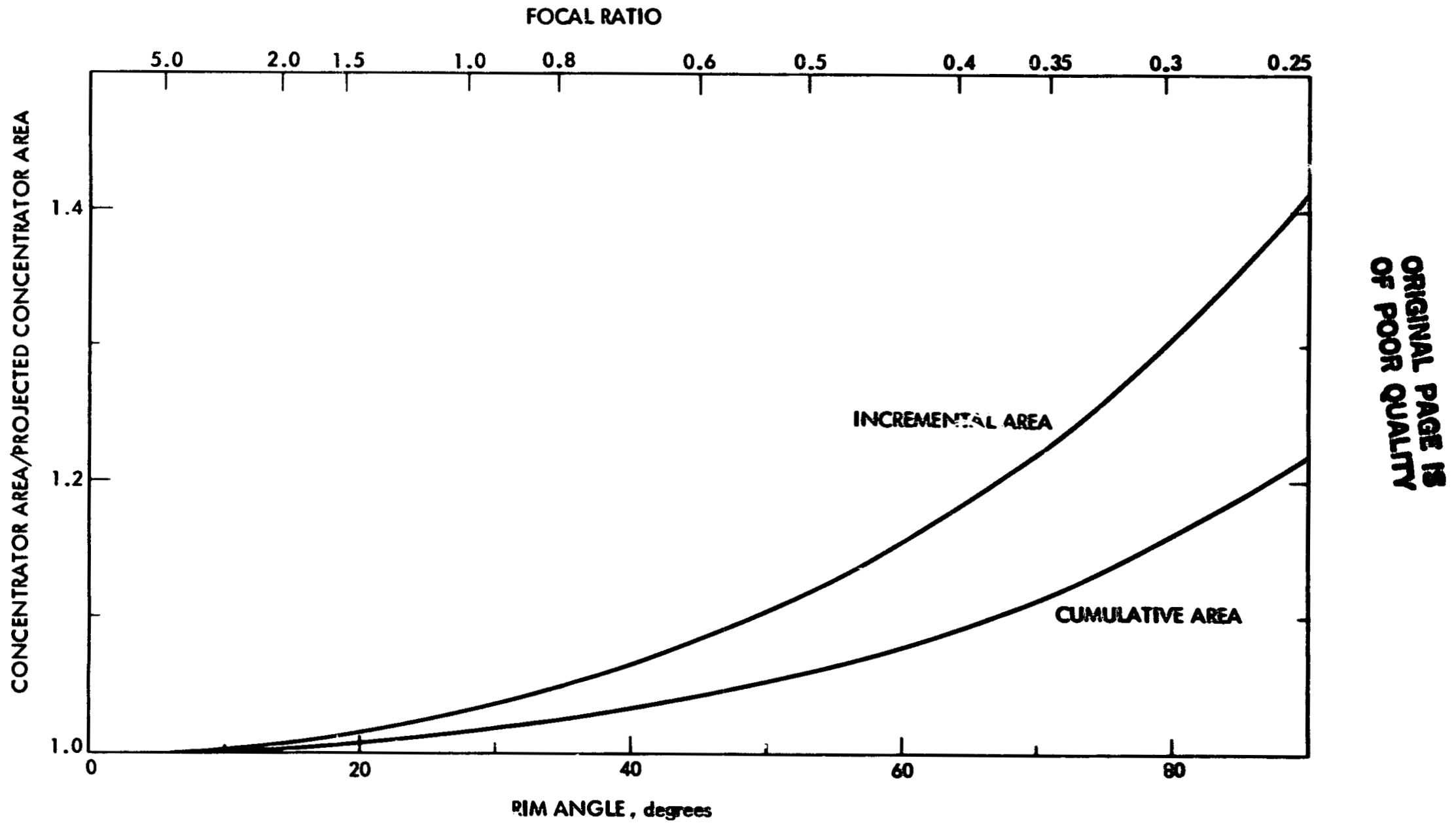

Figure 28. Effect of Focal Ratio upon Ratio of Concentrator Area to Projected Concentrator Area. 


\section{Optamal paez 18 \\ OF POOR QUALTY}

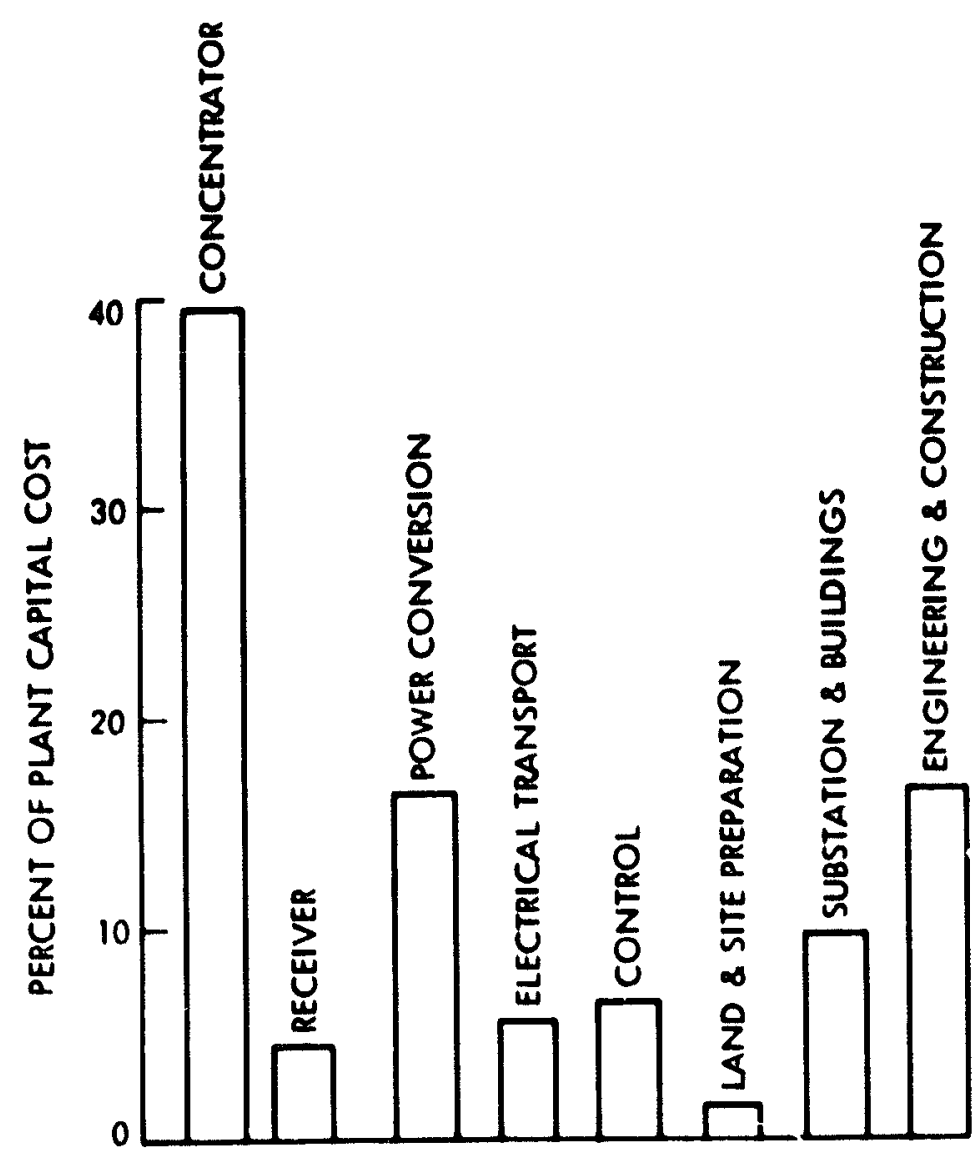

Figure 29. Distribution of Capleal costs for Solar thermal Puwer Plant. (Profected.)

System type: Jish-Brayton clectric. Production rate: 25,000 modules per year. Plant slae: 5 Mve.

Batied on data from Reforence 25. 


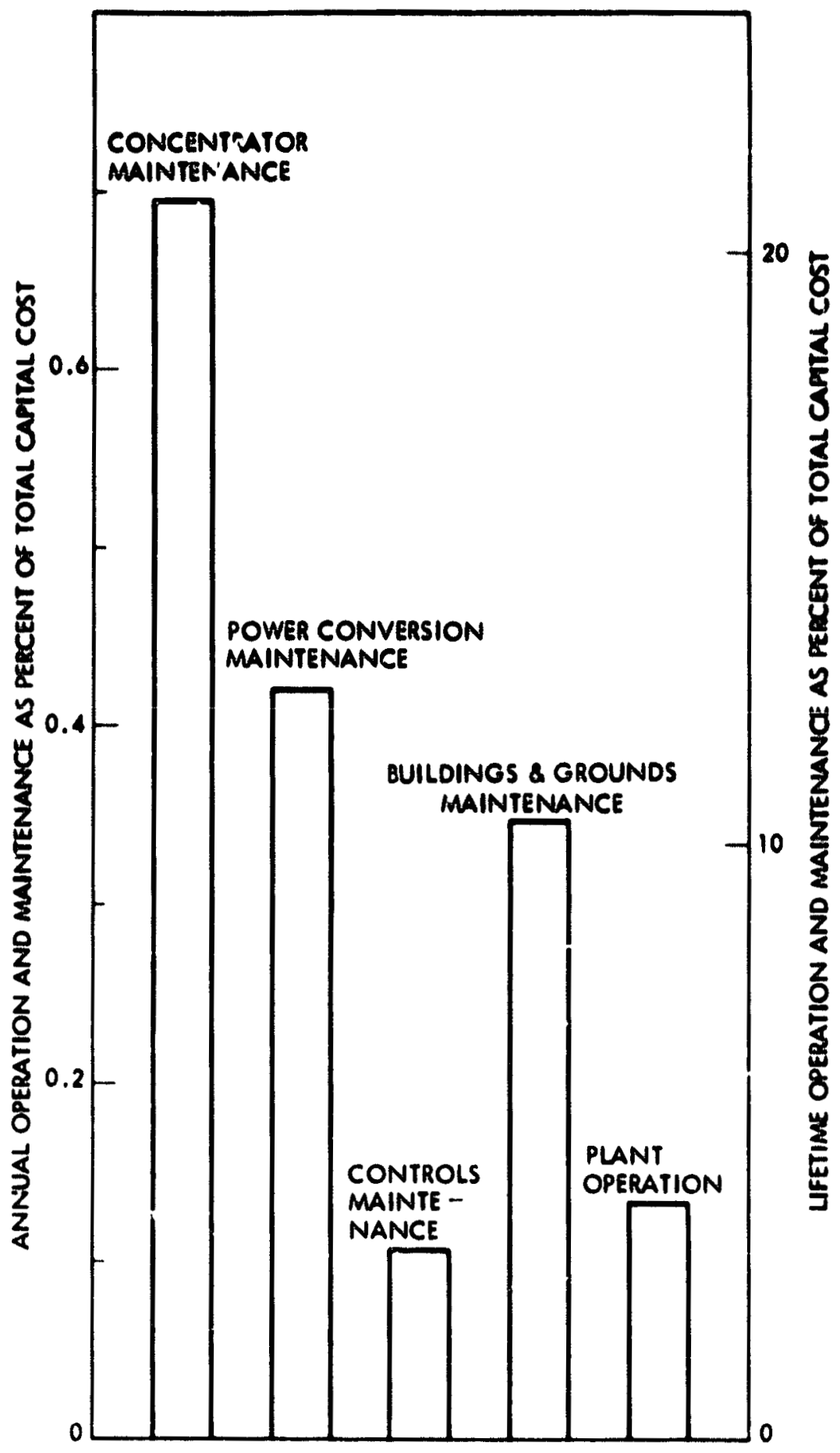

Figure 30. Distribution of Operations and Mafintenance Costs for Solar Thermal Power Plant as Percent of Total Cost in Constant Dollars. (Profected.)

Same plant as Figure 29. Plant lifetime 30 years. Based on data of Reference 25. 


\section{ORIOHNaL page is \\ OF POOR QIIALITY}

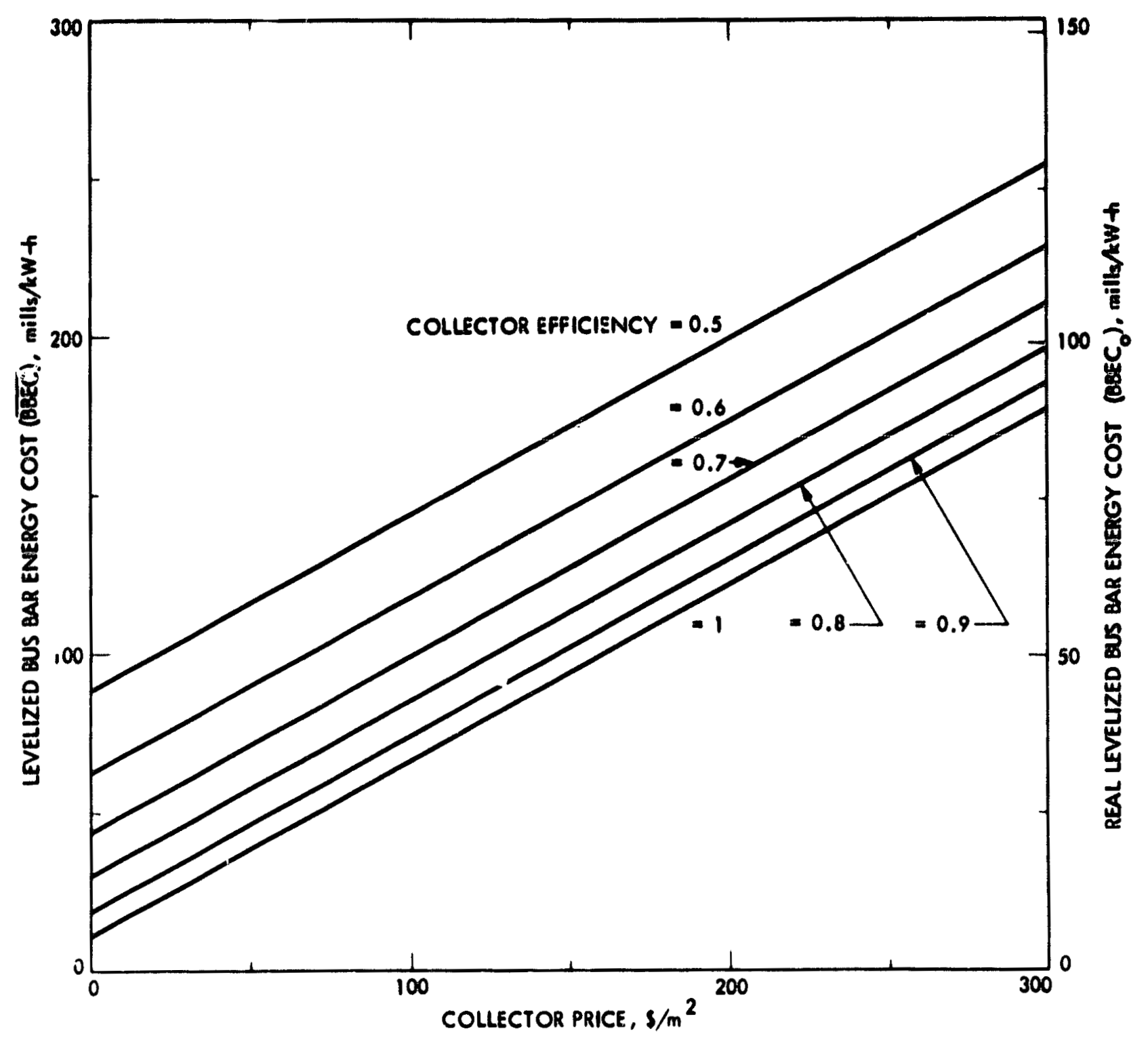

Figure 31. Effect oi Collector Price and Efflclency upon wost of Electrictey Produced. (Projected.)

Baseline system except as noted. 


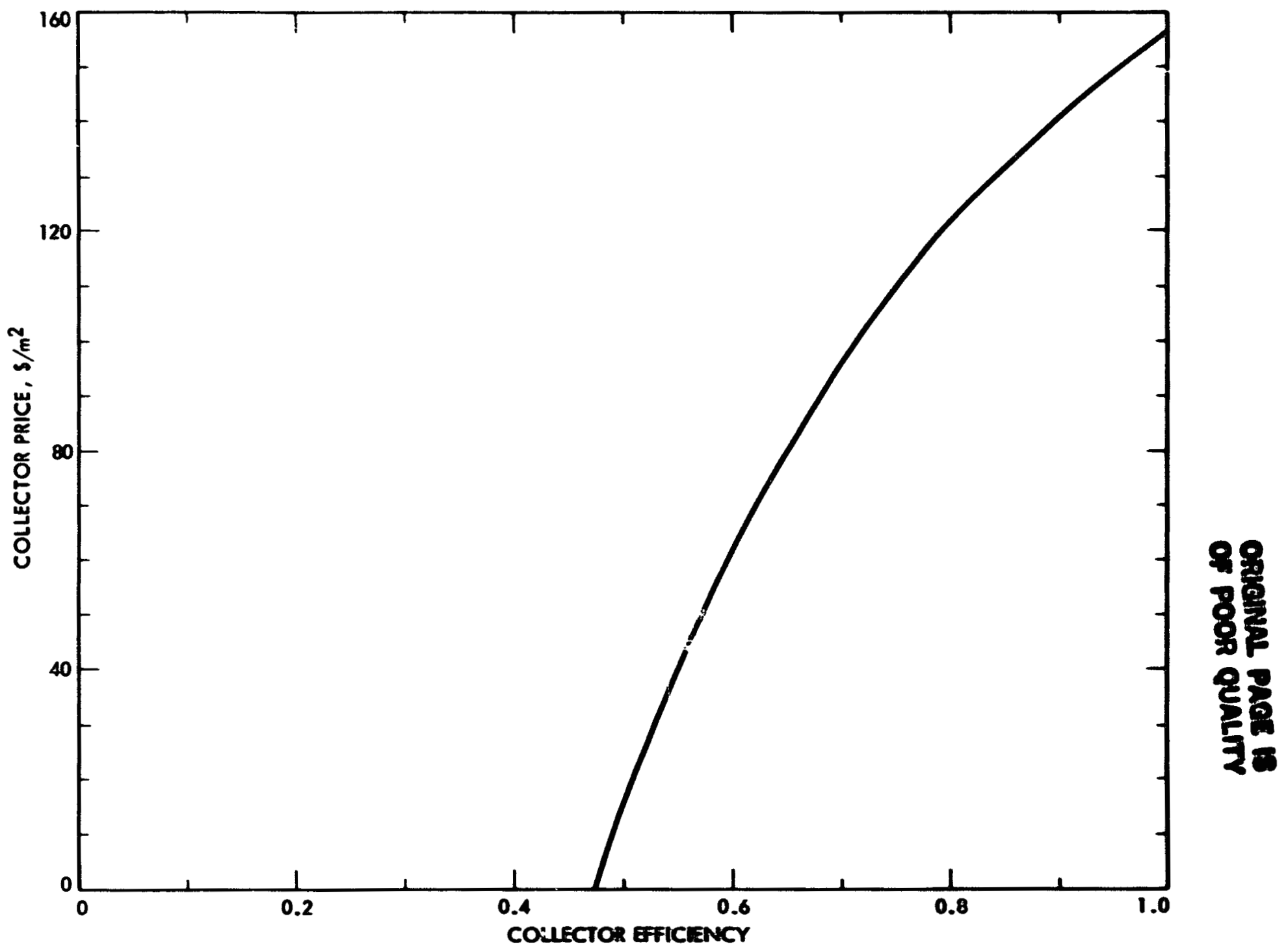

Figure 32. Trade-off of Collector Price Versus Collector Efficiency at Constant Cost of Electricity Produced. (Projected.)

$\overline{\mathrm{BBEC}}=97 \mathrm{mills} / \mathrm{k}, \mathrm{h}$. Baseline system, except as noted. 


\section{ORIOINAL PAGE IS \\ OP POOR QUALTY}

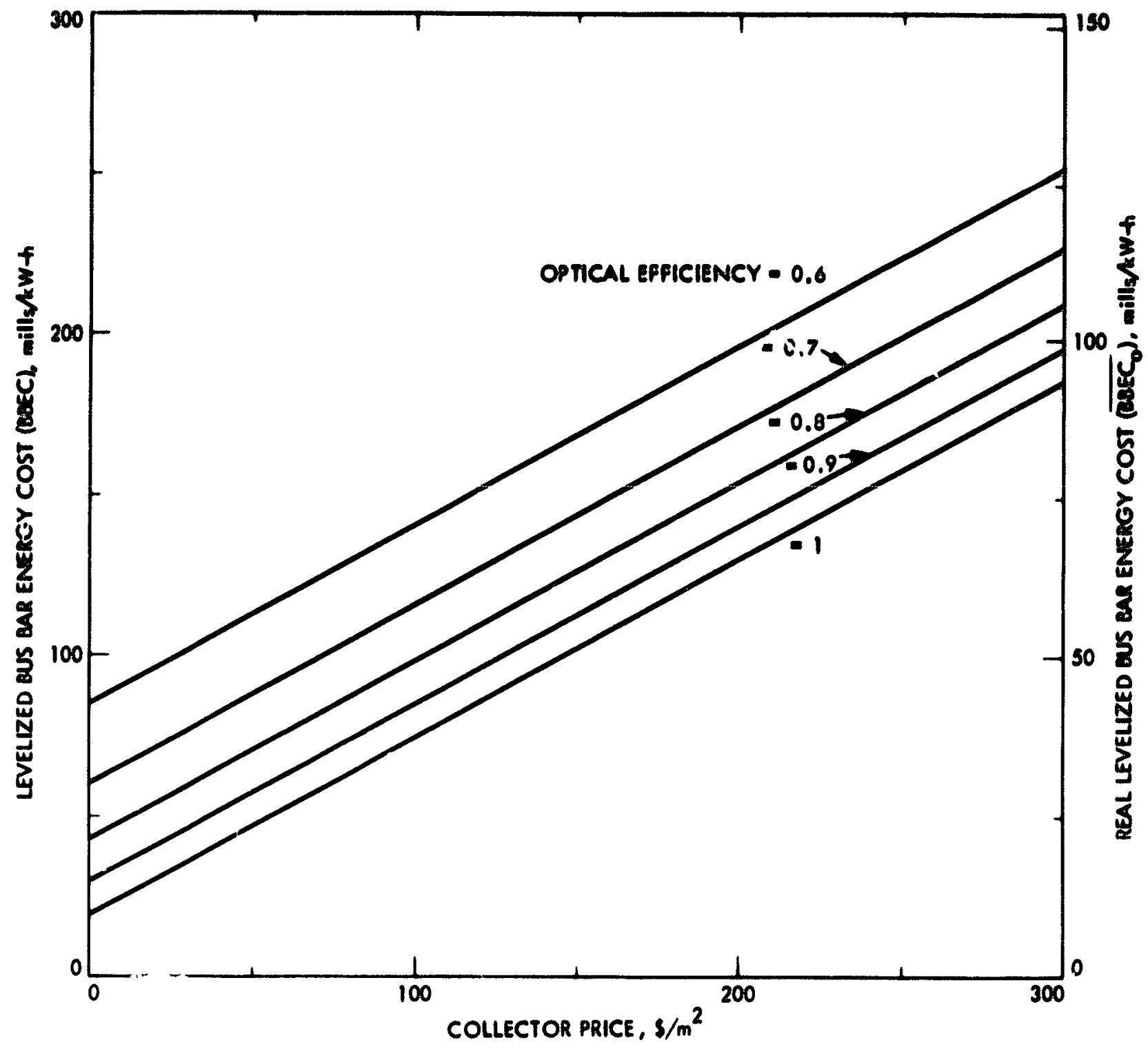

Figure 33. Effect of Optlcal Efficlency and Collector Price upon Cost of Electricity Produced. (Projected.)

Baseline system except as noted. 


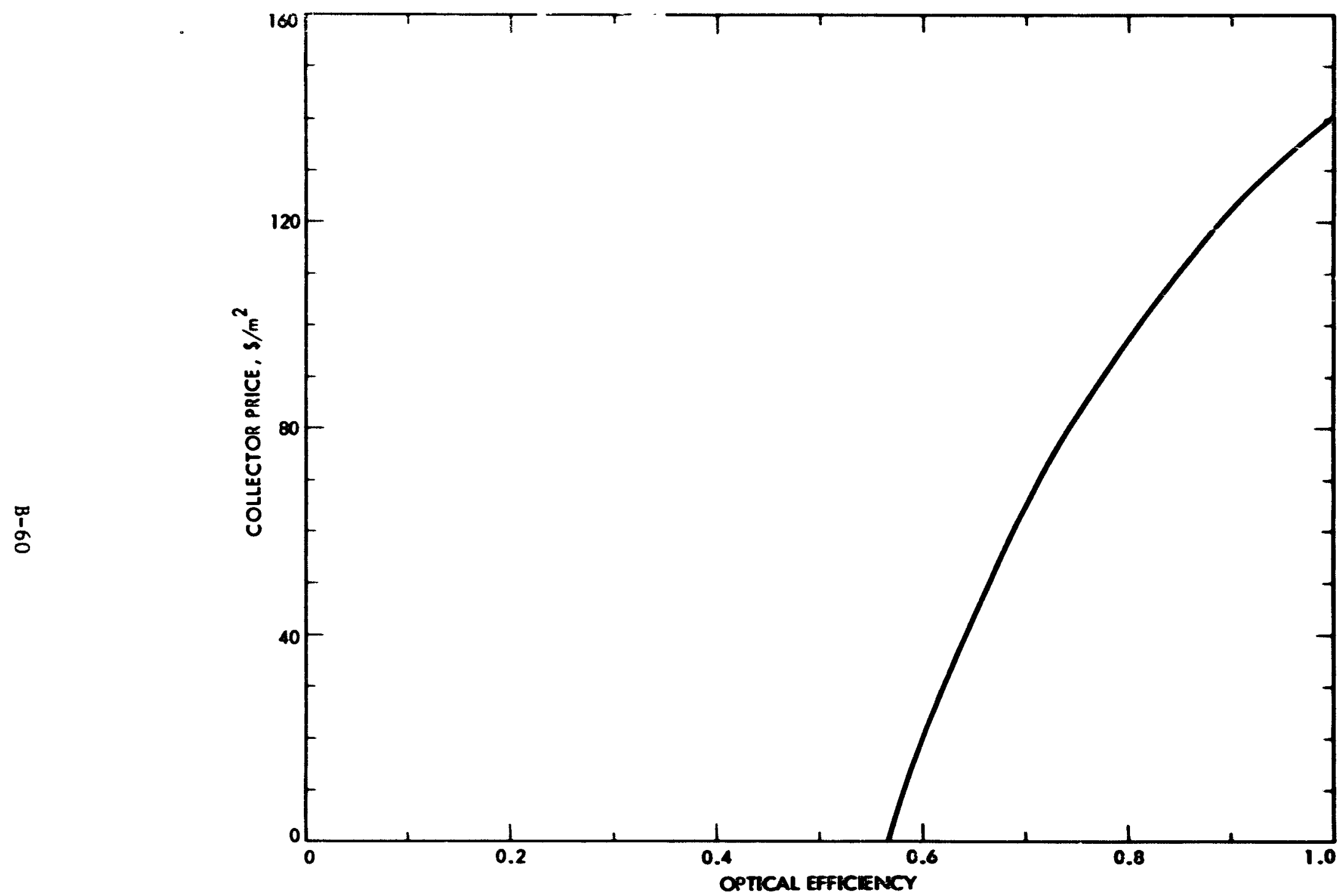

Figure 34. Trade-off of Collector Price Versus Optical Efficiency at Constant Cost of Electricity Produced. (Projected.)

Baseline system except as noted. 


\section{ORIGINAL PAEE is
OF POOR QUALITY}

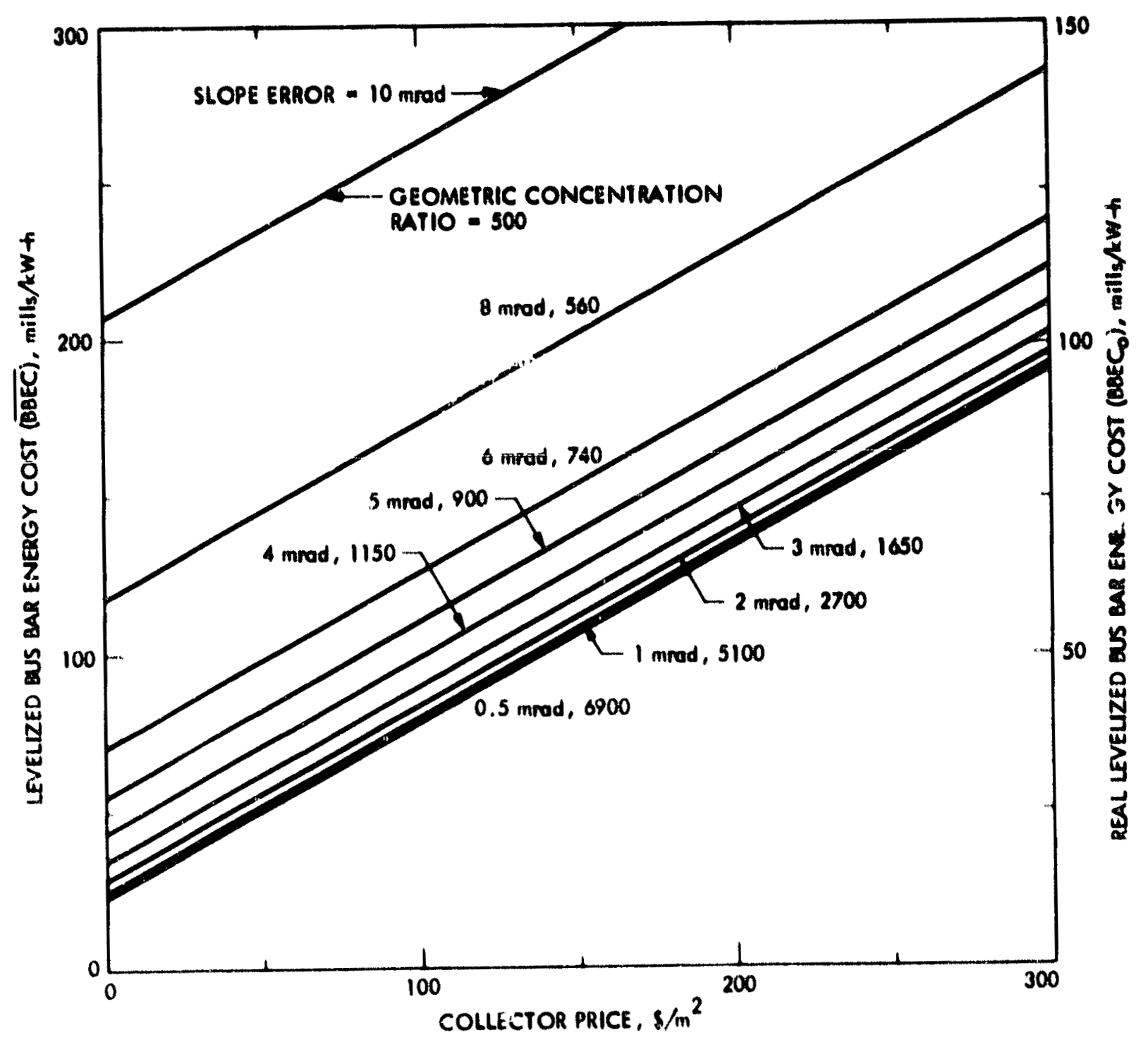

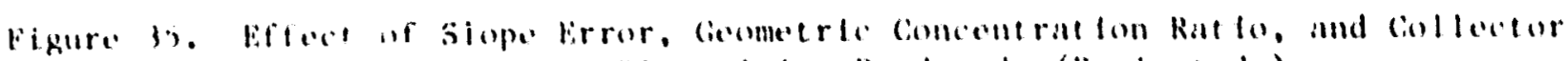

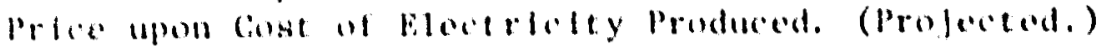




\section{ORIGINAL PAGE IS \\ OF POOR QUALTT}

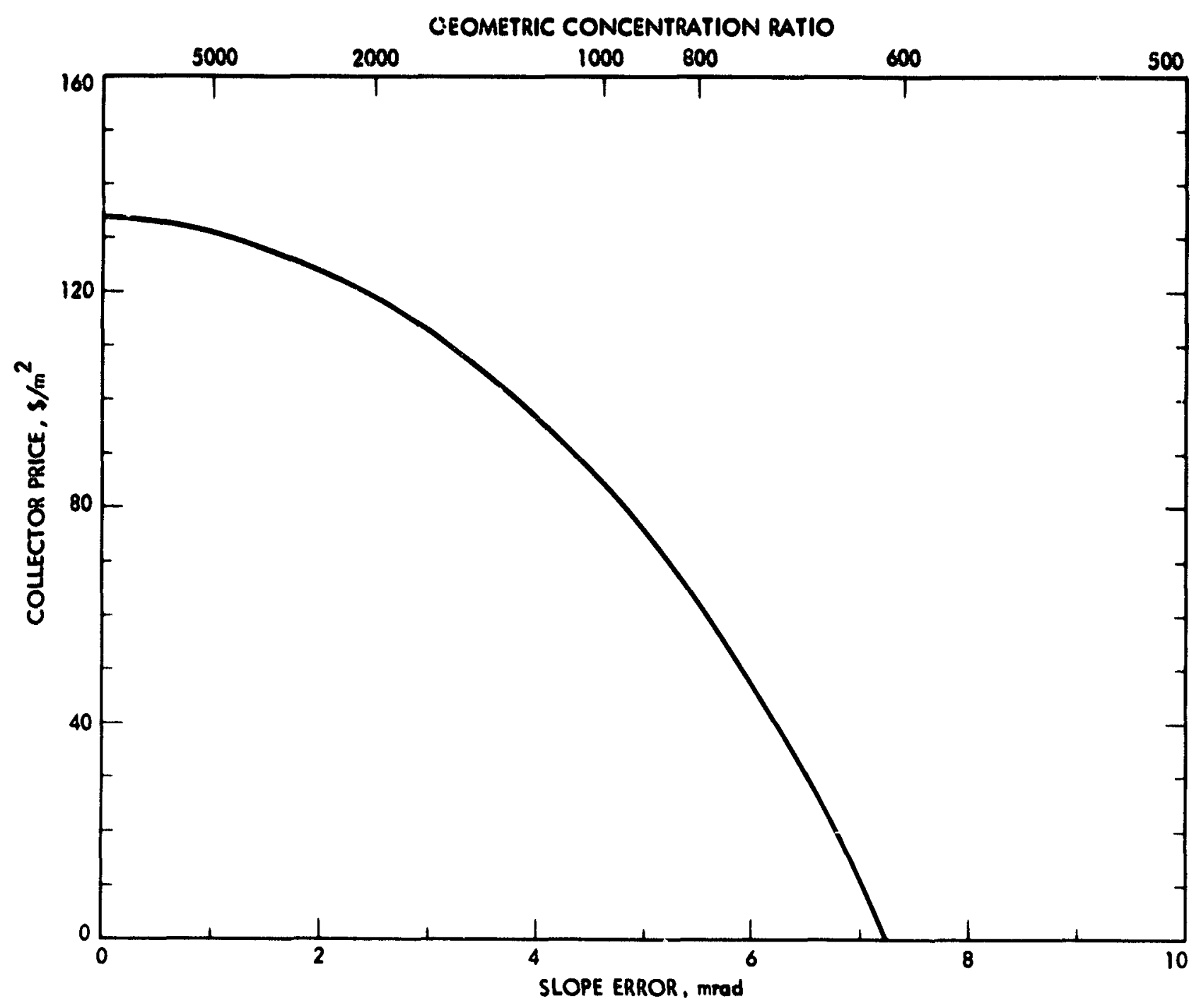

Figure 36. Trade-Off of Collector Price Versus Slope Error and Geometric Concentration Ratio at Constant Cost of Electricity Produced. (Projected.)

$\overline{\mathrm{BBEC}}=97 \mathrm{mfl1s} / \mathrm{kW}-\mathrm{h}$. Baseline system except as noted. Receiver aperture optimized for each slope error. 


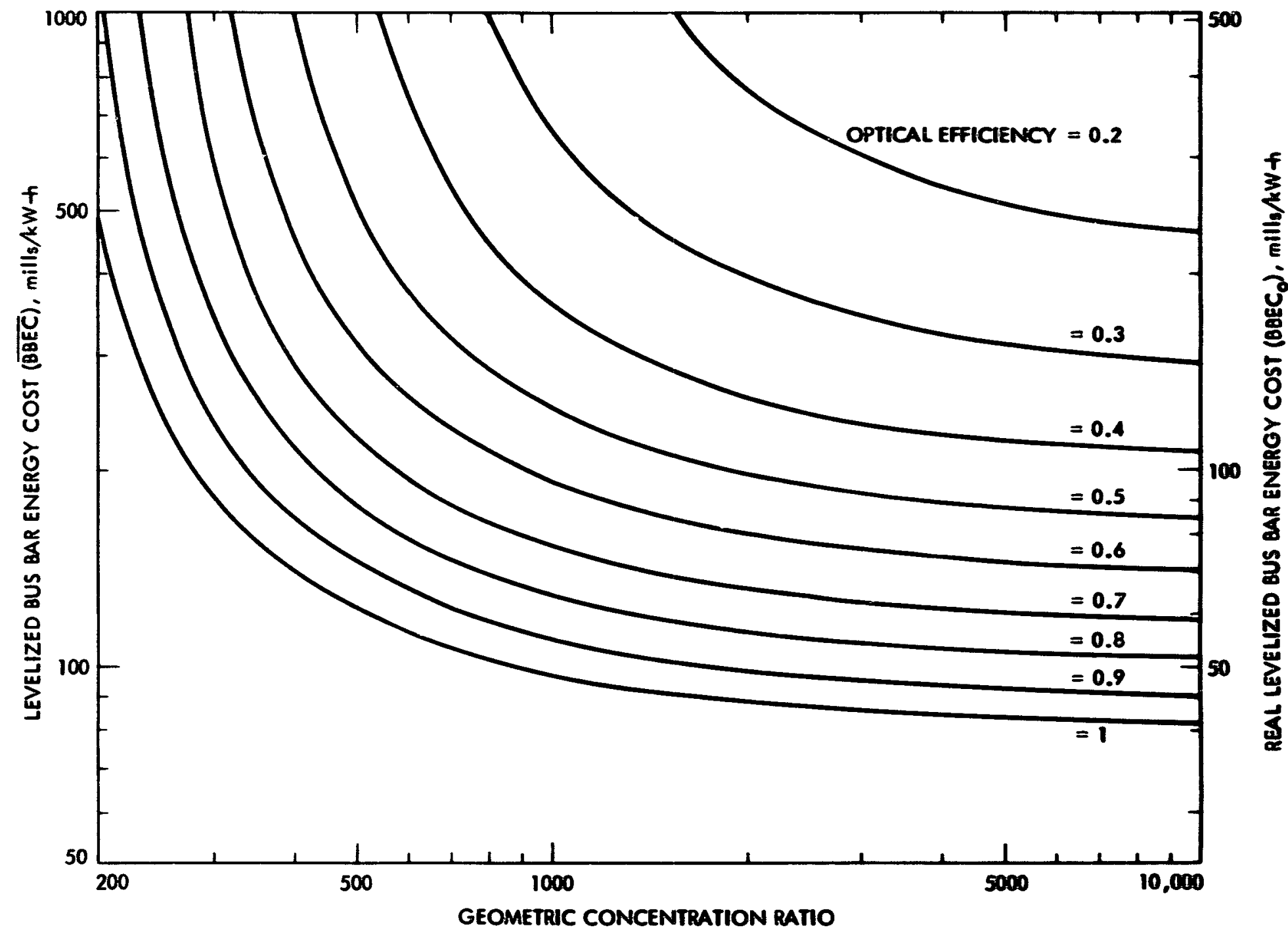

Figure 37. Ef fect of Optical Performance upon Cost of Electricity Produced. (Projected.) Baseline system except as noted. (For collector efficiencies, see Figure 5.) 


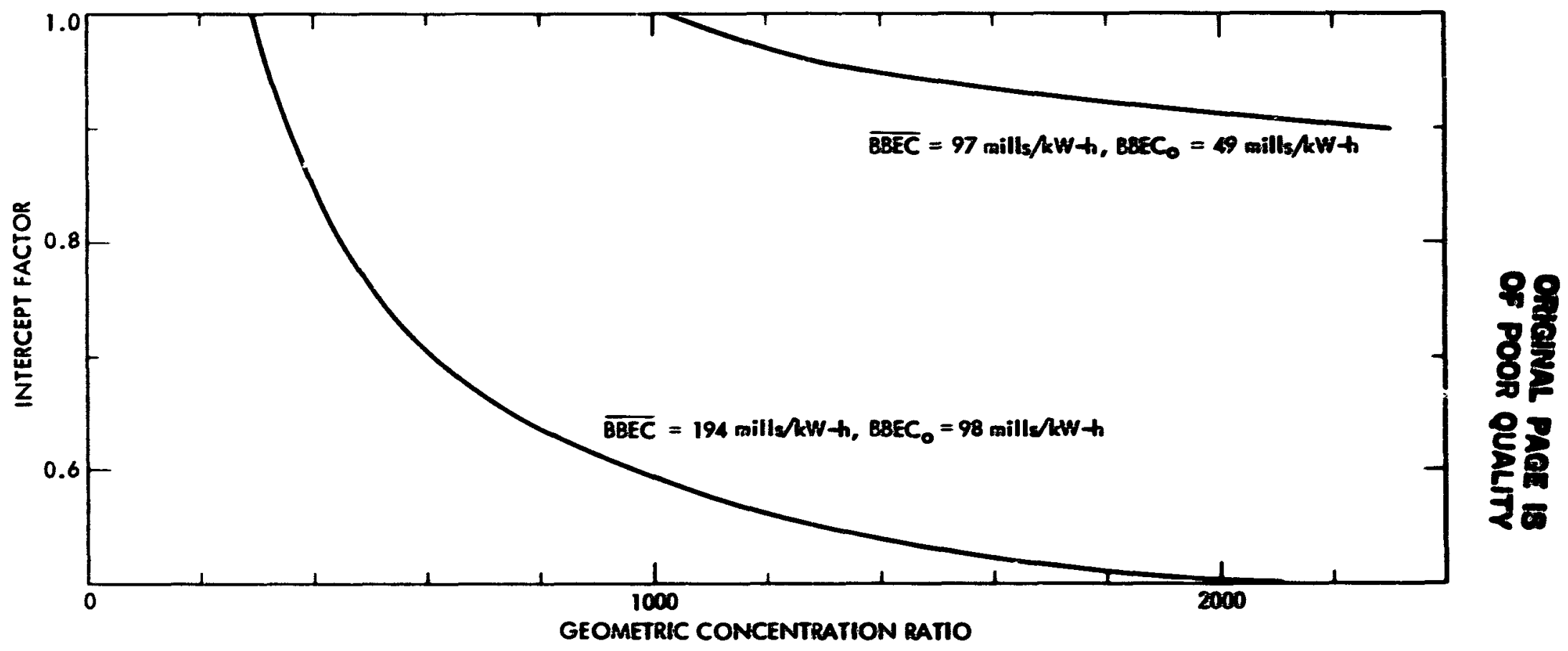

Figure 38. Trade-Off of Optical Efficiency Versus Geometric Concentration Ratio at Constant Cost of Electricity Produced. (Projected.)

Baseline system except as noted. 
RECEIVER TEMPERATURE, ${ }^{\circ} \mathrm{F}$

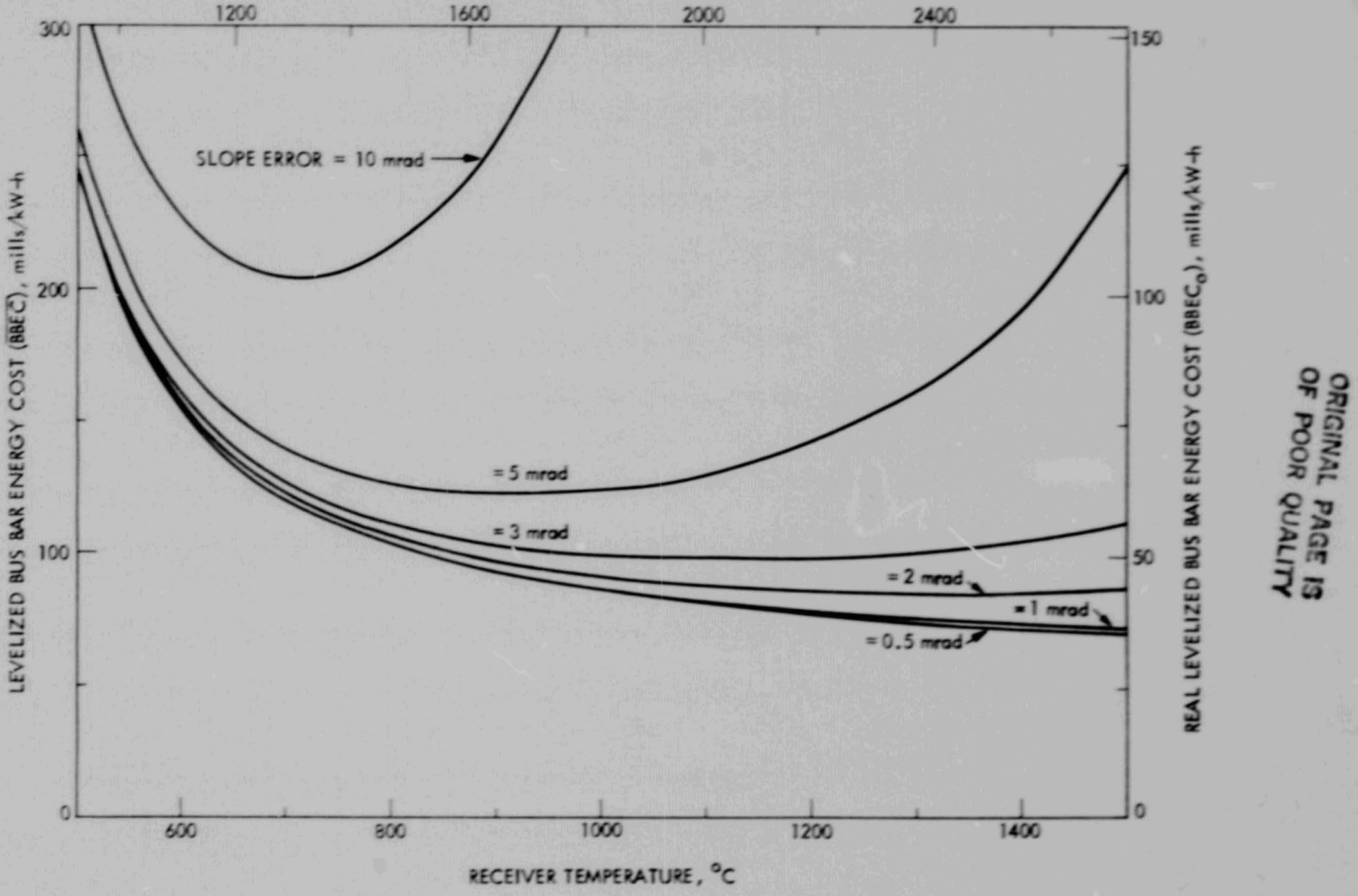

Figure 39. Effect of Slope Error upon Cost of Electricity Produced at Various Receiver Temperatures (Projected) Baseline system except as noted. Receiver aperture optinized. Plant costs assumed to depend on efficiencies, but to be otherwise independent of temperature. (For collector efficiencies, see Figure 19; for power conversion efficiencies, see Figure 17a.) 